\title{
Las asociaciones de desarrollo de la comunidad en Costa Rica durante el decenio de 1970
}

\author{
Miguel Ángel Mondol Velásquez \\ Consejo Institucional de Investigación, Vicerrectoría de Investigación, Universidad Estatal a Distancia, San José, Costa Rica; \\ mmondol@abogados.or.cr
}

Recibido 3-VI-2009 Corregido 1-IV-2009 Aceptado 7-V-2009

\begin{abstract}
The community development associations in Costa Rica during the 1970s. In 1967 the Legislative Assembly of Costa Rica established the National Community Development Directorate (DINADECO) to support local community development associations, made up of neighbors who shared goals of social and economic improvement for their community. Here I describe and analyze, within the national context, the history of DINADECO between 1968 and 1978, a period in which there were 807 community associations and 26 regional associations. By $1978,90 \%$ of districts had at least one association. The economic results were surprising: the national agricultural added value grew higher than of other Latin American countries pooled. Growth in the added value of industrial production was even greater and more prolonged. But the wealth produced was distributed unequally: $20 \%$ of the richest families in the area became $11 \%$ richer between 1971 and 1977. But many farmers lost their land and entered in some kind of sub-employment, and 125000 were forced to emigrate. I propose the new hypothesis that there were multiple communicating and complementary relationships among associations and municipalities in this period. At the end, the deficit accumulated by the model of economic growth brought the end for many development associations in the 1970s. The effect of the decision, made by the Carazo Odio administration (1978), of inserting DINADECO in a Ministry with little political power (Culture Ministry) and of reducing DINADECO's budget, would be a good topic for future research.
\end{abstract}

KEY WORDS

History of rural development, development models, municipality -association interactions, poverty, enrichment, Latin American economic model.

Hace cuarenta años se creó la Dirección Nacional de Desarrollo de la Comunidad (DINADECO) mediante la Ley 3859, promulgada el 7 de abril de 1967. La ley le asignó una tarea principal a DINADECO: promover, constituir y apoyar a las Asociaciones de Desarrollo de la Comunidad. Las Asociaciones de Desarrollo de la Comunidad (ADC) son organizaciones formales de base constituidas por vecinos que comparten objetivos de mejoramiento económico y social para su comunidad.

La primera Asociación de Desarrollo de la Comunidad se constituyó la tarde del 18 de febrero de 1968 en la comunidad de Santa Eulalia de Atenas. Hoy suman casi 3000. Tantas organizaciones, distribuidas por todo el país son razón suficiente para justificar su estudio. Pero hay algo más.
DINADECO y las asociaciones han transitado por diversas etapas. Este estudio sólo se referirá a un primer periodo de DINADECO, comprendido entre febrero de 1968 (constitución de la primera asociación) y mayo de 1978 (conclusión de la administración Oduber-Quirós).

Durante este periodo se constituyeron 807 asociaciones y 26 uniones cantonales. Es decir una proporción muy significativa del total existente. Más importante es que en estos primeros diez años se alcanzó una cobertura prácticamente total del país. Para 1978, el 90\% de los distritos tenía por lo menos una asociación.

Otra particularidad de este periodo es la radicalidad de los significados que se le atribuyen. Para unos fue angelical. Para otros satánico. Los primeros subrayan la mística de sus primeros promotores y dirigentes comunales. 
El número de asociaciones constituidas y la cantidad de obras realizadas. Son los que sueñan con la posibilidad y necesidad de un retorno de DINADECO a sus dorados primeros años.

Enfrente están quienes satanizan a este primer periodo de DINADECO y de las asociaciones. Para ellos fueron los años de la derrota del "auténtico movimiento popular comunitario expresado en las Juntas Progresistas". También significa el triunfo de la estrategia geopolítica del gobierno norteamericano en la década de los setenta. Incluso afirman que los primeros promotores del desarrollo comunal actuaron como "intelectuales orgánicos de la burguesía nacional".

El presente estudio desea, vehementemente alejarse de ambas posiciones (la celestial y la satánica) y quiere observar a DINADECO y a las asociaciones de esos años desde una perspectiva diferente. ¿Cuál? aquella que relacione el contexto nacional -es decir, lo que ocurría en el país en esos años- con la institución y las asociaciones. Y ¿cómo? pues mirando los mecanismos mediante los cuales las asociaciones se insertaron, de una u otra forma en ese contexto nacional. Es decir, qué hicieron y por qué lo hicieron.

Creemos que los resultados de esta investigación contribuirán a entender mejor cómo el Estado costarricense tejió relaciones con las comunidades mediante las Asociaciones de Desarrollo.

Además el esfuerzo será importante para quienes intentamos entender un tema que comienza a insinuarse en las agendas investigativas de los centros académicos costarricenses: el tema de las relaciones entre el Estado y la sociedad civil local.

El propósito general de la investigación fue, primero, identificar y analizar los argumentos que tradicionalmente se utilizan para explicar la creación de un modelo organizacional denominado Asociación de Desarrollo de la Comunidad (ADC) y luego, a partir de la crítica contra tales argumentos inferir causas estructurales que, a nuestro entender, originaron dicho modelo organizativo.

\section{METODOLOGÍA}

\section{Objeto de estudio}

El objeto de estudio fue el modelo organizativo llamado "Asociación de Desarrollo de la Comunidad" ADC. Estas organizaciones formales de base están conformadas por vecinos que comparten objetivos de mejoramiento económico y social para su comunidad de residencia. El artículo 58 del Reglamento' a la Ley 3859 define así los fines principales de las asociaciones: Estimular la cooperación y participación activa y voluntaria de la población en un esfuerzo total para el desarrollo económico, social y cultural de la comunidad.

Las ADC son organizaciones de tipo formal, territorial y de base popular. Son organizaciones formales porque su constitución, actuaciones, relaciones y disolución están determinadas por la Ley 3859 del 7 de abril de 1967 y su respectivo reglamento. Son territoriales porque su accionar está circunscrito a un área determinada en el acta constitutiva de cada asociación. Son de base popular porque sus afiliados son personas mayores de quince años vecinos de esa área territorial, que ingresan y se desafilian con entera libertad sin distingos de posición económica, ideológica, política, religiosa, racial o de sexo. Todos pueden elegir y todos pueden ser electos en la Junta Directiva de su respectiva asociación. ${ }^{2}$

El estudio recurrió, estrictamente, a fuentes secundarias de información. De estas fuentes se obtuvieron datos primarios (sin elaborar) y datos secundarios (elaborados). Las principales fuentes fueron:

a) Bibliografía expresamente relacionada con el tema del desarrollo comunal costarricense.

b) Datos secundarios, de carácter oficial, sobre DINADECO y las Asociaciones de Desarrollo Comunal.

c) Datos primarios (sin elaborar) del Departamento Legal y de Registro de DINADECO.

d) Datos primarios provenientes de los Presupuestos de la República, periodo 1970-1978.

e) Datos primarios del Tribunal Supremo de Elecciones sobre munícipes electos durante el periodo 19701978.

f) Datos primarios del contexto socio-económico provenientes de la Dirección General de Estadística y Censos.

g) Datos secundarios sobre el contexto socio-económico, principalmente provenientes de OFIPLAN (hoy MIDEPLAN).

\section{Periodo del estudio}

El estudio abarca el periodo 1968-1978. El primero de estos años se eligió porque fue constituida la primera Asociación de Desarrollo de la Comunidad. El último, 1978, porque es el cierre de las dos administraciones liberacionistas, contiguas, que impulsaron al desarrollo comunal institucionalizado en el país. Hay que subrayar, además, la importancia de este periodo: entre 1968 y 1978 se constituyeron 807 Asociaciones de Desarrollo de la Comunidad, es decir, un tercio de las asociaciones vigentes en la actualidad. 


\section{La población}

Durante el periodo en estudio se constituyeron 807 Asociaciones de Desarrollo de la Comunidad en 79 cantones. En el periodo 68-77 hubo unos 15000 directivos electos en esas 807 Asociaciones.

\section{Recolección de la información}

El estudio se diseñó para utilizar fuentes secundarias de información.

a) La primera y principal fue el Departamento Legal y de Registro de la Dirección Nacional de Desarrollo de la Comunidad, allí recolectamos:

- El listado total de Asociaciones de Desarrollo de la Comunidad constituidas desde el año de 1968.

- El nombre de todos los directivos de todas las asociaciones en la muestra, pero constituidas entre enero de 1968 y diciembre de $1973^{3}$, para los dieciséis cantones de la muestra 4 .

b) Otra fuente secundaria importante fue el Departamento de Archivo del Tribunal Supremo de Elecciones. Allí se nos facilitó copia de las Declaratorias Oficiales de eventos electorales ocurridos en los años 1970, 1974 y 1978. De las declaratorias obtuvimos:

- El nombre de todos los munícipes electos en los dieciséis cantones de la muestra, en los años 1970, 1974 y 1978.

- El resultado de las elecciones, a nivel municipal, en los años 1970, 1974 y 1978.

c) La Biblioteca de la Asamblea Legislativa de Costa Rica. Allí de los Presupuestos Ordinarios de la República, obtuvimos las partidas específicas giradas a las Asociaciones de Desarrollo de la Comunidad, incluidas bajo el Título 30: Transferencia a. ${ }^{5}$ La información se obtuvo para los años 1970, 1971, 1972,1973, 1974, 1975, 1976, 1977 y 1978.

\section{Organización de la información recolectada}

La información se distribuyó de la siguiente manera:

a) Las Asociaciones de Desarrollo de la Comunidad, constituidas entre enero de 1968 y diciembre 1978 fueron distribuidas por años y por distritos administrativos según el Censo de 1973.

Para su análisis, se estratificaron las Asociaciones de acuerdo con la ubicación del cantón, en el Cuadro 1 se aprecia el resultado.

b) Cada una de las partidas específicas girada a las Asociaciones de Desarrollo durante el periodo 70-78 fue clasificada por cantones y destino.
CUADRO 1

Número de cantones por región, según datos del año 1973

\begin{tabular}{lc}
\hline \multicolumn{1}{c}{ Región } & No. de cantones \\
\hline Área Metropolitana & 12 \\
Valle Central & 35 \\
Resto del país & 32 \\
Total & 79 \\
\hline
\end{tabular}

FUENTE: Censo de población de 1973.

c) El nombre de los directivos de las Asociaciones de Desarrollo de la Comunidad se clasificó de la siguiente manera: para cada uno de los cantones se escogió aquellas asociaciones constituidas hasta 1977. ${ }^{6}$ Para cada una de estas asociaciones se eligieron, mínimo, tres Asambleas Generales ordinarias ${ }^{7}$ consecutivas, en cada una de las cuales se pretendía renovar a toda la junta directiva de la asociación. Los nombres de los directivos electos en dichas asambleas fueron clasificados por cantones.

d) Obtuvimos un registro de 14157 nombres de directivos de asociaciones junto con su cargo y cantón donde fueron electos. Estos 14157 nombres se ordenaron alfabéticamente y se observó, mediante un programa de computación simple: a) cuáles apellidos y nombres se repetían; este subconjunto se llamó directivos reelectos.

e) Obtuvimos un registro de casi 3000 munícipes electos en los 79 cantones durante el periodo 70-78. Cada munícipe se clasificó con el puesto municipal y año en que fue electo. Esta lista se comparó con la de los directivos. Aquellos nombres y apellidos presentes en las dos listas formaron el subconjunto directivos-munícipes.

f) A partir de esta organización primaria de la información recolectada, se posibilitaron otras maneras de organizar los datos. Temporalmente: el periodo 1968-1978 se subdividió, generalmente, en dos sub-periodos que coinciden con diferentes administraciones gubernamentales:

- Sub-periodo 1968-1973, administración Trejos Fernandez y administración Figueres Ferrer.

- Sub-periodo 1974-1978, administración Oduber Quirós y administración Carazo.

g) Espacialmente, además del distrito y el cantón, se utilizaron otros niveles para organizar la información. Dos fueron principales: a) el nivel regional, según, OFIPLAN ${ }^{8}$; b) el nivel subregional, según esa misma entidad: Subregión Metropolitana, Subregión Resto de San José, Subregión Resto de la Región Central, Subregión Chorotega, Subregión Brunca, Subregión Pacífico Central, Subregión Huetar Norte y Subregión Huetar Atlántica. 
h) Un problema particular: Tanto para organizar la información como para ponderar algunas variables ${ }^{9}$ recurrimos al Censo de Población de 1973. Estuvimos conscientes de las tres limitaciones implicadas en su utilización.

- Primera: El Censo proporcionaba la información de población para un año determinado (1973). Sin embargo, en la investigación utilizaríamos otras variables con valores para varios años (de 1968 a 1978). Esa fue una limitación. Porque cuando utilizáramos el año 1973 (año censal) como promedio de la serie de datos 1968-1978, los resultados podrían subvalorarse o sobrevalorarse ya que la distribución de las otras variables no fue uniforme -ni mucho menos- durante todo el periodo. Por ejemplo, la variable número de asociaciones, tuvo un peso mucho mayor en el sub-periodo 1974-1978, que en el sub-periodo anterior. Para disminuir los efectos de este problema optamos por estimar la variable "población" como el promedio de los años 73 (año censal) y 1978 (estimaciones de población de OFIPLAN), para calcular la densidad organizacional.

-Segunda: El Censo de 1973 mostraba, por cantones, la población total, la población menor de 10 años y la población mayor de 12 años. Sin embargo, por la naturaleza del estudio, requeríamos la población igual o mayor de 15 años que era precisamente el rango de edad que permitía la afiliación de un habitante en una Asociación de Desarrollo. Tuvimos que tabular este dato por cantones para el listado de edades simples que tenía el Instituto Nacional de Estadística y Censos y proyectarlo, de manera simple, para el año 78. Luego obtener el promedio al cual hacíamos referencia en el párrafo anterior.

- La tercera limitación, también relacionada con el censo de 1973 fue la siguiente: hubo que compatibilizar la división administrativa que presentaba el censo de 1973 con la de años posteriores. Así, los listados de asociaciones de DINADECO decían, por ejemplo que tal asociación había sido constituida en el distrito Platanares de Pérez Zeledón. Sin embargo, en el Censo de 1973 no aparecía ese distrito, por la sencilla razón de que todavía no se había constituido. El distrito se constituyó años después. Entonces lo que hicimos fue incluir la información relativa al distrito Platanares en el distrito (o distritos) de donde administrativamente se desprendió.

\section{RESULTADOS}

\section{Creación de DINADECO y las asociaciones de desarrollo de la comunidad}

\section{Antecedentes $^{1}$}

DINADECO no surge bajo la inspiración momentánea de un grupo de técnicos y políticos en la década de los sesenta. El nacimiento de DINADECO se inscribe dentro de una muy larga tradición del Estado costarricense relacionada con la promoción de la organización comunitaria. Recordemos como ejemplo que en el campo de la educación desde 1849 -es decir en los albores mismos del Estado Nacional- surgieron las Juntas de Instrucción Pública institucionalizadas luego por el decreto 52 del 17 de julio de $1885 .^{2}$ En el campo de la salud, por decreto gubernamental de julio de 1920 surgieron las Juntas Sanitarias Patrióticas e inmediatamente después las Juntas Patrióticas Progresistas "integradas por tres ciudadanos honorables nombrados por el poder legislativo y seleccionados de listas enviadas por las comunidades a este poder"; 3 y en la década de los cuarenta proliferaron los comités de deportes cantonales y distritales; en la década del sesenta los Comités de Salud Pública.

No debe extrañar entonces que al finalizar los años sesenta del siglo veinte encontráramos en el país una diversidad de esfuerzos institucionales relacionados con la promoción de la organización comunal. La exposición de motivos de la Ley 3859 que crea a DINADECO hace un buen recuento de estos esfuerzos ${ }^{4}$ todos sectoriales.

Por ello en una fecha tan temprana ${ }^{5}$ como 1958 , la administración de don Mario Echandi Jiménez, preocupada por la dispersión de esfuerzos gubernamentales en el campo del desarrollo comunitario inició el proceso de su institucionalización procurando otorgarle además un carácter integral.

En 1958, el gobierno de la República envió a Jamaica a un grupo de técnicos nacionales para que observaran experiencias en desarrollo comunal. ${ }^{6}$ Poco después, en 1959 la administración Echandi Jiménez solicitó asistencia técnica a la Oficina de Asuntos Sociales de Naciones Unidas para constituir el Grupo de Trabajo sobre Desarrollo de la Comunidad en Costa Rica y para capacitar a un grupo de técnicos nacionales en el tema. El 30 de agosto de 1959, el presidente de la República y parte de su gabinete, presiden-con un esplendor inusitado- la primera reunión del Grupo de Trabajo sobre Desarrollo de la Comunidad.

Varias características comunes destacan entre los integrantes de este primer Grupo de Trabajo: todos tenían varios años de laborar en proyectos y programas sectoriales relacionados con la organización y educación comunitarias. En sus respectivas instituciones ocupaban cargos de dirección técnica. Todos eran jóvenes profesionales. La mayoría socialdemócrata, militante del partido Liberación Nacional. En el grupo desde el inicio se observó el liderazgo de quienes provienen del Ministerio de Salubridad Pública.7 Ellos conformaron una especie de "élite técnica" en el campo del desarrollo de las comunidades y en 
esa medida mantuvieron durante la década siguiente un papel de liderazgo en instituciones relacionadas con la organización y participación comunal en Costa Rica independientemente del partido político que gobernase. He aquí algunos ejemplos: ya dijimos que José Luis Ramos sería el primer director de la Oficina Nacional para el Desarrollo de las Comunidades Rurales y luego director de DINADECO; Carlos María Campos responsable del programa de organización comunal en la Caja Costarricense del Seguro Social; Francisco Rojas asesor de la Oficina de Desarrollo de la Comunidad en la Dirección de Bienestar Social del Ministerio de Trabajo; Álvaro Hernández Piedra quien luego sería director de Programación y Evaluación de DINADECO a partir de 1970; Bolívar Cruz quien luego pertenecería al grupo fundador del Instituto Nacional de Fomento Cooperativo etcétera.

En los años 1959-1960, este Grupo de Trabajo sobre Desarrollo Comunal, con la asistencia técnica de la Comisión Económica para América Latina (CEPAL), realizó una primera experiencia sobre desarrollo comunal en una comunidad rural en Aguas Zarcas de San Carlos, la cual fue coordinada con la Junta Progresista local. De la experiencia surge el primer "cartapacio para agentes de cambio en la comunidad".

A la administración Echandi-Jiménez siguió la administración -Orlich Bolmarich-. El nuevo presidente era del partido Liberación Nacional, contrario al partido en el gobierno anterior, sin embargo mantiene y fortalece al grupo de trabajo creado en la administración Echandi Jiménez. En 1962 solicita asistencia técnica de CEPAL para crear el Programa Nacional para el Desarrollo Integral de la Comunidad, el cual funcionaría dentro de la recién creada Oficina de Planificación de la Presidencia de la República.

Durante la administración Orlich-Bolmarich se creó el primer Departamento de Desarrollo de la Comunidad, dentro de la Dirección de Bienestar Social del Ministerio de Trabajo. Francisco Rojas (del Grupo de Trabajo) será su asesor y Athenia Montejo coordinadora del departamento. Ella seis años después sería la encargada del Programa de Adiestramiento y Capacitación en el naciente DINADECO.

Durante esta misma administración Orlich-Bolmarich, en setiembre de 1965 "tras una serie de esfuerzos, reuniones y gestiones se logró que la Asamblea Legislativa aprobara una partida especial para crear la Oficina para el Desarrollo de las Comunidades Rurales", director fue el Lic. José Luis González Ramos, integrante, como dijimos del Primer Grupo de Trabajo sobre Desarrollo de la Comunidad.

También en 1965, la recién constituida oficina apoyó la primera experiencia regional que utiliza la técnica del desarrollo comunal. Se llamó Asociación para el DesarroIlo Regional de la Península de Nicoya y había sido constituida seis meses atrás, en agosto de 1964. Uno de sus principales dirigentes, coordinador e ideólogo fue Armando Araúz un nicoyano, funcionario del Programa Nacional de Desarrollo Integral de las Comunidades quien poco después, en 1966, sería electo diputado por la bajura guanacasteca y desde esa posición, proponente de la ley 3859 Ley sobre Desarrollo de la Comunidad.

En 1966 se le asignó a la Oficina un presupuesto de 150000 colones e inició la preparación del "Proyecto sobre Desarrollo Integral de la Comunidad, bajo la dirección de un comité integrado por Armando Araúz Aguilar, Francisco Rojas y José Luis González Ramos. ${ }^{9}$ [...] A fines de 1966 quedó listo el ante-proyecto y el Poder Ejecutivo lo envió a la Asamblea Legislativa para su estudio y aprobación."10 Y fue este anteproyecto de comisión, con algunas modificaciones, el que sería aprobado aquella tarde del 31 de marzo de 1967 hace ya cuarenta años.

\section{DINADECO}

La tarde del 31 de marzo de 1967, en un ambiente festivo y con el aval de todas las fracciones políticas representadas en la Asamblea Legislativa1 se aprobó la Ley 3859 mejor conocida como Ley sobre el Desarrollo de la Comunidad. Ocho días después el presidente de la República don José Joaquín Trejos Fernández junto a su ministro de Gobernación y Policía puso el ejecútese a la ley.

En su artículo primero la ley creó la Dirección Nacional de Desarrollo de la Comunidad DINADECO:

Créase la Dirección Nacional de Desarrollo de la Comunidad con carácter de órgano del poder ejecutivo adscrito al ministerio de gobernación y policía como un instrumento básico de organización de las comunidades del país para lograr su participación activa y consciente en la realización de los objetivos del plan nacional de desarrollo económico y social.

En su artículo 3, la ley atribuyó a DINADECO sus funciones. Entre las principales estuvieron (y están):

- Planear y promover la participación activa y organizada de las poblaciones en los programas nacionales, regionales o locales de desarrollo económico y social.

- Evaluar permanentemente los programas de desarrollo de la comunidad para garantizar su ajuste a los principios y técnicas adoptadas por la presente ley y su respectivo reglamento.

- Entrenar al personal necesario en los distintos niveles, especialidades y categorías en uso y manejo de las técnicas del desarrollo de la comunidad.

- Inscribir, conforme a esta Ley a las asociaciones y 
grupos para el desarrollo de la comunidad ya existentes o que lleguen a establecerse".

\section{Etapas institucionales ${ }^{11}$}

La historia de la primera década del DINADECO puede subdividirse en cuatro etapas.

a) La primera corresponde al año 1967, cuando el presidente de la República, don José Joaquín Trejos Fernández nombró como primer director de DINADECO a un dirigente comunal de San Carlos, don William Quesada -quien a pesar de las diferencias partidarias- recibe todo el apoyo del pequeño staff liberacionista que venía trabajando en la Oficina para el Desarrollo de las Comunidades Rurales. Las dos tareas principales durante estos primeros meses de la institución fueron: a) la preparación del primer presupuesto institucional para el año 1968; y b) la elaboración del Reglamento a la Ley 3859 para lo cual el gobierno contrató asistencia técnica de DESAL (Desarrollo Económico y Social para América Latina) una entidad que por aquellos años -bajo la dirección de jesuitas- se especializaba en la promoción de la participación popular en América Latina.

b) La segunda etapa abarcó los años 1968-1969 ambos de la administración Trejos Fernández. El presidente para suplir la renuncia de don William nombró al ex gobernador de la provincia de Heredia y Licenciado en Derecho Jorge Luis Arce Sáenz como segundo director de DINADECO. Para 1968 la Asamblea Legislativa asignó un presupuesto de 939000 colones. Al año siguiente el presupuesto disminuyó a 639000 colones. ${ }^{12}$ Según estimaciones DINADECO tuvo en esta etapa un promedio de 40 funcionarios ${ }^{13}$ los cuales operaban bajo el organigrama que se muestra en la Figura 1.
Durante esta segunda etapa y específicamente la tarde del 18 de febrero de 1968 se constituyó la primera Asociación de Desarrollo de la comunidad en Santa Eulalia de Atenas. Entre esta fecha y el final de 1969 los funcionarios de campo de la naciente institución (unos veinte) con dos vehículos rurales y mucho esfuerzo lograron constituir 94 asociaciones más a lo largo y ancho del país.

c)Tercera etapa (mayo 1970-mayo 1974). En febrero de 1970 fue electo presidente de la República don José Figueres Ferrer. Una preocupación de su gobierno fue la modernización del agro. Para ello suscribió un acuerdo de préstamo con la Agencia Internacional de Desarrollo (AID) ${ }^{14}$ para financiar el Primer Plan Nacional de Desarrollo Agropecuario. ${ }^{15}$ Este plan pretendía reforzar los componentes de extensión agrícola, crédito, educación agrícola, cooperativas, mercadeo y tenencia de la tierra, todos orientados al desarrollo rural. Como nuevo director de DINADECO, fue nombrado José Luis González Ramos. Él observó la posibilidad de incrementar el presupuesto de la institución utilizando los recursos de ese acuerdo de préstamo entre el gobierno y la AID. Junto con Phillip Thompson, ${ }^{16}$ ahora funcionario de la AID convencieron a la administración Figueres Ferrer de incluir a DINADECO en el Plan Nacional Agropecuario así la institución reforzaría su presupuesto con medio millón de dólares durante un periodo de cuatro años además el gobierno se comprometió -como contrapartida- a aumentar el presupuesto de la institución (Fig. 2).

\section{Con renovados recursos, DINADECO pudo:}

- Incrementar el personal, descentralizar sus operaciones formular el Primer Plan Nacional de Desarrollo de la Comunidad y sobre todo, emprender un extraordinario esfuerzo de capacitación y concientización para dirigentes y funcionarios de la institución. En este

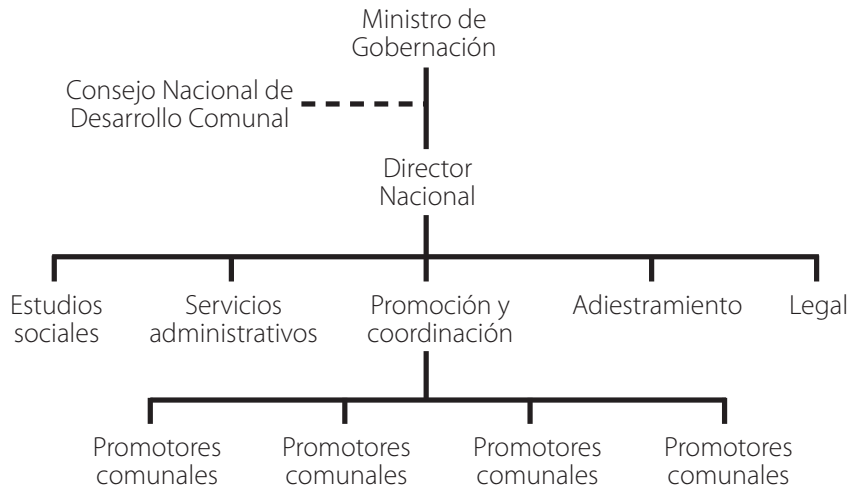

FIG. 1. Organigrama de DINADECO (1968-1973) 


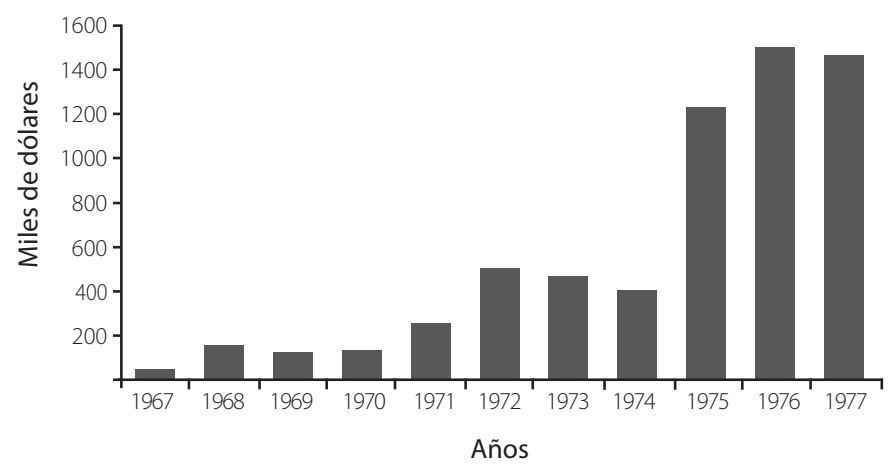

FIG. 2. Presupuesto total de DINADECO (1967-1977) en miles de dólares.

FUENTE: Elaboración con base en datos de DINADECO Departamento de

Programación, sección de Estadística, 1978.

sub-periodo, el Departamento de Capacitación, elaboró, editó y difundió miles de ejemplares de folletos que contenían reflexiones sobre los problemas nacionales. Los más destacados de ellos fueron "Miguel Hernández" y “¿Por qué? Estas publicaciones escritas eran complementadas con programas radiales. Hubo también, en muchas comunidades, las Jornadas de Desarrollo de la Comunidad, donde los vecinos reflexionaban sobre sus necesidades en relación con las causas estructurales que las provocaban y enfatizando la búsqueda de soluciones a través de la organización popular.

- La institución contrató asistencia de Acción Internacional Técnica, (AITEC), una firma fundada en Nueva York con experiencia en programas de acción comunitaria en Brasil, Perú y Venezuela. La asistencia técnica se brindó durante 1971 y $1972 .{ }^{17}$ Destaca el apoyo a una investigación pionera, sobre 101 comunidades costarricenses, cuyo informe fue editado en el libro Tipología de comunidades costarricenses.

- Pese al incremento de recursos DINADECO no aumentó, proporcionalmente, la constitución de Asociaciones de Desarrollo de la Comunidad. Entre 19701973 se constituyeron 103 asociaciones. Es decir, en cuatro años DINADECO constituyó casi igual número de asociaciones que las constituidas durante los dos años anteriores, pero sí fue notable el esfuerzo en capacitación y asistencia técnica a las Asociaciones de Desarrollo de la Comunidad ya existentes (Fig. 3).

d) Cuarta etapa (mayo de 1974-diciembre de 1978).

La asistencia técnica de AITEC proporcionó los lineamientos básicos para la formulación del Segundo Plan Nacional de Desarrollo de la Comunidad. Este Plan, elaborado en los primeros meses de 1974, se enfrentó a un obstáculo abismal: se habían agotado los recursos financieros del convenio entre el gobierno de Costa Rica y AID, que mejoraron, sustancialmente, la estructura y el funcionamiento de la institución durante el periodo anterior.

La nueva administración gubernamental del licenciado Daniel Oduber Quirós encontró una salida: el Programa de Desarrollo Social y Asignaciones Familiares (PRODESAF). Este programa había sido promulgado como ley de la República en la navidad de 1974. Punto medular de la ley fue su artículo 10, que obligaba a mejorar la condición socioeconómica de los grupos de población más necesitados en razón de su bajo o ningún ingreso. La ley creó como entidad coordinadora a la Dirección General de Desarrollo Social y Asignaciones Familiares, dependiente del Ministerio de Trabajo y Seguridad Social. El accionar de la dirección, sin embargo se haría a través de las instituciones ya establecidas, con el propósito -manifiesto pero incumplido- de no incrementar la burocracia pública. Amparándose en ello, DINADECO entonces pudo establecer un convenio con el Programa de Asignaciones Familiares, comprometiéndose a comités de vecinos para atender las necesidades del Programa, promoverlo en sus comunidades y servir de vínculo entre la comunidad y las instituciones relacionadas con el PRODESAF. En contrapartida, éste dotó de un presupuesto paralelo a DINADECO.

El incremento presupuestario permitió a DINADECO:

- Aumentar su personal, sobre todo de campo (151 personas en 1977). ${ }^{18}$

- Con más funcionarios y recursos, DINADECO se descentralizó en más oficinas y pudo así, durante este periodo constituir 551 Asociaciones de Desarrollo de la Comunidad, en todo el país, durante el periodo 19741977; además constituyó 431 Comités de Desarrollo ${ }^{19}$ 


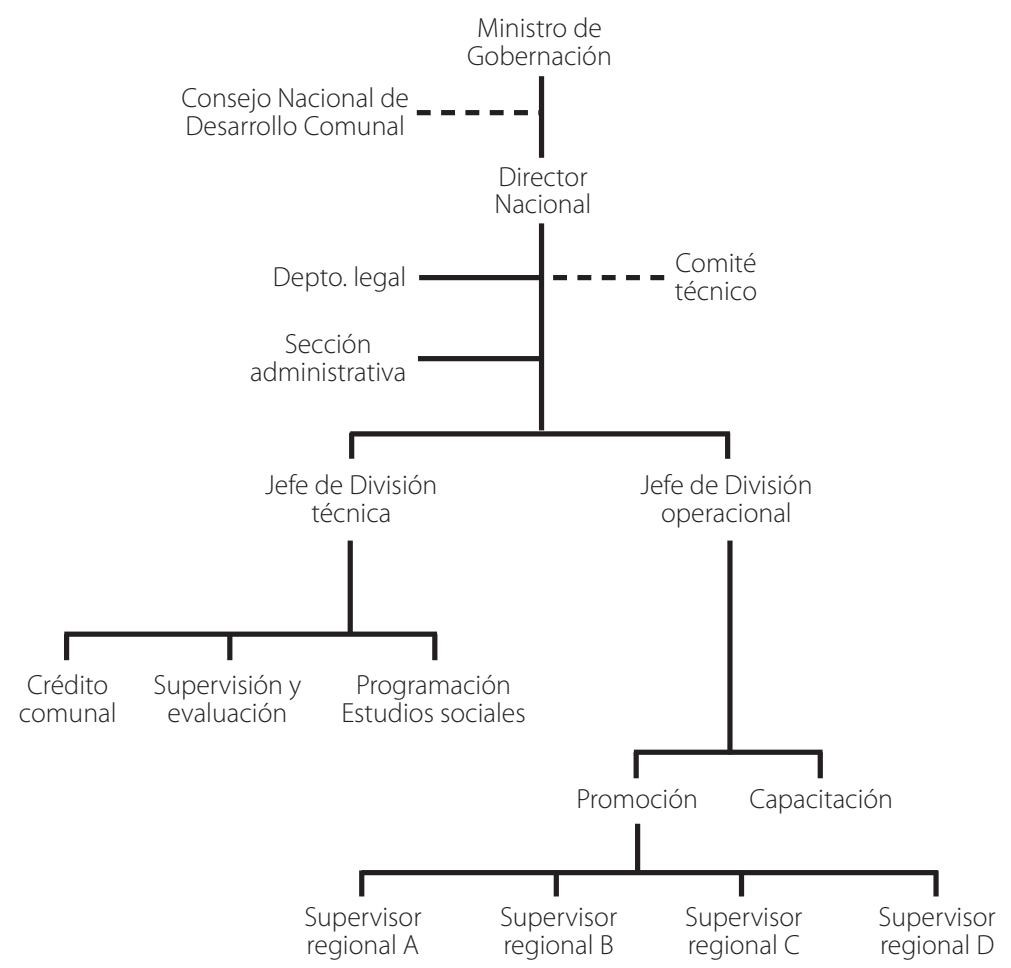

FIG. 3. Organigrama de DINADECO (1979-1978)

mayormente orientados a satisfacer las demandas del Programa de Asignaciones Familiares. ${ }^{20}$

Así, con un DINADECO creciente en recursos y orientado por la administración Oduber Quirós a alcanzar la meta de 1000 asociaciones, cierra el periodo bajo estudio de esta investigación.

\section{Las Asociaciones de Desarrollo de la Comunidad}

El siete de abril de 1967 el presidente Trejos Fernández ratificó la Ley 3859 mediante la cual se creó DINADECO. Esta ley establecía que la forma específica como la entidad cumpliría las funciones que se le asignaban, sería constituyendo, registrando y asesorando a las Asociaciones de Desarrollo de la Comunidad. Pero ¿qué es una Asociación de Desarrollo de la Comunidad? Habría, por lo menos, dos perspectivas desde donde poder responder a esta pregunta: una perspectiva conceptual y otra jurídica. Veamos la primera. ${ }^{21}$

\section{Marco conceptual para las Asociaciones de Desarrollo}

Detrás del término desarrollo comunal existe un concepto -o varios conceptos- que le fundamentan. En su sentido más general se le asocia con el concepto de "so- lidaridad comunitaria para el mejoramiento colectivo". La definición básica proviene de los años cincuenta y es de Naciones Unidas:

"Es un proceso complejo en el que hay dos elementos esenciales: la participación de la población misma en los esfuerzos para mejorar su nivel de vida dependiendo en todo lo posible de su propia iniciativa y el suministro de servicios técnicos y de otro carácter que estimulen la iniciativa, el esfuerzo propio y la ayuda mutua para aumentar su eficacia" (BID 1966).

En Costa Rica este concepto tuvo una fragua de casi un siglo. Por eso, cuando a principios de la década de los sesenta el Estado inició su institucionalización, encontró sobre el tapete, por lo menos tres conceptos de desarrollo comunal, operantes en las instituciones.

a) Un primer concepto tuvo relación con la mayoría de los proyectos institucionalizados sobre "desarrollo comunal", "educación comunitaria", "participación comunal", o cualquiera fuese el apellido que se les diera y que operaban bajo un concepto restringido de desarrollo comunal el cual sólo subrayaba una complementación -y en el mejor de los casos, la coordinación- de los esfuerzos gubernamentales con los esfuerzos comunales para la 
construcción de obras físicas en el nivel local. Este concepto era muy propio de la estrategia de desarrollo comunal que impulsaba el gobierno norteamericano desde la década de los cincuenta. 22 En Costa Rica, un ejemplo de esta corriente se presentaba en el Ministerio de Transportes, el cual tenía un departamento encargado de formar comités para que contribuyeran a la construcción de caminos, escuelas y centros comunales.

b) Una segunda acepción del término "desarrollo de la comunidad", ampliaba la visión restringida del concepto anterior. Desde esta nueva perspectiva el desarrollo comunitario sería parte esencial de la prestación de un servicio gubernamental. En lo intrínseco de la prestación del servicio está el mandato de que la comunidad se organice y participe. Porque ello garantizaría eficiencia y eficacia en la prestación del servicio. Tal vez el mejor ejemplo de esta segunda acepción para el desarrollo de la comunidad estuvo en el Ministerio de Salubridad de aquellos años.

En efecto desde los años veinte, el Ministerio de Salubridad (hoy Ministerio de Salud) consideraba la organización comunitaria como parte misma de la prestación de los servicios de salud. No se trataba sólo de mejorar la prestación del servicio. La participación organizada de la comunidad era parte esencial en la prestación del servicio. Así lo venía practicando el Ministerio desde los heroicos días de la lucha contra la malaria y así se continuaba practicado en la década de los sesenta, en las jornadas de vacunación infantil y en la estructuración del sistema de atención primaria en salud. Eso explicó, en gran medida, los éxitos de ese Ministerio en la erradicación de varias enfermedades epidemiológicas.

c) Un tercer acercamiento conceptual provenía de la Comisión Económica para América Latina (CEPAL). Como sabemos, durante la década de los sesenta y los setenta, Naciones Unidas, pero principalmente el dúo CEPALUNESCO estuvieron insistiendo en una idea que les parecía central para lograr el desarrollo latinoamericano, o por lo menos, para salir del subdesarrollo. El discurso oficial del dúo CEPAL-UNESCO, en el periodo inmediatamente posterior a la Segunda Guerra Mundial insistió, siempre, en que mientras los latinoamericanos no cambiáramos patrones de pensamiento y conducta que ellos llamaban tradicionales (arcaicos) y propios de las sociedades subdesarrolladas, no podría ser viable nuestro tránsito al desarrollo. ${ }^{23}$ En la Costa Rica de los años sesenta, algún sector del Ministerio de Educación Pública y la Oficina de Bienestar Social del Ministerio de Trabajo, se adscribieron a este concepto.

En Costa Rica, las primeras iniciativas para institucionalizar el desarrollo comunal provenían justamente de la CEPAL. Recuérdese que este fue el organismo al cual recurrió la administración de don Mario Echandi Jiménez para que creara y asesorara al primer grupo de trabajo sobre desarrollo comunal en Costa Rica. También fue CEPAL la entidad asesora de la primera experiencia práctica de desarrollo comunitario en Aguas Zarcas de San Carlos. No en vano, un producto de esta experiencia práctica fue el primer cartapacio para "el agente de cambio" costarricense.

d) Finalmente, estaba el grupo DESAL (Desarrollo Económico y Social para América Latina) el cual pretendía ir más allá de los conceptos de la CEPAL. DESAL estuvo liderado por el jesuita Róger Veckemanns y funcionaba con sede en Santiago, Chile. DESAL, además de continuar insistiendo, junto a CEPAL, en la necesaria transformación de actitudes del ser latinoamericano, proponía que las organizaciones de base como las Asociaciones de Desarrollo de la Comunidad, debían participar políticamente en la toma de decisiones a nivel cantonal, provincial y nacional y así -decía DESAL- romper con la "marginación política" que acompañaba a la "marginalidad económica" de las mayorías pobres latinoamericanas.

El grupo DESAL fue contratado por el gobierno de don José Joaquín Trejos Fernández, a finales en 1966, para que apoyara a la comisión encargada de redactar el anteproyecto de la Ley 3859 y posteriormente el Reglamento para esa misma ley.

\section{Asociaciones de Desarrollo: perspectiva jurídica}

El modelo conceptual -o mejor, los modelos conceptuales- vigentes y presentes en 1966, de alguna forma se expresaron en el modelo jurídico que construyó la comisión encargada de redactar el proyecto de Ley 3859.

El artículo 11 del Reglamento a la Ley 3859 conceptuaba así a las asociaciones: "Las Asociaciones para el Desarrollo de la Comunidad son organismos comunitarios de primer grado, con una circunscripción territorial determinada. Son entidades de interés público, aunque regidas por las normas del derecho privado." 24

El artículo 15 de la ley establecía la posibilidad de que DINADECO promoviera y constituyera dos tipos de asociaciones: integrales y específicas. Las primeras, con fines amplios y constituidas por un mínimo de 100 vecinos. Las segundas, con fines o propósitos restringidos, conformadas por un mínimo de 25 vecinos mayores de 15 años.

De base territorial pero con todas las posibilidades de ampliar esa base hasta alcanzar los niveles cantonales, provinciales, regionales y nacionales, tal como lo establece el artículo 41 de la ley: "Dos o más asociaciones de desarrollo de la comunal pueden fusionarse en una sola, formar uniones, federaciones y confederaciones." 
La Ley 3859 establecía, además, en sus artículos 14, 19,20 y 38 una serie de privilegios para este modelo organizativo. En primer lugar y de oficio se les declara de interés público. El artículo 19, por su parte, les otorga un porcentaje fijo anual de lo que el Estado recaude del impuesto sobre la renta. Se les exoneraba de impuestos y se facultaba a la Asamblea Legislativa para que ordene transferencias de dinero a las asociaciones. Se permitió y estimuló a las dependencias del poder ejecutivo, municipalidades e instituciones autónomas y semi-autónomas para que trasladen bienes a las Asociaciones de Desarrollo de la Comunidad.

Sin embargo, la contrapartida que les exigía el Estado a las Asociaciones de Desarrollo por estos privilegios, también fue muy clara y significativa. Explícitamente la ley establecía claros vínculos subordinantes de este modelo organizativo con la burocracia estatal, representada en DINADECO. Para decirlo en pocos términos, a cambio de privilegios financieros y jurídicos, DINADECO decidiría sobre su promoción y constitución. Vigilaría celosamente su funcionamiento y podría declarar la disolución de Asociaciones de Desarrollo de la Comunidad, con un argumento tan general como el "no ajustarse a los fines para los cuales fue creada".25

\section{Las críticas}

En el capítulo anterior describimos el proceso de institucionalización del desarrollo comunal costarricense. Al final de ese proceso, surgieron DINADECO y las Asociaciones de Desarrollo a la vida nacional. Hubo que esperar una década para que se iniciara un fuerte movimiento crítico hacia ambos. Surgió en el seno de la academia y se orientó a criticar el origen y los fines tanto de la institución como de sus productos, es decir, de las Asociaciones de Desarrollo de la Comunidad.

\section{Las críticas}

En nuestra revisión bibliográfica hemos encontrado censuras, que por lo reiteradas, se erigen como típicas. Son, básicamente, tres:

a) La Dirección Nacional de Desarrollo de la Comunidad (DINADECO) y las Asociaciones de Desarrollo Comunal surgen como una estrategia del gobierno norteamericano.

b) La Dirección Nacional de Desarrollo de la Comunidad y las asociaciones surgen como una respuesta estatal contra las Juntas Progresistas.

c) La Dirección Nacional de Desarrollo de la Comunidad y las Asociaciones de Desarrollo son producto de una estrategia política, del partido Liberación Nacional para realizar oposición efectiva a la Municipalidad en aquellos municipios dondeelectoralmenteese partido era débil o había perdido el control municipal.

Veamos, con mayor detalle, cada una de ellas.

a) Una estrategia para la contrainsurgencia del gobierno norteamericano:

Estudiosos del desarrollo comunal costarricense le atribuyen un origen externo y relacionado con los intereses geopolíticos del gobierno norteamericano, específicamente, con los de la administración Kennedy. En términos generales -dicen estos académicos- el triunfo de la revolución cubana (1959) y su "viraje" hacia la Unión Soviética -"eje del mal" en aquellos años- era un mal ejemplo para los pueblos latinoamericanos. Un ejemplo que podría fomentar insurgencias y focos revolucionarios, vinculados con los intereses nacionales y populares. Este espectro azoraba los intereses norteamericanos. Temían que una ideología populista orientando a los movimientos sociales, pronto derivase hacia posiciones socialistas, antinorteamericanas.

Frente a tan oscuros temores, el gobierno norteamericano había diseñado, a partir de la Conferencia Hemisférica de Punta del Este (Uruguay) una estrategia general de contrainsurgencia que denominó Alianza para el Progreso y dentro de esta estrategia general, estrategias particulares como los Cuerpos de Paz y la práctica del desarrollo comunal.

En relación con el desarrollo comunitario, la idea implícita era que el involucramiento de los pobladores de las comunidades rurales y empobrecidas, con sus gobiernos en tareas de modernización local les alejaría de tentaciones revolucionarias; primero, porque los comprometía ideológicamente con el gobierno; segundo, porque solucionaban problemas que eventualmente podrían llevarlos a posiciones contestatarias.

Algunos estudiosos del desarrollo comunal costarricense trasladan esta misma línea de pensamiento al país. Atribuyen el origen del desarrollo comunitario costarricense a las mismas razones que explican su nacimiento en América Latina, es decir, le atribuyen sus orígenes y fines vinculados a una estrategia norteamericana de contrainsurgencia. Así, uno de los autores más difundidos señala que:

La creación de DINADECO y la Ley de Asociaciones de Desarrollo Comunal a mediados de los años sesenta, en el gobierno de Trejos Fernández, obedece a dos razones fundamentales.

Por un lado constituye una respuesta nacional a todo un planteamiento internacional ligado al programa de la Alianza para el Progreso. Este programa, desarrollado por 
el gobierno de los Estados Unidos financiaba una serie de programas en los distintos países de América Latina y tenía como condición que los vecinos de las comunidades hicieran comités dirigidos y controlados por los gobiernos. Este programa internacional era una reacción del gobierno norteamericano para evitar que las luchas vecinas y sindicales se desarrollaran mucho por la situación creada por el triunfo de la revolución en Cuba en 1959 (Argüello 1983).

Siguiendo esta misma forma de pensar, otros académicos, encuentran razones más específicas. Consideran por ejemplo que uno de los derivados del Programa de la Alianza para el Progreso fueron los Cuerpos de Paz, brigadas voluntarias de jóvenes norteamericanos que venían a radicar a los países tercermundistas para apoyar tareas de desarrollo comunitario, tales como la construcción de acueductos rurales, escuelas y salones comunales. En la visión crítica de estos académicos, la función latente, implícita, de estos jóvenes voluntarios norteamericanos habría sido la de apoyar tareas de contrainsurgencia en los países subdesarrollados. ${ }^{26}$

\section{b) Destruir a las Juntas Progresistas:}

Articulada con la idea anterior (origen externo y relación con los intereses norteamericanos), otra concepción supone el nacimiento de DINADECO en una estrategia específica para destruir al movimiento de las Juntas Progresistas. ${ }^{27}$ Quienes así argumentan ${ }^{28}$ consideran que estas agrupaciones sí eran expresiones organizadas de la voluntad popular, que eran contestatarias al Estado costarricense y que por ello este decide destruirlas creando, en su lugar, las Asociaciones de Desarrollo Comunal.

El movimiento comunal autónomo existente en Costa Rica y en la mayoría de los países latinoamericanos, por las características ya descritas, resultaba no sólo incómodo, sino peligroso para las políticas y programas reformistas a nivel nacional y continental, que buscaban modernizar y adecuar el capitalismo, atenuando las tensiones sociales, creadas y aceleradas por la desigualdad en la distribución de la riqueza.

En Costa Rica la lucha entre el Programa de Desarrollo Comunal estatal y el movimiento comunal autónomo se inició en los primeros años de la década de los sesenta y se intensificó en la década siguiente (Mora 1989).

Tanta insistencia se ha puesto en este argumento, que hasta los estudios académicos más recientes repiten, con una propiedad a prueba de duda, que: "El Estado creó las Asociaciones de Desarrollo como alternativas a las juntas con el fin de apropiarse del terreno de dinamismo comunal".29

c) Una estrategia del partido Liberación Nacional:

Una tercera explicación sobre el origen del desarrollo comunal en Costa Rica alude al interés de un partido político para controlar el espacio local.

Quien concretó esta crítica fue el exministro de Planificación Nacional, don Wilburg Jiménez. Decía don Wilburg:

Cuando llegó al poder el profesor José Joaquín Trejos Fernández se dio la circunstancia de que su agrupación política logró alcanzar los principales puestos de dirigencia en la mayor parte de las municipalidades de todo el país. Este hecho de inmediato despertó resquemores entre la agrupación opositora, sobre todo que la campaña había sido particularmente violenta y los ánimos quedaron exaltados. Como una forma de crear un contrapoder dentro del régimen municipal, el partido opositor tuvo la idea de crear una institución paralela alas municipalidades, que posteriormente llegó a ser DINADECO. Tal situación creó un enfrentamiento muy fuerte entre las municipalidades $y$ las Asociaciones de Desarrollo Comunal (Rivera 1995).

\section{Crítica a las críticas}

Después de navegar -aún superficialmente como lo hicimos en el capítulo anterior- por la historia de DINADE$\mathrm{CO}$, sentimos inconformidad con estas tres críticas relacionadas con el por qué fue creada la institución. Llega uno a considerar que estas tres críticas, aún siendo ciertas y aún actuando conjuntamente son insuficientes para explicar de manera adecuada el surgimiento del desarrollo comunal institucionalizado en el país. ${ }^{30}$ Veamos por qué.

\section{Crítica a la primera crítica}

En relación con la primera crítica, aquella que considera un origen externo e impuesto para DINADECO y las asociaciones, es decir, aquella que subraya y con doble línea roja, la influencia de la administración norteamericana del presidente Kennedy en la génesis del desarrollo comunal costarricense. Contra esta tesis surgen, cuando menos, los siguientes contra argumentos.

a) De una manera diferente a lo que ocurrió en otros países latinoamericanos, las primeras iniciativas oficiales para institucionalizar el desarrollo comunal en Costa Rica precedieron al triunfo de la Revolución Cubana. Queremos decir con esto que, si como argumenta uno de los principales exponentes de esta tesis, ${ }^{31}$ esta revolución desencadenó temores en la administración norteamericana que se tradujeron en el diseño y exportación de estrategias como el desarrollo comunal con fines básicamente estratégicos, eso no ocurrió -exactamente así- en el caso costarricense. Aquí y desde 1958, con el inicio de la administración Echandi Jiménez, se iniciaron las primeras acciones oficiales para crear una instancia pública que rigiera un programa nacional de desarrollo comunal. Recuérdese que en 
ese año se había enviado a Jamaica una misión especial de técnicos para observar, allá, el programa de desarrollo de la comunidad.

b) Más aún: la fecha en que el gobierno de Costa Rica inicia estas gestiones dista mucho -un quinquenio- del comienzo del Programa Alianza para el Progreso y, consecuentemente, de la llegada de los Cuerpos de Paz.

c) Tampoco existía por acá ese clima de efervescencia populista o revolucionaria que reclamara, con urgencia, el diseño de estrategias anti-insurgentes, tipo desarrollo comunal. En 1958, lo que más azoraba al país era el regreso del doctor Calderón Guardia.

d) La solicitud de asistencia técnica de la administración Echandi Jiménez, se dirige, expresamente y desde el principio hacia Naciones Unidas y, en particular, hacia CEPAL. Como vimos, esta entidad tenía un planteamiento sobre el desarrollo comunal, muy divergente en relación con el planteamiento de la AID. Algún académico costarricense afirma que incluso el gobierno de los Estados Unidos veía con demasiadas reservas el pensamiento que se fraguaba al interior de la CEPAL. ${ }^{32}$

e) Finalmente habría que agregar que desde que se inician las gestiones para oficializar el desarrollo comunal en Costa Rica, todo ${ }^{33}$ el proceso corre a cuenta de un gru$\mathrm{po}^{34}$ de técnicos nacionales, con un largo currículum en proyectos de desarrollo comunitario. La mayoría de ellos adscritos ideológicamente a la social-democracia. ${ }^{35}$

f) Descartada la estrategia norteamericana como pecado original del desarrollo comunitario costarricense, sí deberíamos decir que es ingenuo pensar que la AID (agencia de cooperación norteamericana) y el mismo gobierno norteamericano no influyeron para que el modelo resultante de DINADECO y de las asociaciones encajara dentro de su estrategia anti-insurgente, la cual ya para mediados de la década de los sesenta, sí tenía un perfil muy definido. Pero y esto es lo importante, por el hecho de que el proceso había iniciado temprano y había sido puesto en manos de un grupo de técnicos, ${ }^{36}$ con una visión propia del desarrollo nacional, siempre la influencia norteamericana fue tardía -en relación con otros países latinoamericanos- y siempre la influencia norteamericana fue mediada por ese filtro doméstico.

\section{Crítica a la segunda crítica}

Vayamos ahora a la segunda crítica. Dice: ${ }^{37}$ la Dirección Nacional de Desarrollo de la Comunidad y las asociaciones surgen como una respuesta estatal contra las Juntas Progresistas.

Recordemos brevemente que las Juntas Progresistas nacieron a principios de la década de los veinte, del siglo pasado; treinta y cinco años después llegaron a federarse en una organización de tercer grado, la Federación Nacional de Juntas Progresistas y prácticamente desaparecieron a partir de 1983. En sus mejores momentos -década de los sesenta- llegaron a ser como trescientas, ubicadas principalmente en el Valle Central y en el Área Metropolitana de San José. Encabezaron luchas importantes por servicios públicos comunitarios (electricidad, agua, transporte público) y por la defensa a la soberanía nacional. ${ }^{38}$

a) Hay aquí una perversidad que es necesario develar desde el principio. Los autores que defienden esta posición atribuyen a las Juntas Progresistas una pureza en su composición y en sus relaciones que no es cierta. Con ello las hacen aparecer como "políticamente puras" ante las "políticamente contaminadas Asociaciones de Desarrollo". Y eso no es cierto. En la década de los sesenta, un grupo de Juntas Progresistas -las más beligerantes en la defensa de la soberanía nacional y por la reivindicación del derecho ciudadano a servicios públicos baratos y de calidad- estaban adscritas a un partido de la izquierda costarricense. Así lo reconocen, incluso, algunos de quienes suscriben la crítica a las Asociaciones de Desarrollo de la Comunidad. ${ }^{39}$

b) En segundo lugar las Juntas Progresistas no fueron un todo homogéneo. ${ }^{40}$ No todas participaban de la estrategia confrontativa que caracterizó a algunas de las Juntas Progresistas urbanas. Creadas desde la década de los veinte, hubo muchas -sobre todo en la parte rural del país- que funcionaban bajo el mismo concepto de desarrollo de la comunidad con el que luego funcionarían las Asociaciones de Desarrollo Comunal. Recuérdese aquí, a manera de ejemplo, que la primera experiencia oficial sobre desarrollo comunal, convocada por el primer grupo de trabajo, durante la administración Echandi Jiménez, fue coordinada por la Junta Progresista de Aguas Claras de San Carlos. Así es que, cuando se crean las primeras asociaciones, muchas de las Juntas Progresistas, atraídas por las ventajas financieras del nuevo modelo, por propio interés deciden transformarse en Asociaciones de Desarrollo Comunal. Más aún: en los primeros años de los setenta, algunas Asociaciones de Desarrollo de la Comunidad se prestaron para trasladar recursos de la Asamblea Legislativa hacia las Juntas Progresistas, vía partidas específicas.

c) Junto a lo dicho, el argumento más significativo para minimizar esta crítica dirigida contra los fines del desarrollo comunal, es que a todas luces, resultaría absurdo que el Estado (es decir, algo más que un partido y algo más que un gobierno) hubiese hecho un esfuerzo de la constancia descrita (una década de discusiones, proyectos experimentales, etc.) y de la magnitud descrita (un centenar de asociaciones constituidas durante los veinte primeros meses de funcionamiento de DINADECO) 
sólo para librarse de la pesadilla de las Juntas Progresistas, que por lo demás ya habían ingresado a una fase de declive a finales de la década de los sesenta. ${ }^{41}$

d) Nuevamente tendremos que argumentar aquí que lo anterior no implica que el Estado no deseara eliminar a las Juntas Progresistas. Pero si ese fue su objetivo cuando creó a DINADECO y a las Asociaciones de Desarrollo, deberíamos suponer una absoluta irracionalidad del Estado, pues para eliminarlas o limitarlas bastaba con un esfuerzo infinitamente menor. Nuestra posición es que la creación del modelo Asociación de Desarrollo -con todos los privilegios que ese modelo implicaba para las comunidades- hizo desaparecer a las ya debilitadas Juntas Progresistas pero como una consecuencia secundaria o terciaria. Como argumentaremos después el objetivo estatal para crear DINADECO y al modelo Asociación de Desarrollo obedecía a pretensiones mayores e intensas. Pretensiones incluso compatibles con la existencia de Juntas Progresistas.

\section{Crítica a la tercera crítica}

La tercera crítica dice, aproximadamente, lo siguiente: la Dirección Nacional de Desarrollo de la Comunidad y las Asociaciones de Desarrollo son producto de una estrategia política, del partido Liberación Nacional para realizar oposición efectiva a la municipalidad en aquellos municipios donde electoralmente ese partido era débil o había perdido el control municipal.

a) Esta crítica parecería tener una lógica inherente. En efecto, los partidos políticos actúan para adquirir y concentrar el poder. Sería natural que allí donde lo pierden, instauren mecanismos organizativos para recuperarlo o contrastarlo. Uno de esos mecanismos serían las Asociaciones de Desarrollo. Esta lógica resulta más clara cuando a su favor se invocan casos convincentes. ${ }^{42}$ Sin embargo, hay otra evidencia en contrario. Más fuerte, según nosotros.

b) Preguntamos: ¿para qué tan ardua estrategia de Liberación Nacional, si en las elecciones de 1970 -inicios de DINADECO- ese partido ganó prácticamente todas las municipalidades del país, con un porcentaje de votación que superó el 50\%? Desde esta perspectiva, es lógico entonces contraargumentarle a don Wilburg Jiménez $z^{43}$ diciéndole que no habría razones objetivas para que Liberación -presente en el nacimiento de DINADECO- utilizase a la institución para ese propósito político específico.

c) También podríamos preguntarnos que si, efectivamente esa fue una estrategia de Liberación Nacional durante esos primeros años de DINADECO, no se explicaría que ese mismo partido, en ese mismo periodo, fortaleciera al Régimen Municipal con la elaboración de un nuevo Código Municipal (que inauguraba los Consejos de Distrito) y la creación del Instituto de Fomento Municipal (IFAM). Desde esta nueva perspectiva suena mejor el argumento de don Roy Rivera ya citado, quien decía: "Podemos decir que el Partido Liberación Nacional propulsó dos formas de construir o reconstruir'lo local', una por medio del IFAM y el ordenamiento municipal y la otra, por medio de DINADECO y el sistema de asociaciones de desarrollo; cada una de las cuales privilegió, en distintos tiempos y según la coyuntura política".44

d) Nuevamente necesitamos aclarar que lo anterior no significó que en coyunturas y espacios muy específicos los partidos políticos se apoyaran en las asociaciones para "combatir" o "complementar" a las municipalidades. Es decir, para tener un mayor acceso al poder político local. Pero este, para nosotros, no es el asunto de fondo.

Nos parece que el asunto de fondo es que DINADECO y las Asociaciones de Desarrollo de la Comunidad, son, desde el inicio, un asunto de Estado, tema de Estado, proyecto de Estado. No son, principalmente, un asunto de gobierno o de partido. Como tal, -aunque pueden verse involucrados- supera los intereses de un gobierno y de un partido político (cualquiera). Algunos indicios que tienden a verificar esta hipótesis son los siguientes: los primeros esfuerzos gubernamentales para institucionalizar el desarrollo comunal y el proceso mismo de su institucionalización siempre se caracterizaron por superar diferencias políticas entre partidos y gobiernos. Baste recordar la sesión solemne, presidida por el presidente y su gabinete, cuando se constituye al Primer Grupo de Trabajo sobre Desarrollo Comunal. Baste recordar, que ese grupo no era afín, políticamente, al presidente de ese entonces. Baste recordar la continuidad que le da la administración Orlich Bolmarich -políticamente contraria a la anterior-al Grupo de Trabajo. Baste recordar la aprobación unánime, en la Asamblea Legislativa de la Ley $3859 . .$. o basten las palabras de un ex vicepresidente de la República, quien en 1979, reconocía:

"La ley de Desarrollo Comunal para mí es, lo decía anoche, la ley institucional más importante que se ha dictado en Costa Rica después de las garantías sociales "( Alfaro 1981).

Efectivamente. El tema DINADECO fue un asunto de Estado.

\section{El contexto nacional}

Justamente el problema central de las críticas a DINADECO y a las asociaciones es que suponen que ambas surgieron fuera del Estado costarricense: por encima (intereses extranjeros) o por debajo (intereses de un gobierno o de un partido). Esta falsa posición es responsable de que 
observemos, también, un defecto común de todas las críticas sobre el origen del desarrollo comunal costarricense. Ese elemento es la ausencia de un marco de referencia que contextualice la crítica. Así, por ejemplo, quienes consideran al desarrollo comunal como un producto directo de la Alianza para el Progreso, omiten referirse a la situación económica, social, política del país que explique y justifique tal relación. Y quienes entienden al desarrollo comunal como un resultado directo de una estrategia estatal para desaparecer a las "incómodas" Juntas Progresistas, también omiten referirse a la situación del país, en esos años.

Para la mayoría de los críticos (ya sea la crítica positiva o negativa) el surgimiento del desarrollo comunal obedece a una relación causal, específica y unívoca: el desarrollo comunal aparece como una estrategia para combatir posibilidades contestatarias o subversivas. Nada más; o, bien desarrollo comunal surge para favorecer la participación popular. Punto.

Es claro que esta ausencia de contexto en las críticas debilita el poder explicativo de ellas. Si queremos avanzar, será necesario que nos refiramos al contexto nacional y su evolución durante el período bajo estudio. Aún cuando esa referencia no sea exhaustiva.

\section{La Costa Rica de los años cincuenta}

Como punto de partida, podríamos plantearnos los problemas estructurales, objetivos, de la formación social costarricense ${ }^{45}$ en los años precedentes al surgimiento de DINADECO y las asociaciones.

La Costa Rica de principios de la década de los cincuenta no llegaba al millón de habitantes. El 55\% de la PEA se concentraba en el sector agropecuario. ${ }^{46}$ El $41 \%$ del $\mathrm{PIB}^{47}$ se generaba allí, el $95 \%$ de las exportaciones salían de ese mismo sector. ${ }^{48}$ El $86 \%$ del valor de nuestras exportaciones -sí, el $86 \%$ - radicaba en tres productos: café, banano y cacao. ${ }^{49}$ Predominaban en el agro costarricense técnicas rudimentarias de producción. Además, sólo una quinta parte del territorio tenía algún uso agropecuario o forestal. ${ }^{50}$

Entonces, siguiendo la línea de pensamiento de Offe, urgía cambiar. Para la tecnocracia costarricense estaba claro que un problema estructural de la formación social costarricense, en la década de los cincuenta, era incrementar y diversificar la producción agropecuaria. ${ }^{51}$ Así lo veía también -y en primera instancia- la CEPAL y así lo veía también el grupo político que había tomado la conducción del Estado después de la revolución de 1948. Coincidían también en comprender que los cambios no provendrían del sector empresarial. Sería necesaria una muy activa participación estatal. ${ }^{52}$

\section{Un periodo de cambios}

Desde mediados de la década de los cincuenta, el gobierno de don José Figueres Ferrer había puesto en marcha un modelo de crecimiento económico cuyos fundamentos fueron, por una parte las premisas de la CEPAL y por otra, la naciente ideología social-democrática prevaleciente en el grupo que le acompañó en su ascenso al poder. ${ }^{53}$ En particular, Figueres siempre estuvo de acuerdo con la CEPAL en cuatro medidas de política económica: a) la tecnificación y diversificación agropecuaria; b) el incremento de la producción ganadera; c) la tecnificación del sector secundario; y d) el incremento de la participación del Estado para el logro de los fines anteriores. ${ }^{54}$ La base de estas premisas fue lo que Solís llama la "utopía tecnológica" de Figueres. En otras palabras, una "revolución tecnológica" que incrementara sustancialmente la productividad del campo y de la industria.

En términos generales podemos afirmar que este nuevo modelo de crecimiento económico costarricense marchó viento en popa, sin grandísimos contratiempos, hasta finales de la década de los setenta. ${ }^{55}$

En efecto, en términos estrictamente económicos y para ese periodo, podemos afirmar que el modelo fue exitoso en dinamizar los sectores primario y secundario de la base productiva nacional. Veamos.

\section{El crecimiento económico en el sector agropecuario}

Durante el período 1957-1978 el PIB agropecuario nacional prácticamente se triplicó. ${ }^{56}$ Fue un crecimiento muy importante, con tasas anuales que difícilmente se volvieron a repetir. Por ejemplo, durante el sub-periodo 1966-1970, un informe del BID señalaba que, en relación a Latinoamérica, Costa Rica mostró una mayor tasa de crecimiento del valor agregado del sector agropecuario.

Sin embargo, sobre tan significativo incremento deberíamos acotar lo siguiente:

a) El crecimiento del PIB agropecuario no fue uniforme durante el período. Hubo sub-períodos de un crecimiento extraordinario, seguidos de sub-periodos no tan notables. Grosso modo podríamos establecer dos grandes sub-periodos: a) de 1957 a 1973 un crecimiento mayor; $y$ b) de 1974 a 1980 un crecimento mucho menor.

b) El crecimiento del PIB agropecuario fue mayor en las grandes explotaciones. En 1973 -única cifra disponible- la mitad del valor total de la producción agropecuaria se generó en explotaciones agropecuarias grandes, con más de 200 hectáreas. ${ }^{57}$

c) Concordantemente, el notable incremento del PIB agropecuario estuvo relacionado más con el aumento de la productividad (y particularmente en los productos de 
exportación). Entre 1963 y 1978 el producto por persona ocupada se duplicó. ${ }^{58}$

d) El impresionante crecimiento del PIB agropecuario no fue uniforme por tipo de producto. En el subsector de granos básicos, es decir, aquel orientado al consumo nacional y a la subsistencia campesina (frijol, maíz) hubo un ritmo de crecimiento sensiblemente menor al de los productos agropecuarios orientados al mercado externo como el café, la carne de res, la carne porcina y el banano. ${ }^{59}$

e) El papel del estado fue fundamental para el desarrollo del sector agropecuario. ${ }^{60}$ Un elemento de apoyo fue el crédito público, donde se observó una mayor contribución al subsector ganadero. En efecto, porcentualmente, el crédito a la agricultura disminuyó durante el período, pero el crédito a la ganadería se incrementó sustancialmente. ${ }^{61}$

\section{Los aspectos sociales del crecimiento económico en el sec- tor agropecuario}

El agro costarricense fue escenario, durante el período en estudio, de dos diferentes versiones del crecimiento agropecuario. Dos películas distintas en un mismo escenario. Por un lado se observó un dinamismo sin precedentes en las actividades agropecuarias vinculadas a la exportación: café, banano, caña de azúcar, ganado vacuno y porcino y concomitantemente, el crecimiento inusitado de los actores directamente relacionados -dueños- con estos productos. Para citar solo una cifra, en el periodo 1971-1977 (seis años) el 20\% de las familias más ricas en el sector rural incrementaron su participación en el total del ingreso rural en un 11\%. En 1971 percibían el 44\% de los ingresos rurales; seis años después, el 55\%.2

La otra puesta en escena en el sector agropecuario es menos difundida. Se trata de esos pequeños y numerosos actores, de esa multitud de diminutos propietarios agrícolas que producían para el mercado interno y que fueron excluidos de los "factores dinamizantes del crecimiento", como dicen los economistas. Hemos observado que el valor de lo producido por estos pequeños campesinos, en términos relativos, comenzó a decrecer con la implementación de este modelo de crecimiento económico en el agro. ${ }^{63}$ Esta pérdida del valor de la producción en las pequeñas fincas, se reflejó en una menor participación de los sectores más pobres del agro en el ingreso. MIDEPLAN nos informa que en 1971 el 30\% de las familias más pobres del sector rural percibían el $12 \%$ de los ingreso de ese sector. Solo seis años más tarde, en 1977, su participación decayó a la mitad. En este último año, sólo percibieron el $6 \%$ del ingreso total del sector rural. ${ }^{64}$

No es de extrañar, entonces, que se haya incrementado la pobreza en el campo. Ya para julio de 1977 se estimaba que había unas cuarenta y cinco mil familias viviendo en extrema pobreza en el mundo rural. Y había otras treinta mil que no satisfacían sus necesidades básicas (Fig. 4). ${ }^{65}$

La pobreza y la pérdida del valor de su producción empujaron a muchos campesinos hacia la venta o el abandono de sus pequeñas parcelas. Ello pudo haber estimulado un proceso de concentración de la tierra. ${ }^{66}$ OFIPLAN, nos informaba que, entre 1963-1973 "la evaluación de las cifras de los dos últimos censos señalan [...] una acentuada concentración de la tierra a partir de las fincas mayores de 100 hectáreas".67

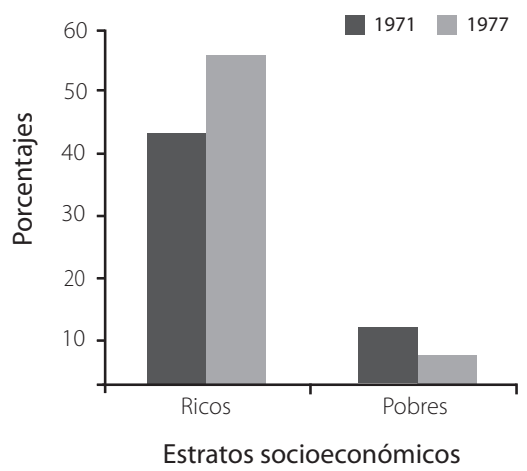

FIG. 4. Distribución del ingreso en el mundo rural, $20 \%$ de las familias más ricas y $30 \%$ familias más pobres (1971-1977).

FUENTE: OFIPLAN, Evolución socioeconómica de Costa Rica (1950-1980). San José: EUNED, 1982, p. 190.

Es muy posible también que por estas situaciones los campesinos se proletarizaran, o, en todo caso, iniciaran o reforzaran prácticas mixtas de ocupación laboral: una fracción de la jornada en sus propias e insuficientes parcelas y otra fracción en la vecina y moderna empresa agropecuaria, que producía para el mercado externo. Con ello se maquillaba el desempleo en el campo.

En cuanto a la proletarización campesina las cifras son evidentes: hubo un incremento, absoluto y relativo, de la PEA asalariada en el agro costarricense. En 1963 había unos 100 000 trabajadores remunerados en la agricultura; diez años después, 27000 más. En 1963 esta categoría de trabajadores representaba el 53\% de la PEA agrícola; en 1973, un 7\% más. ${ }^{68}$

Pero también se incrementó el desempleo. Sobre todo en los últimos años del período, es decir, hacia el final de la década de los setenta. Porque en términos relativos (y en algunas actividades en términos absolutos) el agro costarricense fue perdiendo su tradicional capacidad de 
absorber empleo. En 1963, la mitad de la PEA nacional se ocupaba en el sector primario; diez años más tarde, sólo el $38 \%$. Diez años después, hacia la mitad de la década de los ochenta, sólo 31 de cada 100 trabajadores se ubicaban en el sector primario de la economía nacional. ${ }^{69}$

Se juntaron, pues y como siempre -para el pequeño campesino y jornalero costarricenses- los cuatro jinetes apocalípticos: desempleo, bajos ingresos, concentración de la tierra y falta de servicios públicos. Estos factores, actuando articuladamente explican las fuertes corrientes migratorias que se observaron, en el medio rural costarricense, durante todo el periodo que cubre esta investigación.

OFIPLAN estimó que durante el periodo 1968-1973, el $14 \%$ de los costarricenses mayores de cinco años, cambiaron su cantón de residencia. ${ }^{70}$ Esto equivale a casi un cuarto de millón de personas, las cuales, mayormente impulsadas por la falta de oportunidades en sus cantones de residencia, optaron por desplazamientos geográficos para mejorar su situación. Llama la atención -según el mismo texto- que la mitad de estos movimientos ocurrieron entre las zonas rurales del país.

Los estudiosos del tema establecen relaciones entre los cambios en la estructura agraria ocurridos en el periodo y el desempleo. ${ }^{71}$ También establecen relaciones entre los cambios en la estructura productiva agraria y las corrientes migratorias. Por ejemplo, refiriéndose a la expansión de la actividad ganadera -típica del crecimiento agropecuario durante el periodo- un académico señala que: “En general, los cantones típicamente ganaderos tienden a ser zonas de emigración y muchas de las nuevas zonas de expulsión existentes en el país, son áreas de reciente desarrollo ganadero."72

Cuatro fueron los principales focos de atracción para los movimientos migratorios rurales:

a) Aquel constituido por los cantones de Sarapiquí, Pococí, Guácimo, Siquirres y Matina, todos de la Región Huetar Atlántica y hacia donde inmigraron unos 20000 costarricenses, atraídos, principalmente, por la expansión de la producción bananera durante las décadas sesenta y setenta.

b) Un foco de atracción conformado por los cantones de Buenos Aires y Coto Brus.

c) Aquel integrado por los cantones de Upala, Guatuso, Los Chiles en la zona fronteriza norte (Región Huetar Norte). Eran cantones pobres, carentes de servicios, pero que contaban con la posibilidad de extender el área cultivable, mediante la incorporación de tierras baldías. ${ }^{73}$

d) Finalmente, destaquemos el foco de atracción Área Metropolitana de San José, el cual, durante el subperiodo
1968-1973, tuvo un importante saldo migratorio positivo. Su núcleo más atractor estuvo conformado por los cantones de Curridabat, Moravia, Tibás, Desamparados y Alajuelita. ${ }^{74}$ Es decir, un área geográfica que se extiende en la periferia sur-este de la ciudad de San José. Evidentemente, esta atracción de migrantes se produjo por el dinamismo de la actividad industrial y comercial, la cual se había concentrado en el Área Metropolitana de San José, durante la década de los setenta.

\section{El crecimiento económico en el sector industrial}

Recordemos que junto a la tecnificación del agro -mejor dicho, de una parte- Figueres y la CEPAL invocaban el crecimiento del sector secundario (industrial) para salir del atraso productivo y social de la Costa Rica de los cincuenta. Si bien es cierto que en 1940 el país había decretado una ley industrial, ésta lejos de promover su crecimiento lo inhibía, en tanto pretendía -utópicamente-que ese crecimiento se sustentase sobre el aprovechamiento -hasta en un 75\%-de los insumos nacionales. ${ }^{75}$

A partir de la llegada al poder, del grupo triunfante en la Revolución del 48 y en consonancia con el pensamiento de la CEPAL, ${ }^{76}$ el Estado impulsó una nueva Ley de Protección y Desarrollo Industrial (1959), la cual vino a organizar e incentivar-mediante prebendas fiscales y otras regalías- el crecimiento industrial en el país (no del país). A partir de entonces se observará un extraordinario crecimiento del sector secundario de la economía, ${ }^{77}$ particularmente favorecido, pocos años después, con el ingreso de Costa Rica al Mercado Común Centroamericano durante la administración liberacionista Orlich Bolmarich. Algunos de los rasgos sobresalientes de tal crecimiento son:

a) Todos los indicadores coinciden en subrayar el extraordinario crecimiento de la industria, todavía mucho mayor que el observado en el sector agropecuario. Así,para citar un caso, el PIB industrial creció mucho más rápido que el PIB nacional y especialmente, a partir de la mitad de la década de los sesenta. ${ }^{78}$ En 1959 el PIB industrial representaba el 13,7\% del PIB Nacional; en 1975, significaba el $20 \% .^{79}$ Tanto fue así que, durante el período 1961-1977 Costa Rica mostró el primer lugar en relación al conjunto de países latinoamericanos en cuanto al crecimiento del valor agregado del sector manufacturero. ${ }^{80}$

b) Tan extraordinario crecimiento sólo fue posible mediante un decidido y múltiple apoyo del Estado, proporcionándole un marco jurídico proteccionista; creando infraestructura para la industria; ${ }^{81}$ generando electricidad y otorgándosela -al sector industrial- con precios subsidiados a los servicios públicos de electricidad, por ejemplo; también mediante el crédito otorgado a través del Sistema Bancario Nacional: entre 1960 y 1974 el porcentaje 
de crédito otorgado al sector industrial se duplicó, ${ }^{22}$ pero sobretodo, promoviendo y facilitando la inversión extranjera directa en el sector industrial.

c) La participación de la inversión extranjera directa en la actividad industrial, a partir de la segunda mitad de la década de los sesenta, fue tan notable que bien podría decirse que ella explica el crecimiento industrial. Rodolfo Cerdas llegó a estimar que "el capital extranjero domina más del $85 \%$ de las nuevas industrias integracionistas ${ }^{1183}$ y OFIPLAN estimó, en 1976, que en un cuarto de las industrias grandes, la participación del capital extranjero superaba el $50 \%$ del total..$^{84}$

d) El crecimiento industrial se concentró en las ramas con mayor tecnología incorporada (mayor composición orgánica del capital) y no en las que absorbían mayor mano de obra. ${ }^{85}$ Las pequeñas industrias no fueron incentivadas por la inversión extranjera. La participación de la industria más tradicional (la que emplea en términos absolutos y relativos mayor mano de obra) disminuyó su participación en el PIB industrial. Más específicamente, el subsector de la pequeña industria y artesanía (PMI) contrajo, durante todo el periodo, el número de establecimientos, el número de ocupados y el valor agregado producido. ${ }^{86}$

e) Finalmente, este tipo de crecimiento industrial tendió a concentrarse geográficamente : el $43,6 \%$ de los establecimientos con el $55,8 \%$ del personal ocupado se ubicó en el Área Metropolitana de San José. ${ }^{87}$ El crecimiento industrial estuvo acompañado de un fuerte crecimiento del sector comercio y la construcción, actividades típicamente urbanas.

\section{Los aspectos sociales del crecimiento económico en el sec- tor industrial}

Este dinamismo económico de la Costa Rica urbana, tuvo varias expresiones en el aspecto social. Veamos.

De manera diferente a lo que aconteció en el mundo rural, la pobreza urbana no se extendió durante el periodo en estudio. La proporción de familias en pobreza tendió a disminuir. En efecto, en 1971 se consideró que un tercio de las familias urbanas vivían en pobreza. Ese porcentaje descendió a la mitad, un $17 \%$, en $1977 .{ }^{88}$ Hubo, eso sí, un incremento, leve pero sensible, de la proporción de familias situadas en pobreza extrema. ${ }^{89}$ En efecto, unas 13 000 familias urbanas, ${ }^{90}$ viviendo en situación de extrema pobreza, comenzaban a prefigurar la situación social que en ese entonces fue conocida como "tugurio" y que alcanzaría una fuerte expresión en la década siguiente.

Para el final del periodo bajo estudio -después de 1973- la desocupación urbana comenzó a crecer. La actividad industrial mostraba sus dificultades para absorber la mano de obra que desocupaban otros sectores, como el agropecuario..$^{91}$ En el sector de la construcción la tasa anual de desempleo aumentó en los años 1973-1976 y volvió a aumentar en los años 1979 y en $1980 .^{92}$ Durante todo el periodo, un problema central de los trabajadores del mundo urbano costarricense fue el de la vivienda. Recuérdese que la población urbana del país creció, de manera importante, a través de toda la década de los setenta. Esto implicó la demanda por viviendas y servicios públicos, una presión que difícilmente el Estado -en ese entonces- pudo satisfacer. ${ }^{93}$

\section{El papel del Estado}

Ya hemos visto la decidida y eficaz participación del Estado tanto en el crecimiento del sector industrial como del sector agropecuario. Esta participación no fue casual, fue prevista ${ }^{94}$ y fue significativa, e implicó un crecimiento extraordinario del mismo aparato estatal. ${ }^{95}$

Como sabemos, múltiples fueron las formas que asumió este nuevo rol estatal: desde la creación de instituciones específicamente orientadas a apoyar la gestión productiva agropecuaria o industrial (ejemplo INA) hasta la canalización prioritaria del crédito y la inversión pública hacia dichos sectores, desde crear marcos jurídicos proteccionistas para esas actividades, hasta otorgarle lugar prioritario en la agenda de las inversiones públicas para la construcción de la infraestructura física que permitiera el crecimiento agropecuario e industrial.

Eso es lo cuantitativo. Pero lo cualitativo y a nuestro juicio más trascendente es cómo el Estado asumió ese rol protagónico para el crecimiento agropecuario e industrial durante el periodo 1955-1980.

Importa, aquí, destacar dos estrategias estatales:

a) El Estado costarricense fue capaz de ejercer este rol de impulsor de la actividad agropecuaria e industrial sin generar conflictos irresolubles entre clases o fracciones de clase. ¿Cómo? Primero, aseguró que el modelo de crecimiento industrial no fuese antagónico con los intereses de la "oligarquía agropecuaria" ni con los intereses del énclave bananero. En efecto, el crecimiento industrial ni alteró la estructura agraria a favor del campesinado, ${ }^{96}$ ni le robó fuerza de trabajo a la oligarquía agropecuaria. Antes bien, parcialmente absorbió la fuerza de trabajo que desocupó ese tipo de crecimiento agropecuario. Por ejemplo, aqueIla que desocupó el "latifundio capitalizado"97 fue parcialmente absorbida por el naciente proceso industrializador. Esta contribución del sector industrial, redujo, sensiblemente, el problema de la desocupación campesina.

Tampoco -y muy importante- este vigoroso apoyo estatal fue financiado con cargas impositivas a los dueños 
de los medios de producción. Al contrario, el Estado exoneró y con generosidad, a la producción agropecuaria e industrial. ${ }^{98}$

Pero para poder actuar así el Estado tuvo que endeudarse interna y externamente. Además, mediante endeudamiento el Estado incursionó en una agresiva política de transporte, energía, etc., incluso llegó a concebirse, en la administración Oduber, como Estado empresario.

Así, antes de sumar cargas tributarias a los dueños del capital, el Estado costarricense prefirió endeudarse -y al corto plazo. ${ }^{99} \mathrm{Al}$ finalizar el periodo bajo estudio, hubo de pagar las consecuencias. ${ }^{100}$ Como alternativa también, prefirió abrir generosamente la llave de la inversión extranjera directa como mecanismo de financiamiento a "nuestro" desarrollo agropecuario e industrial. ${ }^{101}$

b) La segunda estrategia fue novedosa en América Latina y habla de las enormes capacidades del Estado costarricense durante el periodo 1955-1980. Nos referimos al apoyo estatal para que este modelo de crecimiento económico se desarrollara con presteza y con legitimidad mediante la implementación de una política social que disminuyera, silenciara o postergara los conflictos sociales que la misma puesta en práctica del modelo generaba. ${ }^{102}$ Sí. Porque el modelo no creció en abstracto. A su paso, dejó secuelas sociales que, muy brevemente ya hemos considerado.

Para aliviar estas consecuencias que dejaba a su paso el modelo de crecimiento, el Estado, durante la década de los setenta, estableció un conjunto de políticas sociales, extremadamente significativas y novedosas en relación con la propia historia del país y en relación al conjunto de países latinoamericanos. ${ }^{103}$ Estas políticas, aminoraron las consecuencias sociales que a su paso dejaba el modelo de crecimiento implantado desde la segunda mitad de los años cincuenta, pero también aseguraban la reproducción de la fuerza de trabajo que necesitaba ese modelo de crecimiento económico.

\section{Y, finalmente lo más importante:}

Dentro de esta estrategia el Estado costarricense diseñó instancias para sustituir o complementar las instancias tradicionales mediante los cuales las poblaciones (territoriales o sectoriales) organizaban sus demandas. Vio que esas instancias tradicionales -como las municipalidadeshabían devenido en obsoletas o insuficientes. Entonces, diseñó, estableció, privilegió y promovió nuevas instancias, más ágiles y flexibles, con mayor capacidad de presencia y de legitimidad. Instancias que, a la par de organizar las demandas de las poblaciones sumaran sus esfuerzos a los del Estado en un clima de participación legitimante. Instancias, en fin, capaces de movilizar, dinamizar y aportar en el marco de las políticas sociales que se pusieron en práctica durante toda la década de los setenta.

Justamente, la hipótesis central de nuestro trabajo se relaciona con esa pretensión y capacidad estatales. Sostenemos que, la Dirección Nacional de Desarrollo de la Comunidad (DINADECO) y sus productos, las Asociaciones de Desarrollo -vistas desde la perspectiva de este gran marco de las políticas sociales en la década de los setenta- fueron (y son), esencialmente, instancias para organizar, legitimar, canalizar y satisfacer las demandas de las comunidades costarricenses, pero, racionalizadas en función de las necesidades objetivas del modelo de crecimiento económico y social que les dio origen. ${ }^{104}$

Así, las asociaciones fueron mucho más que entidades que actuaron para mitigar pobreza en el mundo rural. Fueron más que instrumentos ideológicos para legitimar el modelo de crecimiento económico y social. Fueron, esencialmente, organizaciones que construyeron con apoyo directo del Estado, condiciones necesarias para la producción y reproducción de ese modelo de crecimiento económico y social.

¿Qué y cómo hicieron las asociaciones para desempeñar esa función? Bueno, es lo que nos correspondería abordar en las próximas tres secciones.

\section{Distribución espacio-temporal de las Asociaciones de Desarrollo de la Comunidad}

Los productos concretos de la institución llamada DINADECO fueron (y son), las Asociaciones de Desarrollo de la Comunidad. El Estado, a través de una especializada burocracia, creó a las asociaciones. Y las creó, teóricamente, ${ }^{105}$ en atención a una demanda comunal, esto es, en respuesta a una presión proveniente de las mismas comunidades. Durante el periodo 1968-1978, DINADECO constituyó 807 Asociaciones de Desarrollo de la Comunidad.

La pregunta que nos persigue es la siguiente: ¿Por qué creó, el Estado estas asociaciones? ¿Para qué?... Intentando una respuesta, en este capítulo relacionaremos la ubicación espacial de las asociaciones, durante el periodo 1968-1978, con los desplazamientos de población económicamente activa que provocó el modelo de crecimiento económico implantado en el país. Una correspondencia en esa relación apuntalaría la hipótesis de que ese modelo organizativo llamado Asociaciones de Desarrollo acompañó -eficazmente- la implantación de ese modelo de crecimiento económico, en su último y más espectacular periodo: 1970-1978.

Sin embargo en la búsqueda de esa respuesta, deberíamos inquirir, primero, sobre cuántas asociaciones se constituyeron en el periodo bajo estudio. Si la respuesta resultante es, muchas, podríamos inferir que 
las asociaciones fueron un instrumento importante de política en manos del Estado costarricense.

También quisiéramos preguntarnos por el cuándo. ¿Cuándo se constituyeron más asociaciones? De la respuesta, podríamos inferir cuál administración del Estado, durante el periodo 1968-1978, le dio mayor importancia a la constitución de asociaciones. Ello también nos permitiría relacionar a las asociaciones con la particular orientación socio-económica de ese gobierno.

Finalmente y siempre en la búsqueda anunciada deberíamos preguntar por el adónde se constituyeron más asociaciones. Porque analizando características de esos lugares, podríamos inferir propósitos comunales y estatales para constituir allí más asociaciones.

\section{Número de Asociaciones de Desarrollo Comunal}

Durante el periodo 1968-1978, DINADECO constituyó 807 Asociaciones de Desarrollo de la Comunidad. Es decir, constituyó un promedio de 73,4 asociaciones por año. ¿Qué significo esta cifra? ¿Mucho o poco? Veamos.

Hasta el día 31 de marzo del $2006^{106}$ DINADECO había constituido, propiamente, 2076 Asociaciones de Desarrollo de la Comunidad. ${ }^{107}$ Entre 1968 y 1978, como dijimos, creó 807 asociaciones y, entonces, entre 1979 y el 2005, DINADECO constituyó el resto: 1269 Asociaciones de Desarrollo de la Comunidad.

Esto quiere decir que en el periodo 1968-1978 DINADECO constituyó un promedio de 73,4 asociaciones por año. Y en el periodo 1979-2005 constituyó un promedio de 47 asociaciones por año; es decir, la mitad. Los datos anteriores dejan muy clara la importancia que el Estado otorgó a la constitución de asociaciones durante el periodo bajo estudio.

Surge la duda: pudieron ser muchas, pero, tal vez, concentradas en pequeñas áreas del país. Para responder a esta inquietud habría que adelantar criterio sobre adónde se constituyeron las asociaciones. Según el Censo de Población de $1973^{108}$ el país se dividía, territorialmente, en 79 cantones y 408 distritos. Sobre esta base, ¿cuál fue la cobertura de las Asociaciones de Desarrollo?

Ya para 1978 -fin del periodo bajo estudio- el 92,5\% de los cantones y el $90 \%$ de todos los distritos del país tenían, por lo menos, una Asociación de Desarrollo.

Entonces, según los datos mostrados, la constitución de asociaciones no sólo fue importante para el Estado, sino que, durante el periodo bajo estudio, comprometió a todo el territorio nacional.

\section{Distribución de asociaciones según periodos guberna- mentales}

Durante el periodo 1968-1978 el Estado costarricense fue administrado por cuatro gobiernos constitucionales: en 1968 y 1969, por la administración Trejos Fernández (Unificación Nacional); entre 1970 y 1973, por la administración Figueres Ferrer (Liberación Nacional); entre 1974 y 1977 por la administración Oduber Quirós (Liberación Nacional) y en 1978 por la administración Carazo Odio (Unidad).

Empecemos por revisar la Figura 5, donde se distribuyen las 807 Asociaciones de Desarrollo Comunal (integrales y específicas) ${ }^{109}$ entre las diferentes administraciones del Estado.

Durante los primeros dos años, 1968 y 1969, correspondientes a la administración Trejos Fernández, DINADECO constituyó un total de 95 asociaciones, es decir, un promedio de 50 por año. Esta es una cifra realmente significativa considerando que, en ese sub-periodo, DINADECO tenía, en total, unos 40 empleados, la mayoría de los cuales estaban dedicados a tareas administrativas. La institución contaba sólo con un par de vehículos rurales para movilizarse por todo el país; además, en ese entonces, sus oficinas estaban centralizadas en San José.

Durante el siguiente sub-periodo, 1970-1973 (administración Figueres Ferrer, cuatro años), DINADECO constituyó 103 asociaciones, esto es un promedio de 25 asociaciones por año, lo cual significa la mitad en relación con el subPeriodo anterior (Trejos Fernández), a pesar de que la institución había más que duplicado su personal, sus equipos y, además, se había regionalizado. ${ }^{110}$

Es en el tercer sub-periodo -administración Oduber Quirós- cuando observaremos un ritmo impresionante en la constitución de asociaciones. Entre 1974 y 1977 se formaron 551 asociaciones, es decir, 138 por año. Ello significó más que quintuplicar el ritmo de constitución de asociaciones en relación con el periodo anterior. ${ }^{111}$ En promedio, cada dos días y medio se constituyó una Asociación de Desarrollo de la Comunidad.

Finalmente, en el primer año de la administración Carazo Odio, la constitución de asociaciones volvió al ritmo pausado de los primeros años de la institución.

Fue entonces la administración de Daniel Oduber Quirós, principal responsable de constituir asociaciones durante el periodo bajo estudio. En efecto, casi el 70\% de las 807 asociaciones las constituyó DINADECO en el gobierno de don Daniel; además, fue la administración que se encargó -por decirlo así- de "llevar" asociaciones hasta los distritos más alejados del centro del país la que más extendió, por el territorio nacional, a las Asociaciones de Desarrollo de la Comunidad. 


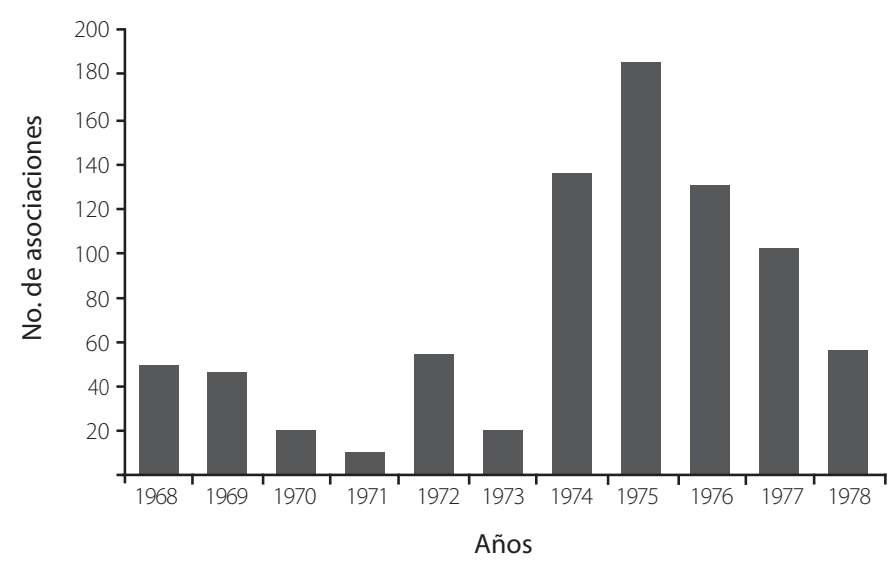

FIG. 5. Número de asociaciones según año de constitución.

Al inicio del periodo (años 1968-1969) había asociaciones sólo en una quinta parte de los distritos administrativos del país (Fig. 6). Esa proporción se duplicó durante el siguiente sub-periodo (1970-1973) cuando el 39\% de los distritos tenían, por lo menos, una Asociación de Desarrollo de la Comunidad. Pero fue en la administración Oduber Quirós cuando DINADECO alcanzó una cobertura, prácticamente total, del país: el $90 \%$ de los 408 distritos administrativos del país tuvieron, como mínimo, una Asociación. ${ }^{112}$

\section{Distribución geográfica de las asociaciones}

Ya hemos visto la importancia que el Estado dio a la demanda comunitaria por constituir asociaciones. ${ }^{113}$ Especialmente durante la administración Oduber Quirós. Deberíamos ahora inquirir, sobre los sitios donde más asociaciones se constituyeron. ¿Por qué tal interés? Porque, como dijimos, observando características de esos sitios, podríamos eventualmente inferir las razones del Estado

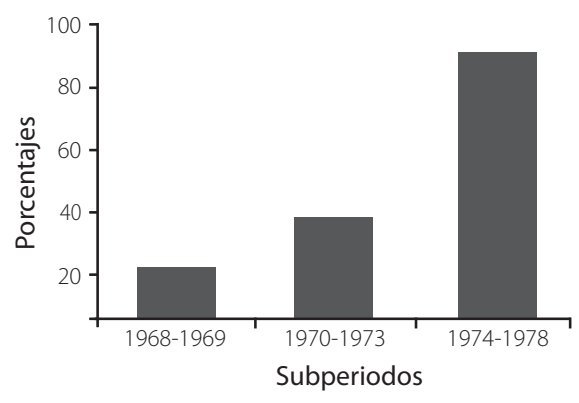

FIG. 6. Porcentaje de distritos con asociaciones de desarrollo comunal. y la sociedad civil para haber creado y difundido ese modelo privilegiado de organización llamado Asociación de Desarrollo de la Comunidad.

\section{¿En la Costa Rica central o en la Costa Rica periférica?}

Durante el primer sub-periodo del estudio (1968 a 1973) casi dos terceras partes de las asociaciones constituidas se ubicaron en la Región Central del país, ${ }^{114}$ que como sabemos, concentra la mayor cantidad de población. En lo que sigue, siempre definiremos a la Región Central tal como lo hizo la Oficina de Planificación de aquellos años: una extensa porción geográfica que casi coincide con el Valle Intermontano Central. Incluye los cantones de las Sub-regiónes Metropolitana, Resto de San José y Resto de la Región Central. Estos cantones pueden ser identificados en el Cuadro 2.

Que durante los primeros años, la mayoría absoluta de las Asociaciones de Desarrollo Comunal se haya localizado en la Región Central del país, tiene su lógica. Recordemos que allí se concentraba la mayoría de la población costarricense y en consecuencia hubo una mayor demanda para constituir ese nuevo y atractivo modelo organizacional llamado Asociación de Desarrollo. A esta explicación habría que agregar la limitación de recursos en DINADECO, lo cual obstaculizó su penetración al interior del país.

Pero si durante estos primeros años (1968-1973) se constituyeron más asociaciones en la Región Central del país, también es cierto que allí había más población, con lo cual, se incrementaban las probabilidades de constituir asociaciones. Sería más satisfactorio, para la investigación, crear un indicador que relacione población con número de asociaciones constituidas y al cual llamaríamos "densidad organizacional". ${ }^{15}$ 
CUADRO 2

Porcentaje de asociaciones constituidas, por regiones y periodos

\begin{tabular}{lccc}
\hline Región & $\begin{array}{c}\text { Período } \\
\text { 1968-1973 }\end{array}$ & $\begin{array}{c}\text { Período } \\
\text { 1974-1978 }\end{array}$ & $\begin{array}{c}\text { Período } \\
\text { 1968-1978 }\end{array}$ \\
\hline Central & 65,7 & 46,3 & 51,1 \\
Periférica & 34,3 & 53,7 & 48,9 \\
Total & 100 & 100 & 100 \\
\hline
\end{tabular}

Así, en términos proporcionales a su población, en el primer sub-periodo bajo análisis (1968-1973) el número de asociaciones por habitante fue muy similar, tanto en la Región Central como en el resto del país, (región Periférica). $Y$ en el siguiente sub-periodo, administración Oduber Quirós, (que fue cuando se constituyó el 68,2\% de las asociaciones) la tendencia se inclinó, francamente, a favor de la Regiones Periférica del país (Cuadro 3). Aquí y en lo que sigue, llamaremos Región Periférica la parte del territorio nacional fuera de la Región Central. Incluye cinco subregiones periféricas: Chorotega, Pacifico Central, Brunka, Huetar Norte y Huetar Atlántica. Los respectivos cantones pueden identificarse en el Apéndice estadístico, Cuadro A-1.

\section{¿En los distritos centrales o en los distritos periféricos?}

Ahora cabría preguntarse adónde -en qué parte- de los cantones se constituyeron más asociaciones: ¿En la parte central de los cantones de las regiones o en los distritos periféricos de ellos? ¿En el distrito primero de cada cantón, donde tradicionalmente hay más población y servicios, o en cualquier otro de los distritos del cantón, ${ }^{116}$ en los cuales, generalmente, hay menos población y servicios? Observando el Cuadro 4, concluiremos que -en cualquier región- el mayor número de asociaciones se constituyó fuera de los distritos centrales, o distritos primeros de

\section{CUADRO 3}

Asociaciones de desarrollo comunal (densidad organizacional*), según sub-periodos y regiones

\begin{tabular}{lccc}
\hline Región & $\begin{array}{c}\text { Período } \\
\text { 1968-1973 }\end{array}$ & $\begin{array}{c}\text { Período } \\
\mathbf{1 9 7 4 - 1 9 7 8}\end{array}$ & $\begin{array}{c}\text { Período } \\
\mathbf{1 9 6 8 - 1 9 7 8}\end{array}$ \\
\hline Central & 1,8 & 3,8 & 5,6 \\
Periférica & 1,8 & 8,6 & 10,4 \\
Costa Rica & 1,8 & 5,4 & 7,2
\end{tabular}

* Número de asociaciones por cada 10000 habitantes mayores de 15 años. Para los cálculos de densidad organizacional la población es el número promedio de habitantes mayores de 15 años en los años 1973 y 1978 según estimaciones de OFIPLAN. los cantones. Y esto fue cierto desde el principio, desde los primeros años de la institución. Veamos.

Resumiendo, sabemos ahora que durante todo el periodo, pero en particular en su segunda fase (administración Oduber Quirós) hubo una mayor intencionalidad (comunitaria y estatal) para constituir asociaciones en las regiones periféricas del país. Y no sólo allí, sino en sus partes más rurales o periféricas (con menos población y servicios públicos), lo cual también resulta también válido para la propia Región Central.

\section{Distribución por sub-regiones}

La pregunta que sigue es la siguiente: ¿en cuál o cuáles de las sub-regiones periféricas hubo mayor concentración de asociaciones? En términos relativos a su población mayor de 15 años, el Cuadro 5 muestra la respuesta.

La lista la encabeza la Región Chorotega donde -a lo largo del periodo-se registraron 12 asociaciones por cada 10000 habitantes mayores de 15 años. Las otras regiones periféricas se encuentran en una situación similar (excepto el Pacífico Central) con densidades demográficas de más de 11 Asociaciones por cada 10 mil pobladores.

En sentido inverso, las subregiones más centrales (Metropolitana y Resto de San José) muestran densidades organizacionales muy bajas, en relación con las periféricas.

\section{CUADRO 4}

Porcentaje de asociaciones en los distritos perifericos de los cantones, por regiones y sub-periodos

\begin{tabular}{lccc}
\hline \multicolumn{1}{c}{ Región } & $\begin{array}{c}\text { Período } \\
\text { 1968-1973 }\end{array}$ & $\begin{array}{c}\text { Período } \\
\text { 1974-1978 }\end{array}$ & Total \\
\hline Central & 75,7 & 75,0 & 75,2 \\
Chorotega & 40,0 & 68,4 & 64,5 \\
Brunca & 88,9 & 69,0 & 72,4 \\
Huetar Atlántica & 58,3 & 55,4 & 55,9 \\
Huetar Norte & 69,2 & 71,4 & 71,1 \\
Total & 72,7 & 70,9 & 71,4 \\
\hline
\end{tabular}

Nota: Por razones de distribución administrativa de los distritos preferimos utilizar aquí la división por regiones (según OFIPLAN) y no la de sub-regiones que utilizaremos en los siguientes cuadros.

Nótese que la Sub-Región Huetar Norte tuvo una de las mayores densidades organizativas. Esta subregión fue considerada por OFIPLAN ${ }^{117}$ como aquella cuya población tenía menor nivel de instrucción, lo cual podría perfectamente traducirse, en un indicador de un menor acceso de su población, a servicios públicos básicos. Así 
estimaba OFIPLAN que el 19,3\% de los habitantes mayores de 10 años, en la Huetar Norte, eran analfabetos. El mayor porcentaje entre seis regiones del país. Calculaba también que la Huetar Norte era la sub-región con menor acceso a una red pública o privada de cañería. Sólo el 38\% de las viviendas tenía ese servicio. Era, además, de muy baja densidad demográfica: 10,5 habitantes por kilómetro cuadrado, con la población más joven del país y con una

\section{CUADRO 5}

Densidad organizacional según sub-regiones y periodos*

\begin{tabular}{lccc}
\hline \multicolumn{1}{c}{ Sub-región } & $\begin{array}{c}\text { Período } \\
\text { 1968-1973 }\end{array}$ & $\begin{array}{c}\text { Período } \\
\text { 1974-1978 }\end{array}$ & Total \\
\hline Metropolitana & 0,9 & 1,4 & 2,3 \\
$\begin{array}{l}\text { Resto de } \\
\text { San José }\end{array}$ & 2,0 & 4,6 & 6,6 \\
Resto de & 3,5 & 8,4 & 11,9 \\
Región Central & & & \\
Chorotega & 1,4 & 10,6 & 12,0 \\
Pacífico Central & 1,7 & 5,2 & 6,9 \\
Brunca & 1,9 & 9,2 & 11,1 \\
Huetar Atlántica & 1,8 & 7,8 & 9,6 \\
Huetar Norte & 2,6 & 8,8 & 11,4 \\
Costa Rica & 1,8 & 5,4 & 7,2
\end{tabular}

*Número de asociaciones por cada 10000 habitantes mayores de 15 años.

estructura ocupacional mayormente compuesta por trabajadores por cuenta propia y trabajadores familiares y un dato importantísimo: la sub-región con la mayor atracción de migrantes en todo el país. ${ }^{118}$ En síntesis: una sub-región muy pobre, con escaso desarrollo capitalista del agro y la más atractora de población entre todas las otras sub-regiones del país.

\section{Distribución por cantones}

El inconveniente de observar la distribución de asociaciones por Regiones es que la información está muy agregada: se pierden diferencias intra-regionales importantes. Por ello, sería necesario observar esta misma información pero en el nivel cantonal.

En el Cuadro 6 hemos seleccionado los diez cantones con mayor densidad organizacional. ${ }^{119}$

En el total de estos 10 cantones la densidad organizacional fue más del doble del promedio nacional $(7,2)$.

A simple vista parece un subconjunto disperso pero no es así. Situados en un mapa (Fig. 7), muestran una lógica geográfica muy definida. Efectivamente conforman seis áreas geográficas muy delimitadas.

El mapa de la Figura 7 permite apreciar que existieron cinco sub-regiones todas con alta densidad organizaciones, pero cada una de ellas con términos demográficos particulares (Cuadro 7).

El Cuadro 7 nos permite las siguientes reflexiones:

a) Llama la atención, dentro de nuestra ya conocida sub-región Huetar Norte un espacio geográfico que para nuestros efectos hemos preferido llamar sub-región Frontera Norte por tratarse de cantones colindantes con Nicaragua. Esta sub-región presentó una muy alta densidad organizacional de casi 12 asociaciones por cada 10000 habitantes. En sus cuatro cantones con mayor densidad organizaciónal fue de más de 18 Asociaciones. Esta sub-región tuvo también la mayor tasa de crecimiento demográfico en el periodo 1973-1984 y todos los cantones que la constituyen mostraron tasas migratorias positivas, relativamente altas tanto en el sub-periodo 1968-1973,

CUADRO 6

Cantones con mayor densidad organizacional*

\begin{tabular}{lc}
\hline Cantón & $\begin{array}{c}\text { Densidad } \\
\text { organizacional }\end{array}$ \\
\hline Turrubares & 35,7 \\
Alfaro Ruiz & 22,2 \\
Talamanca & 21,6 \\
Upala & 21,2 \\
Matina & 20,1 \\
Guatuso & 20,0 \\
Buenos Aires & 19,0 \\
León Cortés & 18,1 \\
Tarrazú & 17,4 \\
Nandayure & 15,9 \\
Costa Rica & 7,2 \\
*Número de asociaciones por cada 10000 habitantes.
\end{tabular}

como en el sub-periodo $1973-1984 ; ;^{120}$ es decir, fue una región típicamente atractora de población y por un periodo extenso.

b) Después está la sub-región que podríamos llamar Vertiente Atlántica Central, conformada por los cantones de Matina, Talamanca y Sarapiquí. Tuvo una densidad organizacional muy alta y una tasa de crecimiento demográfico también muy alta. En ambos casos, muy similar a la sub-región Frontera Norte. De manera parecida 


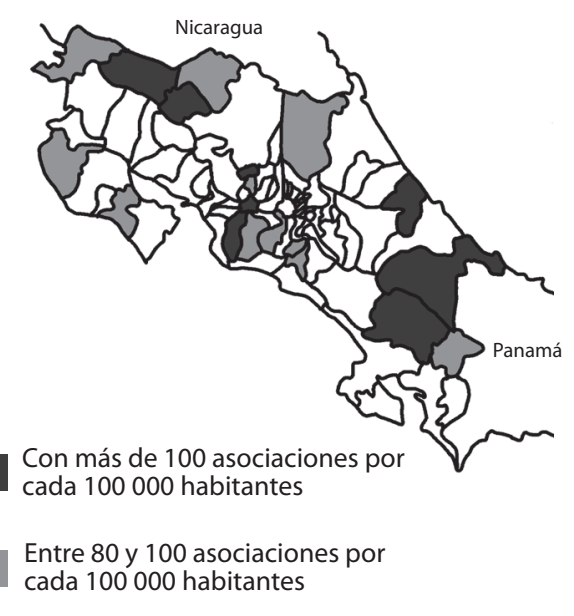

FIG. 7. Cantones con mayor densidad organizacional (1968-1978). (Población base 1973).
La tasa de crecimiento poblacional $(48,1 \%$ en el periodo intercensal) siempre fue superior al promedio del país. La densidad organizacional fue de unas 17,1 asociaciones por cada 10000 habitantes mayores de 15 años.

d) Sigue la sub-región Sur de la Península de Nicoya, con los cantones de Santa Cruz y Nandayure, que perdieron población en el periodo intercensal y mostraron, en ambos sub-periodos tasas negativas altas de migración. La densidad organizacional fue alta, pero menor a la de las otras cinco subregiones aquí consideradas.

f) Y, finalmente, está la sub-región Caraigres, conformada por un grupo de cantones ubicados a unos 60 kilómetros al sureste de San José, son: Puriscal, Acosta, León Cortés, Turrubares y Tarrazú; todos son cantones típicamente expulsores de población, con altas tasas negativas en ambos sub-periodos. Demográficamente no crecieron en el periodo intercensal y su densidad organizacional es

CUADRO 7

Características de cantones con mayor densidad organizacional*

\begin{tabular}{|c|c|c|c|c|}
\hline Sub-región & Cantones & $\begin{array}{c}\text { Densidad } \\
\text { organizacional }\end{array}$ & $\begin{array}{l}\text { Tasas de migración } \\
\text { (Censos } 1973 \text { y 1984) }\end{array}$ & $\begin{array}{c}\text { Tasa de crecimiento } \\
\text { poblacional (1973-1984) }\end{array}$ \\
\hline Frontera Norte & $\begin{array}{l}\text { Upala } \\
\text { Guatuso } \\
\text { La Cruz } \\
\text { Los Chiles }\end{array}$ & 18,1 & $\begin{array}{l}\text { Tasas positivas altas en ambos } \\
\text { periodos }\end{array}$ & 59,2 \\
\hline $\begin{array}{l}\text { Vertiente Atlántica } \\
\text { Central }\end{array}$ & $\begin{array}{l}\text { Matina } \\
\text { Talamanca } \\
\text { Sarapiquí }\end{array}$ & 17,2 & Tasas positivas altas en ambos periodos & 56,4 \\
\hline Buenos Aires & $\begin{array}{l}\text { Bueno Aires } \\
\text { Coto Brus }\end{array}$ & 17,1 & $\begin{array}{l}\text { Tasas positivas, altas en el primer periodo, } \\
\text { desciende en el segundo. }\end{array}$ & 48,1 \\
\hline Caraigres & $\begin{array}{c}\text { Turrubares } \\
\text { León Cortés } \\
\text { Tarrazú } \\
\text { Acosta } \\
\text { Puriscal }\end{array}$ & 17,5 & $\begin{array}{l}\text { Tasas migratorias negativas y altas en } \\
\text { ambos periodos. }\end{array}$ & 1,8 \\
\hline
\end{tabular}

también todos los cantones con tasas migratorias muy positivas en ambos sub-periodos (1968-1973 y 19731984). ${ }^{121}$

c) La sub-región que aquí llamaremos Buenos Aires, incluye los cantones de Buenos Aires y Coto Brus ambos fueron muy atractores de población durante el primer sub-periodo en el siguiente su capacidad atractiva decayó significativamente, aunque siempre se mantuvo positiva. alta: 9,3 por cada 10000 habitantes casi tan alta como la que tuvo la sub-región que tenía características contrarias: la Frontera Norte.

Resumiendo: Los cantones donde se constituyeron, proporcionalmente más asociaciones de Desarrollo Comunal durante el periodo 1968-1978, coinciden con cantones donde prevalecen una de estas dos características demográficas: 
- En primer lugar, son aquellos cantones que están fuera de la Región Central, con el mayor crecimiento poblacional y, paralelamente, con tasas migratorias muy positivas (las más positivas del país).

- En segundo lugar, son aquellos cantones que están dentro de la Región Central, con el crecimiento poblacional menor y con las tasas migratorias más negativas del país.

Aquí vale la pena preguntarse: ¿tenían, estos grupos de cantones -muy atractores o muy expulsores- características socio-productivas que nos ayuden a entender, a) ¿por qué expulsaron o atrajeron población?; y b) ¿por qué hubo allí, proporcionalmente, más asociaciones de desarrollo?

La respuesta es sí, efectivamente y a grosso modo es posible evidenciar algunas características para la mayoría de este subconjunto de cantones (Cuadro 8, Fig. 8).

La apreciación anterior da pie para la siguiente reflexión: es posible que la mayor densidad organizacional -mayor número de asociaciones por habitante- se situara en aquellas áreas geográficas del país que experimentaron durante el periodo, cambios significativos en su población esto es áreas que ganaron mucha población o áreas que perdieron mucha población. A su vez estos cambios en la población parecen estar relacionados con la siguiente situación: áreas geográficas, donde los cambios productivos estimularon mucha atracción o mucha expulsión de población.

Demos un ejemplo: es muy posible que la existencia de tierras baldías en la sub-región Frontera Norte, atrajera mucha población. Esa población tenía que asentarse en pueblos preexistentes dotados de pocos servicios, o tenía que crear poblados. Un instrumento útil fueron las asociaciones de Desarrollo de la Comunidad. De ahí una mayor demanda de asociaciones en esa sub-región, pero también una mayor oferta: porque fue interés del Estado costarricense incorporar a esta sub-región al modelo de crecimiento económico que se venía implantando desde la segunda mitad de la década de los cincuenta en todo el país.

Pero ¿y en el caso contrario?... ¿cómo explicar la alta densidad organizacional en áreas expulsoras de población? Bien, intentemos otro ejemplo.

Es posible que la ampliación de la actividad ganadera extensiva expulsara población en la sub-región Sur de la Península de Nicoya. Ante tan evidente posibilidad surgen dos alternativas para explicar la alta densidad organizativa: ${ }^{122}$

a) Es posible que la población remanente intentara mejorar la infraestructura vial para sumarse con éxito al incremento de la nueva actividad productiva (ganadería) y así no tener que emigrar para ello las Asociaciones de Desarrollo de la Comunidad eran instrumentos útiles.

b) También es posible que la población remanente -para no emigrar- comenzara a mejorar servicios básicos y para ello, nuevamente, las ADC eran mecanismos muy válidos.

Recordemos entonces la pregunta original de este capítulo. Es evidente ahora que, por lo menos una buena parte de la constitución de Asociaciones de Desarrollo de la Comunidad y sobre todo en el periodo de Daniel Oduber, obedeció a una lógica muy concreta y totalmente articulada con el modelo de crecimiento agropecuario que el país tuvo durante el periodo bajo estudio. En términos muy simples esa lógica podría resumirse así: las Asociaciones de Desarrollo de la Comunidad acompañaron los movimientos de población (muy positivos y en menor medi$\mathrm{da}$, muy negativos) que fueron producidos por el modelo de crecimiento económico implantado durante el periodo bajo estudio.

Finalmente, para verificar aún más esta hipótesis realizamos un ejercicio de distribuir los cantones del país según su cambio poblacional, ${ }^{123}$ agruparlos en cuartiles y observar, en cada cuartil la densidad organizacional. El resultado se muestra en el Cuadro 9.

Se observa una correlación positiva y significativa entre las tasas de crecimiento poblacional de un cantón y su densidad organizacional.(número de asociaciones por cada 10000 habitantes). Así, en los cantones de rápido crecimiento demográfico, se constituyeron 4,6 asociaciones por cada 10000 habitantes; en los de menor crecimiento, sólo 3,7. ${ }^{124}$

Bueno, hasta el momento hemos enfilado nuestra atención hacia el área rural del país; pero ¿qué sucedió con la constitución de asociaciones en el área urbana?

\section{El mundo urbano}

Venimos insistiendo en que la mayoría de las Asociaciones de Desarrollo Comunal, tanto en términos absolutos como relativos se situaron en la Costa Rica rural. Sin embargo, sabemos que una proporción importante -aunque minoritaria- de ellas fueron constituidas en las áreas más urbanas del país.

Es que aunque en los cantones preponderantemente urbanos del país vivía, en 1973, un 58\% de la población, sólo el $38 \%$ de las asociaciones se ubicaron en ellos. Esta disparidad es la que explica que en los cantones clasificados como urbanos se haya constituido -en todo el periodo 1968-1978- una asociación para cada 3576 pobladores de cualquier edad, mientras que, en los cantones rurales se requirió la mitad. 


\section{CUADRO 8}

Características demográficas y socio-productivas de las sub-regiones con mayor densidad organizacional

\begin{tabular}{|c|c|c|}
\hline Sub-región & $\begin{array}{l}\text { Característica } \\
\text { demográfica }\end{array}$ & $\begin{array}{l}\text { Característica } \\
\text { socio-productiva }\end{array}$ \\
\hline Frontera Norte & $\begin{array}{l}\text { Alto crecimiento poblacional, muy } \\
\text { atractora de población. }\end{array}$ & $\begin{array}{l}\text { Disponibilidad de tierras pero carencia } \\
\text { de servicios básicos. }\end{array}$ \\
\hline $\begin{array}{l}\text { Vertiente Atlántica } \\
\text { Central }\end{array}$ & $\begin{array}{l}\text { Alto crecimiento, muy atractora de } \\
\text { población. }\end{array}$ & $\begin{array}{l}\text { Renovación e intensificación de la } \\
\text { producción bananera. }\end{array}$ \\
\hline Buenos Aires & $\begin{array}{l}\text { Alto crecimiento poblacional, atractora } \\
\text { de población en el periodo 1968-1973. }\end{array}$ & $\begin{array}{l}\text { Disponibilidad de tierras, agricultura } \\
\text { tecnificada (PINDECO). }\end{array}$ \\
\hline $\begin{array}{l}\text { Parte sur de la } \\
\text { Península de Nicoya }\end{array}$ & $\begin{array}{l}\text { Decrecimiento poblacional, expulsa } \\
\text { mucha población. }\end{array}$ & $\begin{array}{l}\text { Crece ganadería de engorde, los pastos } \\
\text { cubren } 70 \% \text { del área utilizada.* }\end{array}$ \\
\hline Caraigres & $\begin{array}{l}\text { Decrecimiento poblacional, típicamente } \\
\text { expulsora. }\end{array}$ & $\begin{array}{l}\text { Cafetaleros, ubicados en zonas de } \\
\text { escasez de tierra. Bajo promedio de } \\
\text { manzanas por familia.* }\end{array}$ \\
\hline
\end{tabular}

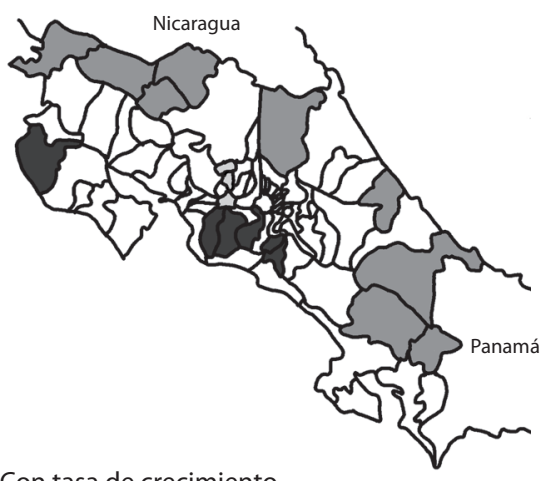

Con tasa de crecimiento

estacionaria o levemente negativa

Con tasa de crecimiento

muy positiva

Con tasa de crecimiento

medianamente positiva

FIG. 8. Cantones fuera de la Región Central con mayor crecimiento poblacional en el periodo 1973-1984

Es importante destacar que esa tendencia hacia una menor constitución de asociaciones en cantones preponderantemente urbanos se dio durante todo el periodo. En efecto, prácticamente desde el inicio, DINADECO privilegió la constitución de asociaciones en los cantones con mayor ruralidad, a pesar de que, en los primeros años la institución carecía de recursos para penetrar en la Costa Rica rural.
CUADRO 9

Densidad organizacionalsegún tasa de crecimiento de la población por cuartiles (1968-1978)

\begin{tabular}{ccccc}
\hline Cuartil & $\begin{array}{c}\text { Tasa de } \\
\text { crecimiento }\end{array}$ & \multicolumn{3}{c}{ Densidad organizacional * } \\
& 1968-1973 & 1974-1978 & 1968-1978 \\
\hline I & 58,8 & 0,8 & 3,9 & 4,6 \\
II & 35,6 & 1,4 & 3,1 & 4,5 \\
III & 22,3 & 1,2 & 3,2 & 4,5 \\
IV & 5,6 & 0,8 & 3,0 & 3,7 \\
Tasa nac. & 29,0 & 1,1 & 3,2 & 4,3 \\
* Número de asociaciones por cada 10 000 habitantes de cualquier edad. La base \\
para calcular densidad no fue un promedio sino la que se establecía en 1973 (de \\
acuerdo al Censo de ese año).
\end{tabular}

\section{Distribución por cantones centrales de las provincias}

Desde la perspectiva del conjunto de los siete cantones centrales de las provincias, es decir, los más urbanos del país, sabemos que se constituyeron 137 Asociaciones durante todo el decenio 68-78. Esto significa que sólo un $17 \%$ de todas las ADC del país se ubicaron en los cantones más urbanos, más poblados y con mayores 
servicios públicos en el país. Fácilmente se desprende la conclusión que no hubo intención estatal de concentrar estas organizaciones en los centros urbanos, sino, como hemos venido diciendo, en las áreas rurales.

Ahora bien: ¿cómo se distribuyeron estas 137 Asociaciones entre los 7 cantones centrales? La respuesta se puede ver en el Cuadro 10.

Notaremos, en el Cuadro 10, que dos terceras partes de las Asociaciones constituidas en los cantones centrales de provincia lo fueron en tres de ellos: Cartago, Alajuela y Puntarenas, Los tres fueron cantones que experimentaron importantes crecimientos de población entre 1973 y 1984.

CUADRO 10

Porcentaje de asociaciones constituidas en cantones centrales de provincias y por periodos

\begin{tabular}{lccc}
\hline $\begin{array}{l}\text { Cantones } \\
\text { Centrales }\end{array}$ & 1968-1973 & 1974-1978 & 1968-1978 \\
\hline San José & 20,0 & 6,9 & 11,7 \\
Alajuela & 24,0 & 18,4 & 20,4 \\
Cartago & 26,0 & 17,2 & 20,4 \\
Heredia & 6,0 & 12,6 & 10,2 \\
Liberia & 6,0 & 9,2 & 8,0 \\
Puntarenas & 12,0 & 25,3 & 20,4 \\
Limón & 6,0 & 10,3 & 8,8 \\
Total & 100,0 & 100,0 & 100,0 \\
Número & 50 & $\mathbf{8 7}$ & 137 \\
\hline
\end{tabular}

Distribución en los cantones de la Sub-región Metropolitana

Ahora bien: junto a los cantones centrales de provincia, los principales cantones urbanos se ubican en la partecentral del país y concretamente, en la sub-región Metropolitana. Efectivamente, esta sub-región está constituida por más cantones urbanos. Son doce cantones del tipo Goicoechea, Desamparados, Alajuelita o Tibás, además por supuesto, del cantón central de San José.

Para todo el periodo 1968-1978 la distribución porcentual de noventa y cuatro Asociaciones constituidas en la Sub-región Metropolitana, entre sus doce cantones fue la que se muestra en el Cuadro 11.

Como podemos observar, seis cantones de la Subregión Metropolitana concentraron más del $80 \%$ del total de Asociaciones. Fueron los cantones de: Desamparados, Central San José, La Unión, Aserrí, Tibás y Goicoechea. Todos ellos cantones de gran crecimiento demográfico durante el periodo y habitados, en mayor proporción, por población obrera.

Veamos ahora esa misma distribución de cantones en el Subregión Metropolitana pero considerando su densidad organizacional. El resultado es el que se muestra en el Cuadro 12.

CUADRO 11

Porcentaje de asociaciones en los cantones de la Subregión Metropolitana (1968-1978)

\begin{tabular}{lc}
\hline \multicolumn{1}{c}{ Cantón de la Sub-región } & Porcentaje de asociaciones \\
\hline Central San José & 17,0 \\
Escazú & 3,2 \\
Desamparados & 22,3 \\
Aserrí & 10,6 \\
Goicoechea & 8,5 \\
Alajuelita & 2,1 \\
Coronado & 5,3 \\
Tibás & 9,6 \\
Moravia & 3,2 \\
Montes de Oca & 3,2 \\
Curridabat & 2,1 \\
La Unión & 12,8 \\
Total & 100,0 \\
\hline
\end{tabular}

El resultado es una distribución similar a la que se había presentado utilizando porcentajes (Cuadro 11). Hay diferencias: el cantón central de San José -merced a su gran población- muestra una densidad baja. Lo mismo podríamos decir de Goicoechea y Tibás. Aparece, significativamente, el cantón de Coronado. Por densidad organizacional encabezan la lista el cantón de Aserrí y la Unión.

Ahora bien: la ubicación geográfica de estos cantones con una mayor densidad organizacional, conforman una franja territorial en la periferia sur-este de la ciudad capital.

Es decir: hubo una mayor densidad organizacional justo donde hubo un crecimiento extraordinario de población, porque allí comenzaban a concentrarse las nuevas barriadas de obreros, oficinistas, dependientes y pequeños comerciantes que estaban siendo atraídos por el recién entorno de crecimiento industrial, comercial y de actividades de gobierno que vivió el país -como hemos visto- en la década de los setenta (Cuadro 13). 
CUADRO 12

Densidad organizacional en los cantones de la Sub-región Metropolitana (1968-1978)

\begin{tabular}{lc}
\hline \multicolumn{1}{c}{ Cantón } & Densidad organizacional \\
\hline Central de San José & 1,1 \\
Escazú & 2,0 \\
Desamparados & 4,5 \\
Aserrí & 8,9 \\
Goicoechea & 2,0 \\
Alajuelita & 1,5 \\
Coronado & 5,1 \\
Tibás & 3,7 \\
Moravia & 2,4 \\
Montes de Oca & 1,3 \\
Curridabat & 2,0 \\
La Unión & 8,6
\end{tabular}

\section{Distribución por distritos de la Sub-región Metropolitana}

En los distritos periféricos de la sub-región (tipo Río Azul, San Diego de La Unión, Patarrá de Desamparados y Tirrases de Curridabat), de reciente conformación y carentes de servicios tendieron a concentrarse, en términos absolutos y relativos la mayor parte de las asociaciones de la sub-región (Cuadro 14).

Este conjunto de 18 distritos, donde se concentraron las asociaciones, tuvo en el periodo 1973-1984 un crecimiento poblacional del $82,5 \%$. Una cifra muy alta, considerando que toda el Área Metropolitana de San José -de rápido crecimiento en relación con el país- creció a una tasa del 33,6\%. Queda claro entonces que hubo una correlación entre distritos con mayor crecimiento poblacional y distritos con mayor número de asociaciones.

De manera más general, pero siempre en apoyo a esta hipótesis presentamos el Cuadro 15 donde se evidencia que en los distritos urbanos con mayor crecimiento demográfico fue donde también se concentró el mayor número de asociaciones.

Podemos observar, en el Cuadro 15 que aquellos distritos de la sub-región San José, con crecimiento demográfico negativo de su población, tuvieron una densidad organizacional muy baja: una asociación por cada 10000 habitantes. En el otro extremo, aquellos distritos que duplicaron su población durante el periodo señalado, tuvieron densidades organizacionales muy altas: casi 2,8 asociaciones por cada 10000 habitantes. Es posible, bajo las consideraciones anteriores, que en
CUADRO 13

Densidad organizacional en los cantones de la Sub-región Metropolitana (1968-1978)

\begin{tabular}{cc}
\hline $\begin{array}{c}\text { Cantones con mayor } \\
\text { densidad organizacional } \\
(\text { 1968-1978) }\end{array}$ & $\begin{array}{c}\text { Cantones con mayor } \\
\text { inmigración (1973-1984) }\end{array}$ \\
\hline Coronado & Coronado \\
Moravia & Moravia \\
Tibás & Tibás \\
La Unión & La Unión \\
Santa Ana & Curridabat \\
Desamparados & Desamparados \\
Aserrí & Aserrí \\
& \\
& CUADRo 14 \\
& \\
Densidad organizacional en los distritos \\
periféricos de la Sub-región San José (1973)*
\end{tabular}

\begin{tabular}{lcc}
\hline \multicolumn{1}{c}{ Distrito } & $\begin{array}{c}\text { Densidad } \\
\text { organizacional } \\
\text { poblacional } \\
(1973-1984)\end{array}$ & $\begin{array}{c}\text { Tasa de } \\
\text { crecimiento }\end{array}$ \\
\hline San Diego, La Unión & 10,7 & 123,7 \\
Rancho Redondo, Goico & 8,1 & 21,1 \\
San Jerónimo, Moravia & 7,4 & 105,7 \\
San Rafael, La Unión & 7,4 & 87,3 \\
Tirrases, Curridabat & 6,9 & 297,5 \\
San Juan, La Unión & 6,7 & 30,3 \\
Río Azul, La Unión & 5,6 & 247,3 \\
Concepción, La Unión & 5,2 & 72,6 \\
Patarrá & 5,1 & 72,0 \\
Dulce Nombre, La Unión & 4,7 & 76,1 \\
Damas, Desamparados & 4,6 & 68,0 \\
Pozos, Santa Ana & 4,4 & 58,3 \\
San Rafael, Montes de Oca & 3,8 & 28,3 \\
Piedades & 3,8 & 36,8 \\
Trinidad, Moravia & 3,8 & 111,6 \\
San Miguel, Desamparados & 3,7 & 47,5 \\
San Rafael Abajo, Des. & 3,5 & 100,7 \\
San Felipe & 3,5 & 63,6 \\
\hline Toda la sub-región & 1,6 & 33,6 \\
& & \\
\hline & &
\end{tabular}

*Número de asociaciones por cada 10000 habitantes de cualquier edad. La base para calcular densidad no fue un promedio sino la que se establecía en 1973, de acuerdo al Censo de ese año).

FUENTE: Censos de Población de 1973 y 1984, Registro Nacional de Asociaciones. 
este tipo de distritos periféricos (particularmente en la zona sur-este de San José) surgieran nuevas barriadas, habitadas por inmigrantes del resto del país ${ }^{125}$ y aún del Área Metropolitana de San José, que venían a insertarse en las recién creadas industrias sustitutivas, en las nuevas oportunidades laborales que brindaba un sector comercial

\section{CUADRO 15}

Distribución por cuartiles del crecimiento poblacional y densidad organizacional

\begin{tabular}{ccccc}
\hline Cuartil & $\begin{array}{c}\text { Población } \\
\text { (1973) }\end{array}$ & $\begin{array}{c}\text { Tasa de } \\
\text { crecimiento } \\
\text { poblacional }\end{array}$ & Asociaciones & $\begin{array}{c}\text { Densidad } \\
\text { org.* }\end{array}$ \\
\hline I & 98005 & 100,5 & 29 & 2,8 \\
II & 102633 & 60,7 & 19 & 1,7 \\
III & 111492 & 37,7 & 21 & 1,9 \\
IV & 256389 & $-3,3$ & 25 & 1,0 \\
\hline Total & 568519 & 34,2 & 94 & 1,6
\end{tabular}

*Número de asociaciones por cada 10000 habitantes de cualquier edad. La base para calcular densidad no fue un promedio sino la que se establecía en 1973, de acuerdo al Censo de ese año).

en expansión, o en la oferta burocrática devenida del incremento de la actividad gubernamental. ${ }^{126}$ Es muy posible también que estos pobladores de las nuevas "barriadas", demandaran del Estado la constitución de Asociaciones de Desarrollo como un mecanismo útil para proveerse -con la participación de ellos también- de los servicios públicos y de la infraestructura comunitaria necesaria para su reproducción.

Entonces, para el área urbana, nuevamente se apuntala la hipótesis de que la constitución de asociaciones obedeció a una lógica muy concreta y totalmente articulada con el modelo de crecimiento industrial (y comercial y de servicios) que el país tuvo durante el periodo bajo estudio.

\section{Principales conclusiones de la sección}

Esta sección nos posibilita llegar a las siguientes conclusiones:

1. Por su número y cobertura es indudable que las Asociaciones de Desarrollo de la Comunidad fueron un instrumento de política estatal importantísimo durante el periodo bajo estudio y en particular, durante la administración Oduber.

2. En términos proporcionales a la población regional y subregional, las Asociaciones de Desarrollo de la Comunidad fueron constituidas, principalmente, en las regiones periféricas del país, ${ }^{127}$ y esto fue particularmente cierto durante la administración Oduber Quirós (1974-1977).

3. Dentro de las regiones periféricas hubo mayor densidad organizacional (más asociaciones por habitante) en aquellas con menos servicios públicos.

4. A su vez, en el conjunto de las regiones periféricas se constituyeron más asociaciones (tres veces más) en los distritos periféricos al distrito central; es decir, en los distritos que tenían menos servicios públicos y privados.

5. Sin ser una correlación exacta, las Asociaciones de Desarrollo tendieron a ubicarse en determinadas subregiones del país:

a) En sub-regiones con mayores movimientos de población (sobre todo muy atractoras de población y en menor medida, muy expulsoras de población).

b) En sub-regiones (y cantones) con acelerados procesos de transición en su base productiva.

6. De lo anterior se infiere que en aquellas comunidades, sobre todo rurales, que experimentaron transformaciones en su base productiva ${ }^{128}$ y que a consecuencia de ello, fueron extremas atractoras o -en mucha menor medida- extremas expulsoras de población, tendieron a formar más asociaciones por habitantes. En aquellas comunidades situadas en áreas atractoras de población, muy probablemente la necesidad urgente y sentida para proveerse de servicios básicos e infraestructura vial que les exigía el acelerado proceso de transformación productiva que estaba ocurriendo en ellas, les impelió a crear más asociaciones.

7. Finalmente, en las áreas urbanas del país hubo, en términos relativos y absolutos, menos asociaciones. Sin embargo, un análisis por distritos de la sub-región San José (altamente urbana) demostró que las asociaciones tendieron a ubicarse en aquellos distritos de reciente creación y que estaban en periodo de expansión demográfica, distritos que geográficamente conforman una franja situada en la periferia sur-este de la capital. Nuevamente, podríamos alegar aquí, que la urgente necesidad de servicios públicos (agua, electricidad, escuelas, centro de salud, etc.) originada por esa expansión demográfica -y que a su vez era una resultante del crecimiento industrial y comercial urbano-impulsó a los habitantes de esas comunidades a constituir más asociaciones. Y muy importante: el Estado apoyó esa pretensión porque favorecía también la implantación del modelo de crecimiento industrial y comercial que él propulsaba.

\section{El financiamiento para las Asociaciones de Desa- rrollo de la Comunidad}

Vimos en la sección anterior cómo las Asociaciones de 
Desarrollo: a) fueron importantes instrumentos de política estatal para también; b) acompañar y apoyar los desplazamientos de población -hacia la periferia del país y hacia el Área Metropolitana de San José-; desplazamientos que fueron generados, a su vez, por los cambios en la estructura productiva exigidos por el modelo de crecimiento económico que se venía implantando en el país desde mediados de la década de los cincuenta.

Pero, ¿cómo realizaron tal acompañamiento y apoyo? Lo más observable fue que dispusieron de recursos financieros para construir obras físicas que acogieran a esa población que se desplazaba y además les facilitara el desarrollo de sus actividades productivas.

Para estos fines -aunque no siempre y no en todas partes- las asociaciones dispusieron de recursos financieros. En 1977 DINADECO estimó que el conjunto de las Asociaciones de Desarrollo de la Comunidad habían invertido, durante el periodo 1968-1976, unos 274 millones de colones; es decir, unos US\$37 millones de dólares, al tipo de cambio promedio de aquellos años. ¿De dónde obtenían los recursos para tan importante esfuerzo constructivo? Esa es una primera pregunta que intentaremos responder en las páginas siguientes.

\section{El financiamiento para las Asociaciones de Desarrollo}

El modelo conceptual denominado "Asociación de Desarrollo" proponía un tipo de organización con financiamiento fuerte y estable, es decir, alejado -hasta donde fuera posible- de los vaivenes político-electorales, para ello, el modelo jurídico, incluyó, como vimos, varios artículos en la Ley 3859.

El esfuerzo de los dirigentes y la disposición estatal hicieron que durante el periodo 1970-1978 dos terceras partes del presupuesto de las asociaciones emanara de fuentes externas, principalmente, estatales. En 1983 la distribución porcentual del ingreso de las asociaciones de desarrollo de la comunidad, según fuentes, fue de $65 \%$ para las fuentes externas y de $35 \%$ para las internas.

En el Cuadro 16, vemos con claridad, que la mayor fuente de financiamiento externo fueron las partidas específicas $y$, en proporciones mucho menores pero parecidas, el 1,25\% del impuesto sobre la renta, las ayudas estatales y el crédito, principalmente el que provenía del Banco Popular.

Se concluye entonces que el financiamiento que provenía del Estado fue vital para el trabajo de las asociaciones. Ahora bien: dentro de ese financiamiento sobresalían, como vimos, dos fuentes: a) el llamado $2 \%$ del impuesto sobre la renta; y b) las partidas específicas. En lo que sigue, vamos a referirnos, con mayor detalle a estas dos fuentes.

\section{El 2\% del impuesto sobre la renta}

La Ley 3859 privilegió a las Asociaciones de Desarrollo de la Comunidad otorgándoles, anualmente, un $2 \%$ del impuesto sobre la renta para que financiaran sus actividades. Cuatro ventajas tuvo esta fuente financiera:

a) Era estable. Se establecía por ley. No estaba sujeta a los caprichos o intereses político-electorales. Cada año, una asociación podía programar en su presupuesto -con bastante seguridad- que a sus arcas llevaría un monto previsible de dinero proveniente de un fondo conformado por un $2 \%$ del total del impuesto sobre la renta que el Estado recaudara.

b) Era creciente. Ese monto aumentaba, paralelamente, a una mayor y mejor recaudación estatal del impuesto sobre la renta.

CUADRO 16

Distribución porcentual de las fuentes de financiamiento externas (1983)

\begin{tabular}{lc}
\hline \multicolumn{1}{c}{ Fuentes de financiamiento } & Porcentajes \\
\hline Ayuda institucional & $12,1 \%$ \\
$1,25 \%$ del ISR & $12,8 \%$ \\
Préstamos & $16,2 \%$ \\
Partidas específicas & $59,2 \%$ \\
FUENTE: Juan María Tercero y Olger Salas Fonseca, op. cit., \\
p.170.
\end{tabular}

c) Podía ser empleada discrecionalmente por las asociaciones ya que no tenían un destino específico.

d) Más adelante, con la reforma al artículo 19 de la Ley 3859 , se pudo crear, con una parte de los recursos generados por el 1,25\% del impuesto sobre la renta, un sistema de avales y garantías para que las asociaciones pudiesen obtener créditos rápidos y baratos en el Banco Popular.

Durante el primer sub-periodo (1968-1969) lo que generó esta fuente financiera se distribuyó entre las asociaciones de acuerdo al esfuerzo de cada una. Pero la distribución resultó ser muy inequitativa. Además, pese a la dedicación de sus dirigentes, gran parte del $2 \%$ no se lograba recaudar.

Por todo ello, en 1971, el ministro de Gobernación y el ministro de Hacienda de la administración Figueres Ferrer, con el apoyo de los diputados de la Comisión de Asuntos Sociales de la Asamblea Legislativa impulsaron la Ley 4890, que reformaría el artículo 19 de la Ley 3859 en el siguiente sentido: de ahora en adelante el Estado aportaría, cada periodo fiscal, sólo el 1,25\% del estimado del 
impuesto sobre la renta para las asociaciones y ese monto se distribuiría, equitativamente entre las asociaciones integrales y entre las asociaciones específicas, estas percibirían la mitad de lo que recibieran las integrales.

A partir de entonces, ese estimado del 1,25\% del impuesto sobre la renta para distribuir entre las Asociaciones de Desarrollo evolucionó como se muestra en la Figura 9.

No contamos con información sobre los montos de los créditos con el Banco Popular que obtuvieron las asociaciones durante el periodo bajo estudio, solo sabemos que hacia 1983 -al finalizar el periodo- un 10,6\% del total de ingresos de las Asociaciones de Desarrollo Comunal procedía de créditos obtenidos con el Banco Popular.

\section{Las partidas específicas}

Pese a la importancia de los ingresos provenientes del $1,25 \%$ del impuesto sobre la renta durante el periodo 1971-1978 la fuente más importante de financiamiento para las Asociaciones de Desarrollo fueron las famosas e históricas partidas específicas. Es decir, transferencias de

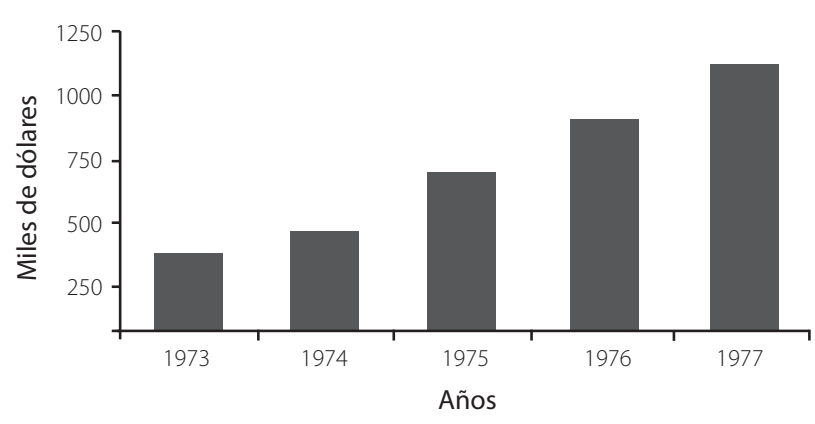

FIG. 9. Presupuesto del $1.25 \%$ del impuesto sobre la renta girado a las asociaciones de desarrollo (1973-1977).

FUENTE: DINADECO, Depto. de Programación, sección de Estadística, 1974. apreciarse que las partidas específicas fueron una fuente externa de financiamiento significativa y creciente para las asociaciones, sobre todo en la administración Oduber Quirós.

Tan importantes fueron las partidas específicas para el funcionamiento de las asociaciones, que decidimos realizar un estudio particular sobre su otorgamiento durante el periodo 1970-1978. He aquí las principales conclusiones de esta investigación.

\section{Número de asociaciones que recibieron partidas específicas}

En el Cuadro 17, observamos que -en una muestra de 16 cantones- el número de Asociaciones de Desarrollo de la Comunidad que recibieron partidas específicas, durante el periodo bajo estudio, fue creciente.

En 1970, sólo un 8,8\% de las asociaciones existentes en los 16 cantones seleccionados, recibieron partidas específicas, en 1974 -hacia la mitad del periodo- el 27,9\% recibían partidas específicas; y en 1978, al final, dos terceras partes de las asociaciones existentes recibieron partidas específicas.

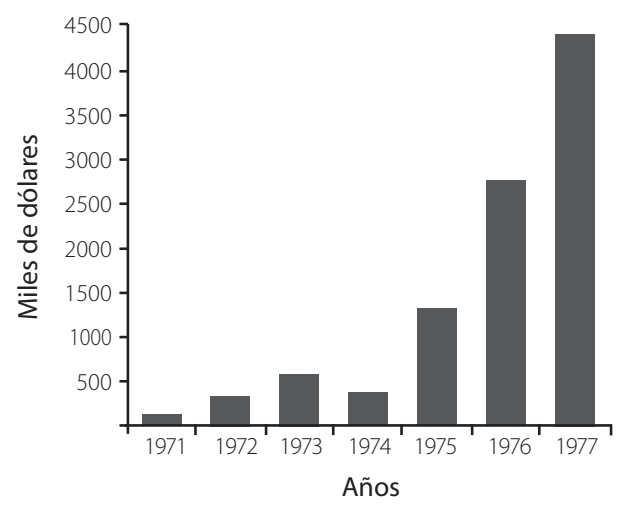

FIG. 10. Monto de partidas específicas para las asociaciones de desarrollo de la comunidad.

FUENTE: DINADECO, Depto de Programación, sección de Estadística, 1978. dinero, con fines específicos, para organizaciones, empresas e instituciones que los diputados incluían, cada noviembre, en la Ley del presupuesto de la República.

¿Cuál fue la importancia financiera, para las asociaciones, de esta fuente de ingresos? En 1978 DINADECO estimó que los montos anuales girados a las Asociaciones de Desarrollo por concepto de partidas específicas habían evolucionado tal y como se muestra en la Figura 10. Puede
Queda clara esta tendencia de un mayor número de asociaciones existentes que recibían partidas específicas. Pero: ¿cuántas y cuánto recibían?

\section{Distribución del número de partidas específicas giradas a las asociaciones}

Entre 1970 y 1978 las Asociaciones de Desarrollo de la Comunidad recibieron casi 5000 partidas específicas en 
el marco de las relaciones formales entre el Estado y estas organizaciones. Las partidas específicas eran recursos financieros públicos, incluidos en la Ley de Presupuesto Anual de la República, recursos sobre los cuales tenía acceso el Poder Legislativo. Por solicitud de los vecinos organizados en Asociaciones de Desarrollo -u otro tipo de

\section{CUADRO 17}

Asociaciones que recibieron partidas específicas por año (muestra de 16 cantones)

\begin{tabular}{cccc}
\hline Año & $\begin{array}{c}\text { Asociaciones } \\
\text { existente }\end{array}$ & $\begin{array}{c}\text { Asoc. que } \\
\text { recibieron } \\
\text { partidas }\end{array}$ & Porcentaje \\
\hline 1970 & 34 & 3 & 8,8 \\
1971 & 34 & 6 & 17,6 \\
1972 & 52 & 14 & 26,9 \\
1973 & 58 & 27 & 46,6 \\
1974 & 86 & 24 & 27,9 \\
1975 & 123 & 40 & 32,5 \\
1976 & 161 & 58 & 36,0 \\
1977 & 182 & 93 & 51,1 \\
1978 & 191 & 127 & 66,5 \\
Total & 921 & 392 & 42,6 \\
\hline
\end{tabular}

FUENTE: Miguel Mondol, "Las Asociaciones de Desarrollo de la Comunidad....", op. cit, pagina 103. Información sobre la muestra de cantones, cfr. idem, pagina 15 y 16

organización- o por motivación de un representante del Poder Legislativo -un diputado- esos recursos podían trasladarse para fines específicos a las organizaciones. En esa misma medida su correcta utilización podía ser fiscalizada por DINADECO -en el caso de las Asociaciones de Desarrollo- y en cualquier caso, por la Contraloría General de la República.

Como vimos en páginas anteriores, estos recursos financieros públicos -o sea, las partidas específicas- no fueron los únicos pero sí fueron los más importantes, vitales para el funcionamiento de las Asociaciones de Desarrollo de la Comunidad. En efecto, por lo menos dos terceras partes del financiamiento con que trabajaron las Asociaciones de Desarrollo en el periodo 70-78 fue financiamiento externo. Y un $60 \%$ de ese financiamiento externo estuvo constituido por partidas específicas.

Conceptualmente la partida específica fue una concreción importante de las nuevas relaciones entre el Estado y la Sociedad Civil local. Mediante la partida específica el Estado hacía concreta y legítima su relación con las organizaciones de la sociedad civil local. Simultáneamente -como veremos más adelante- las inducía a colaborar con los proyectos que eran de interés para el Estado costarricense.

Por su parte, las organizaciones de la sociedad civil local -como las Asociaciones de Desarrollo- encontraban respaldo en el Estado para solucionar necesidades que ellas consideraban esenciales para la comunidad. De esta manera también se legitimaba, desde el punto de vista de la sociedad local, su relación con el Estado.

Hubo, por supuesto, necesidades sentidas por los dirigentes de la Asociación de Desarrollo y compartidas con el interés estatal. Por ejemplo, las obras relacionadas con vialidad (construcción de puentes, caminos vecinales, apertura de trochas...etc), en la mayoría de los casos no sólo eran del interés de la organización sino también del Estado como veremos más adelante en esta investigación.

Como dijimos, durante el periodo 70-78 la Asamblea Legislativa, vía presupuesto de la República, giró casi 5000 partidas específicas para las Asociaciones de Desarrollo de la Comunidad. La inmensa mayoría, más del $87 \%$, se giró durante la administración Oduber-Quirós.

a) Distribución espacial del número de partidas específicas: La distribución por regiones y sub-periodos se muestra en el Cuadro 18.

Una ligera mayoría de las partidas $(55,4 \%)$ se giró para las ADC ubicadas en la Región Central del país. El porcentaje fue muy similar en ambos periodos. Esta diferencia desaparece, por supuesto, cuando se considera la población que habitaba en ambas regiones. Como en la Región Periférica había menos población, el promedio del número de partidas por habitante fue mayor en la Región Periférica.

Profundizando en el tema, habría que agregar que, si bien las ADC de la Región Central -como vimos- tuvieron una ligera ventaja en el número de partidas, también es cierto que la mayoría de esas partidas se giró fuera de la Subregión Metropolitana de la Región Central, la cual, tradicionalmente ha concentrado los mayores aportes del Estado para la dotación de obras y servicios públicos. Así, considerando la Región Central como un conjunto unitario, preguntémonos ¿Cómo se distribuyó, internamente, el número de partidas específicas? Esto lo podremos apreciar en el Cuadro 19.

Las Asociaciones ubicadas en la Subregión Metropolitana (la más poblada del país y con más servicios) sólo obtuvieron menos del $20 \%$ del número total de partidas giradas a las Asociaciones de Desarrollo ubicadas en toda la Región Central. Pero, las sub-regiones 
CUADRO 18

Número de partidas por regiones y períodos (en porcentajes)

\begin{tabular}{lccc}
\hline Región & $\begin{array}{c}\text { Período } \\
\text { 1970-1974 }\end{array}$ & $\begin{array}{c}\text { Período } \\
\text { 1975-1978 }\end{array}$ & Total \\
\hline Central & 53,9 & 55,7 & 55,4 \\
Periférica & 46,1 & 44,3 & 44,6 \\
Total & 100 & 100 & 100 \\
\hline
\end{tabular}

más periféricas de esta Región, -es decir, el resto de San José y la "región central"- obtuvieron, entre ambas, el $80.5 \%$ del total de partidas giradas a las Asociaciones de toda la Región. En conclusión: si bien es cierto las Asociaciones ubicadas en la Región Central acapararon el mayor número de partidas, en el interior de la Región el mayor número de partidas se fue para las subregiones más periféricas, con menores servicios públicos y privados.

En el cuadro siguiente (Cuadro 20) podemos apreciar que en la Región Periférica, las ADC de las subregiones Chorotega, Brunca y Pacífico Central fueron las más beneficiadas con el otorgamiento de partidas específicas. Llama la atención, el extraordinario incremento en el número de partidas giradas a las Asociaciones de la Sub región Brunca, entre los periodos 70-74 y 75-78. Esta subregión, como sabemos, forma parte de la Región Periférica del país.

Con todos los datos anteriores podríamos ir concluyendo que en relación con la distribución del número de partidas específicas, las Asociaciones de Desarrollo de la

\section{CUADRO 19}

Número de partidas por sub-regiones y períodos (en porcentajes)

\begin{tabular}{lccc}
\hline \multicolumn{1}{c}{ Sub-región } & $\begin{array}{c}\text { Período } \\
\text { 1970-1974 }\end{array}$ & $\begin{array}{c}\text { Período } \\
\text { 1975-1978 }\end{array}$ & Total \\
\hline Metropolitana & 32,3 & 17,6 & 19,5 \\
$\begin{array}{l}\text { Resto de } \\
\text { San José }\end{array}$ & 40,6 & 48,4 & 47,4 \\
$\begin{array}{l}\text { Resto de la } \\
\text { Región Central }\end{array}$ & 27,1 & 34,0 & 33,1 \\
Total & 100 & 100 & 100 \\
\hline
\end{tabular}

Comunidad fueron un instrumento eficaz, que contribuyó a la descentralización de los aportes del Estado a la sociedad civil local. Tradicionalmente estos aportes se concentraban en la Región Central del país. Ahora las Asociaciones, intentaban revertir ese proceso. b) Distribución del número de partidas según su finalidad: Siempre en consideración al número de partidas, notaremos en el Cuadro 21, que para ambas regiones y en ambos periodos, los destinos más importantes para el cual se asignaron partidas a las Asociaciones fueron los de infraestructura comunal y vialidad. En ambos periodos y para ambas regiones, dos terceras partes del número total de partidas fueron para esos dos fines.

Recordemos que en las obras de "infraestructura comunal", incluimos algunas como las siguientes: construcción y equipamiento de salones comunales, escuelas,

CUADRO 20

Número de partidas por sub-regiones y períodos (en porcentajes)

\begin{tabular}{lccc}
\hline \multicolumn{1}{c}{ Sub-región } & $\begin{array}{c}\text { Período } \\
\text { 1970-1974 }\end{array}$ & $\begin{array}{c}\text { Período } \\
1975-1978\end{array}$ & Total \\
\hline Metropolitana & 17,4 & 9,8 & 10,8 \\
$\begin{array}{l}\text { Resto de } \\
\text { San José }\end{array}$ & 21,9 & 26,9 & 26,3 \\
Resto de la & 14,6 & 18,9 & 18,4 \\
Región Central & & & \\
Chorotega & 24,7 & 15,8 & 17,0 \\
Pacífico Central & 14,1 & 7,9 & 8,8 \\
Brunca & 1,4 & 12,9 & 11,4 \\
Huetar & 3,6 & 5,1 & 4,9 \\
Atlántica & & & \\
Huetar Norte & 2,3 & 2,6 & 2,5 \\
Total & 100 & 100 & 100 \\
\hline
\end{tabular}

plazas de deportes, centros de nutrición, centros de salud, iglesias. Acueductos, electricidad, alumbrado público y obras de sanidad ambiental.

$Y$, en vialidad, incluimos obras como: carreteras, puentes, caminos rurales, apertura de trochas, etc.

Existen, sin embargo particularidades que deberíamos resaltar:

a) Comparando las ADC de la Región Periférica con las de la Región Central del país, en ambos periodos, las de la Región Periférica obtuvieron más partidas específicas para vialidad.

b) Obtuvieron casi igual porcentaje de partidas para la construcción, mejoras y equipamiento de su infraestructura comunitaria. Esto lo podemos apreciar en el Cuadro 22.

c) Por otra parte, las ADC de la Región Periférica concentraron más, en sólo dos destinos (vialidad e 
CUADRO 21

Número de partidas por períodos y finalidad (en porcentajes)

\begin{tabular}{lccc}
\hline \multicolumn{1}{c}{ Finalidad } & $\begin{array}{c}\text { Período } \\
1970-1974\end{array}$ & $\begin{array}{c}\text { Período } \\
1975-1978\end{array}$ & Total \\
\hline Infraestructura & 43,2 & 41,4 & 41,6 \\
Vialidad & 15,8 & 23,1 & 22,1 \\
Obras varias & 10,4 & 18,1 & 17,1 \\
Agua/Electricidad & 11,5 & 7,8 & 8,3 \\
Transferencia & 3,3 & 5,0 & 4,8 \\
Equipo & 15,2 & 2,6 & 4,3 \\
Vivienda & 0,3 & 1,3 & 1,2 \\
Proyectos & 0,3 & 0,5 & 0,5 \\
Otros & 0,0 & 0,1 & 0,1 \\
Total & 100 & 100 & 100 \\
\hline
\end{tabular}

infraestructura) el total de partidas que recibieron. Tres cuartas partes del número total de partidas fueron para estos dos fines. Si a ellos le agregáramos el $11 \%$ que recibieron en "partidas con fines varios" (o sea, para fines discrecionales de la Asociación y que probablemente las utilizaron en "vialidad"o"infraestructura"), tendríamos que prácticamente el $90 \%$ de las partidas recibidas tenían esas dos finalidades. Pero sobre todo para vialidad. Véase que, en el número de partidas asignadas para este propósito en la Región Periférica, en ambos periodos, más que duplicó el número asignado a las ADC de la Región Central.

Estas observaciones concuerdan plenamente con el tipo y urgencia de necesidades que presentaba la Región Periférica del país, en aquellos años. Esta urgencia era, como sabemos, la construcción de vías de comunicación.

En resumen, en cuanto al número de partidas específicas, las Asociaciones de Desarrollo de la Comunidad recibieron casi 5000 partidas específicas: a) especialmente en la Administración Oduber Quirós; b) las ADC ubicadas en la región periférica obtuvieron, en términos a su población total más partidas específicas y c) en la región periférica las utilizaron casi sólo para dos fines: vialidad e infraestructura comunitaria.

\section{Distribución del monto en partidas girado a las asociaciones}

Como dijimos, las ADC, durante el periodo 70-78 recibieron casi 5000 partidas específicas, por un monto total de 112,5 millones de colones corrientes. Traducidos a dólares - de esos años- ese monto equivalía a unos trece millones y medio de dólares girados a las Asociaciones de
CUADRO 22

Número de partidas por períodos, regiones y finalidad (en porcentajes)

\begin{tabular}{lcccc}
\hline \multicolumn{1}{c}{ Finalidad } & \multicolumn{2}{c}{ Región Central } & \multicolumn{2}{c}{ Región Periférica } \\
& $\begin{array}{l}\text { Período } \\
1970-1974\end{array}$ & $\begin{array}{c}\text { Período } \\
1975-1978\end{array}$ & $\begin{array}{c}\text { Período } \\
1970-1974\end{array}$ & $\begin{array}{c}\text { Período } \\
1975-1978\end{array}$ \\
\hline Vialidad & 9,2 & 14,5 & 23,6 & 33,8 \\
Infraest. & 45,2 & 42,6 & 40,7 & 39,9 \\
Varias & 14,7 & 23,1 & 5,4 & 11,8 \\
Subtotal & 69,2 & 80,2 & 69,7 & 85,5 \\
Otras & 30,8 & 19,8 & 30,3 & 14,5 \\
Total & 100,0 & 100,0 & 100,0 & 100,0 \\
$\mathbf{N}^{\circ}$ total & 347 & $\mathbf{2 3 1 1}$ & $\mathbf{2 9 7}$ & $\mathbf{1 8 4 0}$ \\
\hline
\end{tabular}

Desarrollo de la Comunidad en ese decenio.

Esa suma es importante, si partimos del dato suministrado por las mismas Asociaciones en sus planes de trabajo donde estimaban que la construcción de una escuela rural de cinco aulas, costaba alrededor de 16000 dólares de ese entonces. Eso significa que durante esos nueve años, utilizando sólo el dinero recibido en partidas, las Asociaciones podrían haber construido y equipado (equipo básico) unas 900 pequeñas escuelas rurales.

a) Distribución espacial del monto: Tal como sucedió con el número, el mayor monto en partidas específicas les fue girado durante la Administración Oduber Quirós. El $80 \%$ del total del monto girado durante todo el periodo correspondió a esa administración.

Para empezar, habría que decir que, en términos de montos, las Asociaciones que se ubicaban en la Región Central del país recibieron más dinero en partidas específicas que las que se ubicaban en la región periférica. Y eso sucedió tanto en la Administración Figueres Ferrer como en la Administración Oduber Quirós (Cuadro 23).

Se puede apreciar en el cuadro anterior que el $62.4 \%$ (dos terceras partes) del monto en partidas específicas se dirigió hacia las ADC de la Región Central.. La tendencia es más fuerte que la observada cuando hablamos del número de partidas. En efecto, como se recordará, sólo el 55\% del número de partidas giradas a las ADC iba para la Región Central. Ahora vemos que el $63 \%$ del monto iba para esa Región. Ello significa que, en promedio, cada partida girada a una ADC de la Región Central, fue por un monto superior al de cada partida girada a una ADC de la otra Región, es decir, de la Región Periférica. 
Sin embargo, a estas observaciones habría que hacerle varios comentarios.

i) Si bien es cierto que el mayor monto se fue para las ADC ubicadas en la Región Central, dentro de ésta las mayores cantidades (igual que el mayor número) se dirigieron a las subregiones "periféricas" de la Región Central, es decir, aquellas situadas fuera del centro tradicional del país, que como sabemos es la subregión metropolitana (Cuadro 24).

\section{CUADRO 23}

Monto en partidas por regiones, períodos y finalidad (en porcentajes)

\begin{tabular}{lccc}
\hline Región & $\begin{array}{c}\text { Período } \\
1970-1974\end{array}$ & $\begin{array}{c}\text { Período } \\
1975-1978\end{array}$ & Total \\
\hline Central & 59,6 & 62,7 & 62,4 \\
Periférica & 40,4 & 37,3 & 37,6 \\
Total & 100 & 100 & 100 \\
\hline
\end{tabular}

Observemos que para todo el periodo, menos del 15\% del monto total fue para la subregión Metropolitana; mientras tanto, en la subregión "resto de San José" y en la sub región Central los porcentajes fueron del 28,6\% y del 19,2\% respectivamente. Es decir, si bien es cierto que en la Región Central se concentró el mayor porcentaje del monto, la mayoría de ese monto se dirigió para las ADC situadas fuera de la Subregión Metropolitana, esto es, fuera de la subregión que más población y servicios tenía el país.

ii) La concentración del monto en partidas en la Región Central en relación con todo el país, obedeció a que las ADC situadas en los cantones centrales de las cuatro provincias principales (San José, Heredia, Cartago y Alajuela) recibieron, sólo ellas, una cuarta parte del total del monto distribuido entre las Asociaciones de todo el país. Como sabemos son los cantones más poblados y con mayor número de votantes. Si los excluyéramos la diferencia entre el monto recibido por las ADC de la Región Central y el resto del país sería, evidentemente, menor.

iii) Las Asociaciones situadas en tan sólo dos de esos cuatro cantones centrales, el de Cartago y el de Alajuela absorbieron el $16,7 \%$ del total. Si le sumáramos sólo un cantón más, el central de Puntarenas, tendríamos que en sólo tres cantones centrales se concentró casi una cuarta parte del monto total girado a las Asociaciones. La información puede apreciarse en el Cuadro 25.
CUADRO 24

Monto en partidas por sub-regiones y períodos (en porcentajes)

\begin{tabular}{lccc}
\hline \multicolumn{1}{c}{ Sub-región } & $\begin{array}{c}\text { Período } \\
1970-1974\end{array}$ & $\begin{array}{c}\text { Período } \\
1975-1978\end{array}$ & Total \\
\hline Metropolitana & 28,4 & 13,2 & 14,6 \\
$\begin{array}{l}\text { Resto de } \\
\text { San José }\end{array}$ & 19,8 & 29,5 & 28,6 \\
Resto de la & 11,4 & 20,0 & 19,2 \\
Región Central & & & \\
Chorotega & 22,3 & 12,4 & 13,3 \\
Pacífico Central & 10,6 & 9,8 & 9,9 \\
Brunca & 1,4 & 8,3 & 7,6 \\
Huetar Atlántica & 2,7 & 3,9 & 3,7 \\
Huetar Norte & 3,3 & 3,0 & 3,0 \\
Total & 100 & 100 & 100 \\
\hline
\end{tabular}

iv) Si bien es cierto que las $A D C$ de tres cantones centrales (cabeceras de provincia), en particular y la Región Central, en general, fueron privilegiadas por el monto absoluto recibido, la distribución promedio por habitante favoreció a las Asociaciones localizadas en los cantones periféricos del país.

En efecto, si relativizamos el monto que recibió el conjunto de Asociaciones en cada Región entre la población de esa Región, observaríamos que son las Asociaciones situadas en la Región Periférica del país las que percibieron un monto mayor por habitante (Cuadro 26).

Notamos que en ambos periodos el monto promedio por habitante, siempre fue ligeramente superior en la Región Periférica del país.

v) Analicemos brevemente la distribución del monto girado a las $A D C$, según promedio de dólares por habitante y por subregiones, tal como se presenta en el Cuadro 27.

En la Región Central, la Sub región Metropolitana recibió el menor monto promedio de la Región y del país. Las otras dos subregiones (las más periféricas de la Región Central) obtuvieron el segundo y tercer mayor monto promedio por habitante en relación con todas las subregiones del país.

En la Región Periférica sobresale la subregión Pacífico Central con el mayor monto promedio de todo el país. La Chorotega también obtuvo montos promedios muy significativos.

b) Distribución del monto por finalidad de la partida:Finalmente, el Cuadro 28 nos permitirá analizar la distribución del monto en partidas giradas a las ADC, según la finalidad o destino de la partida por Regiones. 
CUADRO 25

Monto en partidas giradas a las ADC por cantones centrales y períodos (en porcentajes)

\begin{tabular}{lccc}
\hline $\begin{array}{c}\text { Cantones } \\
\text { centrales }\end{array}$ & $\begin{array}{c}\text { Período } \\
\text { 1970-1974 }\end{array}$ & $\begin{array}{c}\text { Período } \\
\mathbf{1 9 7 5 - 1 9 7 8}\end{array}$ & Total \\
\hline San José & 16,5 & 4,8 & 5,8 \\
Alajuela & 3,7 & 7,2 & 6,9 \\
Cartago & 4,6 & 10,3 & 9,8 \\
Heredia & 0,9 & 2,4 & 2,2 \\
Liberia & 0,1 & 0,9 & 0,8 \\
Puntarenas & 6,8 & 6,6 & 6,6 \\
Limón & 0,2 & 0,5 & 0,5 \\
Total & 32,9 & 32,6 & 32,6 \\
\hline
\end{tabular}

CUADRO 26

Monto en partidas por regiones y períodos (dólares por habitante)

\begin{tabular}{lccc}
\hline \multicolumn{1}{c}{ Región } & $\begin{array}{c}\text { Período } \\
\text { 1970-1974 }\end{array}$ & $\begin{array}{c}\text { Período } \\
\text { 1975-1978 }\end{array}$ & Total \\
\hline Central & 0,8 & 5,6 & 6,4 \\
Periférica & 0,9 & 5,7 & 6,6
\end{tabular}

CUADRO 27

Monto en partidas giradas a las ADC por sub-regiones y períodos (dólares por habitante)

\begin{tabular}{lccc}
\hline \multicolumn{1}{c}{ Región } & $\begin{array}{c}\text { Período } \\
\text { 1970-1974 }\end{array}$ & $\begin{array}{c}\text { Período } \\
\mathbf{1 9 7 5 - 1 9 7 8}\end{array}$ & Total \\
\hline Metropolitana & 0,8 & 2,6 & 3,4 \\
Resto San José & 0,8 & 8,1 & 8,9 \\
Central & 0,7 & 8,3 & 9,0 \\
Chorotega & 1,8 & 6,6 & 8,4 \\
Pacífico Central & 1,3 & 8,5 & 9,8 \\
Brunca & 0,1 & 4,9 & 5,0 \\
Huetar Atlántica & 0,4 & 3,5 & 3,9 \\
Huetar Norte & 0,7 & 3,9 & 4,6 \\
Total & $\mathbf{0 , 8}$ & $\mathbf{5 , 6}$ & $\mathbf{6 , 4}$ \\
\hline
\end{tabular}

Del monto total girado a las ADC de la Región Central y durante el periodo $70-78$, el 15,8\% fue para vialidad. Proporcionalmente, las ADC de la Región Periférica recibieron más del doble, en ese mismo periodo para ese mismo propósito. Esta información subraya -y con mayor fuerza- la que ya habíamos consignado cuando hablamos del número de partidas giradas a las ADC. Refleja esta información que la necesidad de caminos vecinales, trochas, puentes, etc.. era más real -o por lo menos sentida así- por los dirigentes de las ADC de la Región Periférica en relación con los dirigentes de la Región Central. En la periféri$\mathrm{ca}$, como vemos en el cuadro anterior, un tercio del total del monto girado a las ADC, fue para obras de vialidad. $Y$ esa primacía fue válida tanto para el periodo 70-74 como para el periodo 75-78.

Los montos en partidas destinados para construir, mejorar o equipar la infraestructura comunitaria (salones comunales, escuelas, centros de salud, plazas de deportes, iglesias, etc..) fueron muy importantes en ambas regiones. Un poco más en la Región Central. Y en ambos periodos.

En tercer lugar, los montos para "obras varias" (verdaderos cheques en blanco para una utilización correcta por las ADC, que como dijimos, mostraban la confianza de los legisladores en estas organizaciones) fueron mucho más significativos para las ADC en la Región Central que en la Periférica.

Finalmente debemos anotar que en estas tres finalidades (vialidad, infraestructura comunitaria y obras varias) se contabilizó, para ambas Regiones más del $80 \%$ del total del monto girado por los legisladores a las $A D C$ en ambos periodos.

\section{Densidad organizacional y financiamiento me- diante partidas especificas en los cantones rurales de la Región Periférica}

Vimos cómo la Región Periférica del país, es decir, aquella que se extiende fuera del Valle Intermontano Central, concentró, en términos proporcionales el mayor número de Asociaciones. También vimos que en ella -aunque con mucho menor intensidad-se concentró, en términos relativos también, el mayor número y el mayor monto en partidas específicas giradas para las Asociaciones de Desarrollo de la Comunidad.

Ahora estamos en condiciones de especificar por tipo de cantón cómo se concentraron las Asociaciones y los montos en partidas específicas girados para ellas.

\section{Cantones muy atractores de población de la Región Periférica}

Digamos, en primer lugar que el Cuadro 29 se refiere a cantones muy atractores de población tanto en el periodo 68-73 como en el periodo 73-84.

Adicionalmente podemos observar que se trata de cantones con muy altas densidades organizacionales. Cinco de los diez cantones triplican el promedio de la densidad nacional (7,2 ADC por cada 10 mil habitantes 
CUADRO 28

Monto en partidas por regiones, períodos y finalidad (en porcentajes)

\begin{tabular}{lcccccc}
\hline \multicolumn{3}{c}{ Finalidad } & \multicolumn{3}{c}{ Región Central } & \multicolumn{3}{c}{ Región Periférica } \\
& $\begin{array}{l}\text { Período } \\
\mathbf{1 9 7 0 - 1 9 7 4}\end{array}$ & $\begin{array}{c}\text { Período } \\
\mathbf{1 9 7 5 - 1 9 7 8}\end{array}$ & $\begin{array}{c}\text { Total del } \\
\text { período } \\
\mathbf{1 9 7 0 - 1 9 7 8}\end{array}$ & $\begin{array}{c}\text { Período } \\
\mathbf{1 9 7 0 - 1 9 7 4}\end{array}$ & $\begin{array}{c}\text { Período } \\
\mathbf{1 9 7 5 - 1 9 7 8}\end{array}$ & $\begin{array}{c}\text { Total del } \\
\text { período } \\
1970-1978\end{array}$ \\
\hline Vialidad & 11,3 & 16,2 & 15,8 & 27,9 & 33,8 & 33,2 \\
Infraestructura & 51,5 & 42,8 & 43,5 & 34,9 & 35,9 & 35,8 \\
Varias & 16,5 & 22,2 & 21,7 & 6,7 & 12,0 & 11,5 \\
Subtotal & 79,2 & 81,3 & 81,1 & 69,6 & 81,7 & 80,5 \\
Otras & 20,8 & 18,7 & 18,9 & 30,4 & 18,3 & 19,5 \\
Total & 100,0 & 100,0 & 100,0 & 100,0 & 100,0 & 100,0 \\
\hline
\end{tabular}

mayores de 15 años es el promedio nacional) y cinco prácticamente la duplican. En su conjunto, diez cantones, duplican la el promedio de la densidad organizacional del país.

Ahora bien, en este grupo de cantones con altas densidades organizacionales y atractores muy fuertes de población, el indicador dólares por habitante ${ }^{129}$ es de 5,5. Lo cual quiere decir que en promedio, cada habitante de cualquier edad en esos 10 cantones recibió 5,5 dólares provenientes de partidas específicas giradas a las ADC ubicadas en esos cantones durante el periodo 70-78. Es una suma ligeramente menor al promedio nacional $(6,8$ dólares por habitante) para Asociaciones ubicadas en cantones muy alejados del centro del país. Debemos consi- derar, además, que tres de los cinco cantones ubicados en la frontera norte superaron el promedio nacional. Igual ocurrió con el cantón de Siquirres.

Vistos en el Cuadro 29 estos 10 cantones parecen aislados. Pero ubicados en un mapa estos doce cantones forman contornos geográficos definidos. Hay por lo menos tres contornos:

a) Zona frontera norte (cantones de Upala, Los Chiles, Guatuso y Sarapiquí)

b) Zona Pococí (cantones de Pococí, Siquirres, Matina y Guácimo)

c) Zona sur (cantones de Buenos Aires y Coto Brus)

\section{CUADRO 29}

Cantones de la Región Periférica muy atractores de población. Tasas migratorias, densidad organizacional y dólares por habitante en partidas específicas giradas a las ADC

\begin{tabular}{lcccc}
\hline $\begin{array}{c}\text { Cantones atractores } \\
\text { de población }\end{array}$ & $\begin{array}{c}\text { Tasa migratoria } \\
(\mathbf{1 9 7 3 )}\end{array}$ & $\begin{array}{c}\text { Tasa migratoria } \\
(\mathbf{1 9 8 3 )}\end{array}$ & $\begin{array}{c}\text { Asociaciones por cada } \\
\mathbf{1 0 0 0 0} \text { habitantes }\end{array}$ & $\begin{array}{c}\text { Dólares por } \\
\text { habitante }\end{array}$ \\
\hline Upala & 6,1 & 6,6 & 21,2 & 7,5 \\
Los Chiles & 4,3 & 19,6 & 12,6 & 4,2 \\
Guatuso & 10,8 & 1,9 & 20,0 & 6,9 \\
Sarapiquí & 37,8 & 10,2 & 12,6 & 3,3 \\
Pococí & 21,9 & 9,6 & 10,9 & 5,7 \\
Siquirres & 9,1 & 18,2 & 7,7 & 7,7 \\
Matina & 12,5 & 4,5 & 20,1 & 4,0 \\
Guácimo & 14,3 & 9,4 & 12,5 & 4,1 \\
Buenos Aires & 9,5 & $-1,9$ & 19,0 & 6,1 \\
Coto Brus & 4,5 & 6,4 & 15,1 & 4,3 \\
Total & - & - & 14,8 & $\mathbf{5 , 5}$ \\
\hline
\end{tabular}


Repetimos, todos son fuertes atractores de población durante un largo periodo (68-84). Todos tienen altas densidades organizacionales, equivalentes a dos o tres veces el promedio nacional. Los habitantes de cuatro de estos cantones (principalmente los de la alejada frontera norte) recibieron recursos por la vía de partidas específicas, superiores al promedio nacional). Ahora preguntémonos:

¿Cuáles características productivas presentaron estos cantones durante el periodo bajo estudio?

a) Zona frontera norte. (Guatuso, Upala, La Cruz, Los Chiles y Sarapiquí), un área colonizada primero por nicaragüenses, atraídos por la recolección de raicilla. En el periodo 50-63 comenzó la inmigración de costarricenses producto de la expansión de la población hacia áreas periféricas. Desde 1963 predominó la economía de subsistencia con un incipiente desarrollo de hacienda capitalista. ${ }^{130}$ Para el periodo 63-73, se incluyó esta zona dentro de la categoría de las áreas rurales "que combinan una expansión de la agricultura de mercado con la colonización espontánea de tierras baldías y que no expulsan población". En el caso particular de los cantones aquí considerados, la actividad para el mercado se da en términos de ganadería. ${ }^{131}$ Además, son fuertes atractores de población.

b) Zona de Pococí. (cantones de Matina, Guácimo, Pococí y Siquirres). Se define como un espacio geográfico que durante el periodo 63-73 tuvo una fuerte expansión capitalista, particularmente en los cantones de Pococí y Siquires. "Ambos se caracterizan por ser el destino de fuertes corrientes migratorias procedentes de muy diversas regiones del país. En el caso de Pococí, la fuerte migración -la más elevada del país- hace subir la población de 17000 habitantes en 1963 a 40000 en 1973, lo que implica una tasa media de crecimiento geométrico anual de alrededor de $9 \%$...Los contingentes de población recibidos por estos cantones se explican por el cultivo de extensas plantaciones bananeras propiedad de empresas multinacionales como la Standard Fruti Co. Y la Del Monte Co. Y de un número limitado de productores asociados. Como resultado de esta gran expansión...el área dedicada a banano pasa de 1251 a 16448 manznas en Pococí y de 605 a 6470 en Siquirres..." 132

c) Zona Buenos Aires: Un tercer subconjunto de cantones (recordemos: todos con densidades organizacionales muy superiores al promedio nacional y atractores de población) estuvo constituido por los cantones de Buenos Aires y Coto Brus, en la subregión Brunca al sur del país. Buenos Aires fue un gran atractor de población antes de 1973 y luego disminuyó su atracción. Coto Brus la mantuvo en los dos periodos censales.

En Buenos Aires, la inmigración hizo aumentar el área bajo fincas de una manera extraordinaria. Entre el 63 y el
73 esa área creció en un 34\%. Además se logra integrar al mercado a través de la ganadería pero incrementa también la economía de subsistencia: se aumentó significativamente el área dedicada al auto-consumo (arroz, (67\% frijoles (150\%) y maíz (136\%)).

Por su parte, Coto Brus, mantuvo su tradicional relación con el mercado a través de la producción cafetalera, pero en el periodo bajo estudio, se produjo la colonización de las tierras baldías situadas en la parte alta del cantón. En este sentido-igual que Buenos Aires- presenta características "que combinan una expansión de la agricultura de mercado con la colonización espontánea de tierras baldías y que no expulsan población", es decir, la misma situación que los cantones de la zona "frontera norte" (Guatuso, Upala, etc.).

\section{Cantones muy expulsores de población de la Región Pe- riférica}

Observemos ahora el segundo subconjunto de 10 cantones con densidades organizaciones mayores al promedio nacional y con tasas migratorias negativas en un periodo largo (dos periodos censales)(Cuadro 30).

Notaremos que todos ellos presentan tasas migratorias negativas tanto para el periodo $68-73$ como para el periodo 73-84. Es decir, son cantones que expulsaron, de manera intensa, población.

Pero en todos ellos también prevalecen tasas de densidad organizacional muy altas. Así, en el conjunto de los diez cantones, la densidad organizacional fue de 14,3 ADC por cada diez mil habitantes, una cifra similar al del subgrupo anterior. Es el doble del promedio nacional $(7,2)$. Interesante: a pesar de que son el inverso del otro grupo de cantones en relación con los movimientos migratorios, estos diez también presentan altas tasas de densidad organizacional.

Por otro lado, en este conjunto de cantones muy expulsores de población, el promedio de dólares recibido por cada habitante en partidas específicas giradas a las ADC fue muy superior al promedio nacional. Fue de 9,5 dólares por habitante y el promedio nacional era, como recordaremos de $\$ 6,8$ por habitante.

A simple vista estos doce cantones expulsores de población parecen unidades aisladas. Vistos en un mapa forman subconjuntos geográficos bastante definidos. Podríamos identificar -como en el caso de los otros 12 cantones- tres áreas geográficas:

a) La Zona sur de la península de Nicoya. (cantones de Santa Cruz, Hojancha y Nandayure).

b) La zona "sur-oeste de la provincia de San José. ( Cantones de Turrubares, Acosta, Puriscal . 


\section{CUADRO 30}

Tasas migratorias, densidad organizacional y dólares por habitante en partidas específicas giradas a las ADC (Período 1968-1978)

\begin{tabular}{ccccc}
\hline $\begin{array}{c}\text { Cantones expulsores } \\
\text { de población }\end{array}$ & $\begin{array}{c}\text { Tasa migratoria } \\
(\mathbf{1 9 7 3})\end{array}$ & $\begin{array}{c}\text { Tasa migratoria } \\
(\mathbf{1 9 8 3 )}\end{array}$ & $\begin{array}{c}\text { Asociaciones por cada } \\
\text { 10000 habitantes }\end{array}$ & $\begin{array}{c}\text { Dólares por } \\
\text { habitante }\end{array}$ \\
\hline Nicoya & -15.3 & -24.1 & 12.2 & 14.9 \\
Santa Cruz & -7.0 & -15.0 & 13.5 & 2.4 \\
Nandayure & -12.1 & -50.2 & 15.9 & 14.2 \\
Hojancha & 3.1 & -57.4 & 12.0 & 13.8 \\
Turrubares & -25.6 & -27.5 & 35.7 & 23.1 \\
Puriscal & -19.0 & -24.2 & 14.8 & 6.2 \\
Tarrazú & -11.9 & -5.2 & 17.4 & 4.9 \\
Acosta & -14.5 & -19.0 & 15.9 & 3.9 \\
Dota & -12.4 & -2.1 & 8.3 & 24.7 \\
León Cortés & -7.8 & -10.4 & 18.1 & 4.1 \\
Total & - & - & 14.3 & 9.5 \\
\hline
\end{tabular}

c) La zona de "Los Santos". (cantones de Tarrazú, Dota y León Cortés).

Veamos ahora las características productivas de estas zonas durante el periodo que nos ocupa:

a) Zona "Península de Nicoya", que estaría conformada por los cantones de Nicoya, Nandayure, Santa Cruz y Hojancha. Fueron cantones que durante el decenio 63-73, mantuvieron importantes sectores de subsistencia pero con una expansión capitalista basada en la ganadería. (y arroz en el caso de Santa $\mathrm{Cruz}^{133}$ ) Nandayure incrementa en un $55 \%$ la superficie en pastos. Aquí disminuye - aún en términos absolutos- la PEA dedicada a la agricultura. En Nicoya aumenta en un $86 \%$ la superficie en pastos, pero disminuye la producción de frijol en un $23 \%$. En todos estos cantones, "el proceso de reducción de la economía no ligada al mercado se da, en parte a través de una muy clara tendencia hacia la concentración de la tierra que tiende a provocar disminuciones en el número total de fincas" Todo ello provoca tasas migratorias negativas y por eso son clasificados como áreas "de expansión capitalista expulsoras de población que mantienen o ven disminuida su PEA agrícola".

b) Sureste de San José. Los cantones de Turrubares, San Mateo, Acosta y Puriscal conforman un cinturón geográfico límite en el sureste del Valle Intermontano Central. Turrubares, estabiliza la economía capitalista basada en la ganadería y se debilita el sector de subsistencia, acompañado de un proceso de concentración de la tierra (el número total de fincas se reduce cerca del $20 \%$ ). Es un expulsor nato de población.
Acosta, Puriscal y San Mateo pertenecen a un conjunto socioproductivo "que vieron expandir sus actividades capitalistas,(ganadería y café en Acosta y Puriscal. Ganadería en San Mateo ${ }^{134}$ ), pero al mismo tiempo, disminuir su PEA agrícola y ser expulsores de población. ${ }^{135}$ En este sentido presentan características similares a los cantones de la zona "península de Nicoya".

c) "Los Santos". Finalmente Tarrazú, Dota y León Cortés logran aumentos importantes en la producción para el mercado: expanden entre el $17 \%$ y el $48 \%$ el área cultivada de café. Junto a esta notable expansión se mantiene (y aún crece) un sector de subsitencia que se observa en el incremento de la superficie cultivada de maíz..Este incremento simultáneo en la economía de subsistencia se podría explicar así..."en Tarrazú, Dota y León Cortés se dan incrementos en el número de fincas y en el total de trabajadores no remunerados, que podrán ser explicados por una subdivisión de las fincas medias". ${ }^{136}$ Esta situación permite que estos cantones -aunque con tasas migratorias negativas- logren absorber parte del crecimiento natural de la población.

\section{Conclusiones de la sección}

En resumen, la mayor concentración de Asociaciones de Desarrollo en el periodo 68-78, en la parte rural del país, tendió a coincidir con un patrón migratorio y socioproductivo que podríamos caracterizar así. Una mayor densidad organizacional en:

a) Cantones con muy fuerte atracción de población o con fuerte expulsión de población. 
b) Cantones que combinaron expansión capitalista ${ }^{137}$ basada, sobre todo, en la ganadería, el banano (Siquirres) pero también el café (Los Santos) y tabaco (Puriscal) con el mantenimiento o disminución de la economía de subsistencia. En algunos casos expulsaron población (cuando debilitaban la economía de subsistencia, como en Turrubares y no había frontera agrícola disponible). En otros casos, atrajeron población (por colonización-como en Upala- o por el dinamismo de la actividad capitalista, como el caso del banano en Pococí y Siquirres).

Entonces en todos estos cantones estuvo presente la dualidad-estructural conformada por la articulación entre un polo de producción para la subsistencia (minifundio: por ejemplo maíz, frijol) y un polo de producción para el mercado (empresa o latifundio capitalizado. ${ }^{138}$ Por ejemplo: café, tabaco, ganado.

En algunos casos esta articulación actuó negativamente sobre el polo de subsistencia y obligó a la migración (cantones expulsores de población. Ejemplo Turrubares). En otros, el dinamismo del polo capitalista ${ }^{139}$ (Siquirres) más la posibilidad de frontera agrícola (Upala) atrajo y retuvo población. Pero siempre y en todos ellos parece haber sido necesaria la permanencia de un mínimo de población económicamente activa, situada en el polo de subsistencia pero que combinaba su actividad con el trabajo asalariado para el polo de expansión capitalista.

Desde esa perspectiva y relacionándola con los datos que ya tenemos sobre la finalidad o destino que se les asignó a la inmensa mayoría de partidas específicas giradas a las Asociaciones -recordemos: vialidad e infraestructura comunitaria- se puede levantar la hipótesis de que las $A D C$, durante ese periodo, en el medio rural costarricense (también en el urbano) contribuyeron a satisfacer dos necesidades urgentes para el desarrollo de lo que entonces se llamaba capitalismo agrario. ¿Cuáles dos necesidades?: En el polo capitalista de esos cantones, la necesidad de infraestructura vial. En el polo de subsistencia -articulado a aquel- la necesidad de otorgarle a la fuerza de trabajo condiciones para su producción y reproducción en un nivel histórico adecuado para la evolución social del país en ese entonces: servicios básicos de salud, de educación, vivienda, seguridad y recreación.

\section{Los directivos de las Asociaciones de Desarrollo de la Comunidad}

Hubo pues una extraordinaria participación de las Asociaciones de Desarrollo en la ejecución de un modelo de desarrollo capitalista del agro costarricense impulsado desde el Estado. Para que esta participación pudiese darse, era necesario, como dijimos páginas atrás que también los dirigentes de las Asociaciones -es decir, los directivos- estuviesen objetivamente comprometidos con las formas y consecuencias relacionadas con la implementación del modelo.

Porque la Asociación es un ente social y jurídico que en lo cotidiano, en la práctica, era conducido por personas las cuales, merced a ese rol de conductores, adquirían el estatus de dirigentes comunales. ¿Cómo eran esas personas?, es la pregunta general que intenta responder este apartado.

\section{El "tipo ideal" del dirigente comunal}

Como venimos diciendo, los recursos provenientes del Estado y los propios, generados por las Asociaciones de Desarrollo, fueron orientados y administrados por vecinos de las comunidades, que al ser electos en sus respectivas asociaciones, devenían en "dirigentes comunales". En relación con ellos, el marco conceptual de las Asociaciones de Desarrollo de la Comunidad, tenía varias pretensiones. ${ }^{140}$

a) Que los directivos fuesen electos los más democráticamente posible. Es decir, en actos (asambleas) con mucha participación de los afiliados. Se buscaba, con ello, una legitimidad democrática no sólo para los directivos, sino para los proyectos que ellos emprendían.

b) Que representasen los intereses de la mayoría de los vecinos de la comunidad respectiva. $Y$ en esa misma medida, que sus características no difirieran sustancialmente de quienes les elegían (afiliados) y de quienes eran sus vecinos.

c) Que no participaran simultáneamente (en tanto directivos) en la estructura municipal o religiosa de su cantón respectivo. Estas participaciones podían dar un sesgo político electoral, o religioso a los dirigentes y así limitar o dividir la participación de los vecinos y afiliados.

d) Que fueran personas honestas, de buena reputación, un presupuesto asociado con la legitimidad que se quería en ellos.

e) Que hubiese renovación constante de los cuadros directivos de la asociación, para evitar el tan criticado "caciquismo"."141

En la práctica, ¿qué y cómo sucedió con estas pretensiones? Este capítulo intentará ofrecer una respuesta. Pero veamos, primero, lo que sucedía con la base social que elegía a estos dirigentes de las Asociaciones. Nos referimos a los afiliados y a los afiliados participantes en la organización.

\section{Los afiliados}

A las Asambleas Constitutivas de las asociaciones, asistía una gran cantidad de vecinos mayores de quince años, 
quienes al firmar el libro de actas, quedaban inscritos como miembros de su respectiva asociación. En promedio, a cada una de estas Asambleas, podrían haber asistido unos 150 vecinos, lo cual se traduce en la siguiente dato: durante la década 1968-1978, aproximadamente 120000 costarricenses, mayores de quince años asistieron a los actos constitutivos de Asociaciones de Desarrollo de la Comunidad.

La mayoría de estas personas que se afiliaban en la Asamblea constitutiva de su respectiva asociación, se limitaron a asistir al acto; otros permanecían sintiéndose miembros de la organización. En 1972, DINADECO y la firma consultora AITEC (Acción Internacional Técnica) ${ }^{142}$ investigaron características de las organizaciones comunales y de los costarricenses, jefes de familia, que decían pertenecer o participar en esas organizaciones. ${ }^{143} \mathrm{El}$ estudio reveló que un $9,3 \%$ del total de más de 1490 jefes de familia entrevistados, dijo ser "perteneciente" a una organización de desarrollo comunal. Este porcentaje colocaba a este tipo de organización en un sexto lugar de un total de 14 organizaciones locales, ponía a las asociaciones detrás de las Juntas de Educación, los Patronatos Escolares, los clubes deportivos, las organizaciones religiosas y las cooperativas. ${ }^{144}$

¿Cuál era el perfil de estos jefes de familia, pertenecientes a las asociaciones? Sabemos, por el mismo Estudio de Tipología de Comunidades que:

- Dos terceras partes de ellos tenían menos de seis años de escolaridad;

- Más de la mitad ganaba menos de cinco mil colones anuales (un estrato pobre, para aquellos años); y

- Más de la mitad eran pequeños agricultores, jornaleros, o trabajadores urbanos no calificados, o estaban desocupados.

En general, la mayoría de los jefes de familia pertenecientes a las asociaciones eran personas con poca escolaridad, trabajadores no especializados y de bajos ingresos, en fin, pobladores pobres en sus respectivas comunidades, pero menos pobres que el resto de sus vecinos. Porque el grupo de los pertenecientes a las organizaciones de desarrollo comunal tenían, en promedio, mayor ingreso y mayor escolaridad que el grupo total de jefes de familia. También, un porcentaje muy importante de los pertenecientes, casi la tercera parte, tenían ocupaciones consideradas de nivel intermedio entre el conjunto de ocupaciones, tales como agricultores medianos, burócratas y trabajadores urbanos especializados.

\section{Participantes en las Asociaciones de Desarrollo de la Co- munidad}

Que casi un $10 \%^{145}$ de los jefes de familia, mayores de
15 años, se declarase perteneciente a una Asociación de Desarrollo no significaba que participara de las actividades de su organización. En justicia ya desde el año de 1972 un problema central del desarrollo comunal costarricense fue el de la participación.

En el estudio de DINADECO-AITEC se reveló que un $58,5 \%$ de quienes se consideraban miembros actuales de la organización, asistía frecuentemente a las actividades planeadas por la organización. Este porcentaje era menor en relación con otras organizaciones locales. ${ }^{146}$ Además y esto era lo verdaderamente preocupante, en el corto periodo de vida de las asociaciones, el porcentaje de quienes asistían con frecuencia a las actividades de su asociación, se había reducido. En efecto, cuando se les preguntó a los ex-miembros de las organizaciones de desarrollo comunal sobre este particular, dos terceras partes dijeron que sí, que ellos sí asistieron a las actividades de la asociación, pero cuando se les preguntaba a los miembros actuales, solo el 58,5\% respondía afirmativamente. Estos datos estarían indicando que, en pocos años, la asistencia de los miembros a actividades de su asociación, no sólo era menor que en otros grupos locales, sino que venía declinando.

Sí. Efectivamente. La participación de los afiliados, desde un inicio, fue un problema central del modelo organizativo llamado Asociación de Desarrollo de la Comunidad.

A la misma conclusión llegaría otro estudio realizado por el Departamento de Programación de DINADECO dos años después. ${ }^{147}$ Allí se decía: "menos del 50\% de los vecinos entrevistados, que conocían a su asociación, participaba en los proyectos que ésta emprendía"148 y en el mismo estudio se leía: "Sólo el 13,9\% de las asociaciones dijo que más del $75 \%$ de sus afiliados estaban activos, es decir, participando."149 Estos datos son ratificados por dos estudios más. En 1970, una investigación conducida por DINADECO, sobre este tema, concluyó: “De un total de 88 asociaciones evaluadas, en un $59 \%$ de los casos se nota una marcada tendencia a reducir la asistencia a Asambleas Generales conforme transcurre el tiempo...siendo en términos relativos, para todo el país un $-61,6 \%$ de variación negativa", ${ }^{50}$ además: "un 38\% de las asociaciones no realizaron sus asambleas en las fechas que les correspondían".151

\section{Los directivos}

Estas características de los afiliados y los participantes en las Asociaciones de Desarrollo de alguna forma presagiaron las características de los dirigentes durante el periodo bajo estudio. Destacan las siguientes: 


\section{Su dinamismo}

La relativa apatía de los pertenecientes tuvo que ser contrastada con una intensa actividad de los directivos de las Asociaciones. Es su característica más sobresaliente.

Así el dinamismo que mostraron las Asociaciones de Desarrollo durante la década de los setenta, estuvo relacionado con un dirigencia comunal muy activa. Un Estudio de Tipología de Comunidades, realizado en 1972 conjuntamente entre DINADECO y la firma asesora AITEC, estableció que los dirigentes del desarrollo comunal (asociaciones) habían participado en más proyectos que los dirigentes de otras organizaciones comunales (Cuadro 31 ).

\section{¿Nuevas características psicológicas?}

¿Cómo explicar este gran dinamismo de los directivos? En la teoría del desarrollo de la comunidad se insistía que el tránsito hacia la "modernidad" debería estar necesariamente impulsado y acompañado por un personaje -el dirigente- provisto de nuevas ideas y actitudes. Sin embargo, en el caso concreto costarricense, existe evidencia empírica que demostraría que el directivo de las Asociaciones de Desarrollo no era, actitudinalmente muy diferente de otros dirigentes comunales.

Evidentemente esos datos refutarían una gran pretensión del modelo inicial del desarrollo comunal. Ésta fue que el directivo y el miembro de las ADC, mediante la acción educadora de DINADECO, pudiesen transformar

CUADRO 31

Promedio de proyectos comunales participados por dirigentes de 4 tipos de organizaciones (1972)

\begin{tabular}{lc}
\hline \multicolumn{1}{c}{ Organización } & Promedio de proyectos \\
\hline Desarrollo Comunal & 2,05 \\
Bienestar Social & 1,92 \\
Junta de Educación & 1,74 \\
Junta Progresista & 1,71
\end{tabular}

FUENTE: Tipología Comunidades, 1973, p.315

sus valores, actitudes y comportamientos hacia otros más "modernos" o relacionados con "el cambio social".

Pero sobre este particular el Estudio de Tipología de Comunidades demostró que los patrones actitudinales del dirigente de las Asociaciones no era -en 1972- muy diferente al de los dirigentes de otras organizaciones comunales. Medidos esos patrones en términos del nivel de orientación comunal u orientación nacional ${ }^{152}$ del dirigente de las ADC resultó, en ambos casos, similar, al de dirigentes de otras organizaciones, como por ejemplo, las Juntas Progresistas (Cuadros 32 y 33).

En cuanto a la propensión de los dirigentes comunales hacia el "cambio social" un estudio realizado a inicios de la década de los ochenta entre directivos de cuatro tipos de organizaciones concluía que: "En términos generales puede afirmarse que los dirigentes de las cooperativas son los que exhiben una posición menos solidaria con los sectores populares de la sociedad y más cercana a las opciones de las clases dominantes. Las siguen las Asociaciones de Desarrollo Comunal...." ${ }^{153}$

\section{Estrato social de pertenencia}

Para entender este gran dinamismo de los directivos de las ADC no bastan, entonces las explicaciones psicologistas relacionadas con "cambio de actitudes". Más favorable y plausible es entenderlo en función del estrato social de pertenencia de la mayoría de los directivos.

Efectivamente la gran mayoría de los directivos de ADC pertenecían a lo que el Estudio de Tipología

\section{CUADRO 32}

Orientación nacional de las actitudes de los dirigentes, según nivel y tipo de organización (1972) (en porcentajes)

\begin{tabular}{lcc}
\hline Nivel & $\begin{array}{c}\text { Dirigente de } \\
\text { Junta Progresista }\end{array}$ & $\begin{array}{c}\text { Dirigente de } \\
\text { Desarrollo Comunal }\end{array}$ \\
\hline Alto & 56,1 & 65,0 \\
Medio & 34,6 & 26,5 \\
Bajo & 9,4 & 8,5 \\
Total & 100,0 & 100,0 \\
\hline
\end{tabular}

FUENTE: Elaboración propia sobre datos de Estudio de Tipología de Comunidades, 1973, p. 309

\section{CUADRO 33}

Orientación comunal de las actitudes de los dirigentes, según nivel y tipo de organización (1972) (en porcentajes)

\begin{tabular}{lcc}
\hline Nivel & $\begin{array}{c}\text { Dirigente de } \\
\text { Junta Progresista }\end{array}$ & $\begin{array}{c}\text { Dirigente de } \\
\text { Desarrollo Comunal }\end{array}$ \\
\hline Alto & 27,7 & 29,3 \\
Medio & 66,1 & 62,3 \\
Bajo & 6,2 & 8,4 \\
Total & 100,0 & 100,0 \\
\hline
\end{tabular}

FUENTE: Elaboración propia sobre datos de Estudio de Tipología de Comunidades, 1973, p. 309 
de Comunidades denominó estratos ocupacionales medios y altos. Así, dos terceras partes de los dirigentes del desarrollo comunal pertenecían a algunos de estas ocupaciones: Trabajador semi-calificado; mediano agricultor propietario; trabajador calificado, trabajador en servicios intermedios, trabajadores de cuello blanco; agricultores grandes propietarios, profesionales no universitarios, empresarios y gerentes y profesionales universitarios (Cuadro 34).

Así, en la muestra total de individuos del Estudio de Tipología de Comunidades, el $60 \%$ de ellos pertenecían al estrato bajo, es decir, pequeños agricultores y jornaleros; servicios urbanos menores y trabajadores no-calificados.

CUADRO 34

Estatus ocupacional: Individuos en la muestra vs. Dirigentes de Desarrollo Comunal (1972) (en porcentajes)

\begin{tabular}{lcc}
\hline Nivel & $\begin{array}{c}\text { Individuos en } \\
\text { la muestra }\end{array}$ & $\begin{array}{c}\text { Dirigente de } \\
\text { Desarrollo Comunal }\end{array}$ \\
\hline Alto & 14,0 & 29,6 \\
Medio & 26,3 & 35,2 \\
Bajo & 59,7 & 35,2 \\
Total & 100,0 & 100,0 \\
\hline
\end{tabular}

FUENTE: Elaboración propia sobre datos de Estudio de Tipología de Comunidades, 1973, p. 160 y 304

Pero sólo el $35 \%$ de los dirigentes del desarrollo comunal pertenecían a ese estrato.

Según el mismo estudio, los individuos miembros del estatus ocupacional "agricultor mediano propietario" y "agricultor gran propietario" fueron los más dinámicos, es decir, los que más habían participado en proyectos comunales. ${ }^{154}$ Este gran dinamismo seguramente influyó en que fueran -proporcionalmente- los estratos ocupacionales más representados en la dirigencia comunal.

\section{Renovación de los directivos en las Asociaciones}

El modelo inicial del desarrollo comunal costarricense pretendía: (a) una alta participación de los afiliados de la Asociación ${ }^{155}$ y (b) una renovación continua de sus cuadros directivos. ${ }^{156}$ Ambas pretensiones - por supuesto- estaban interrelacionadas.

En la realidad la participación de los afiliados fue mínima. ${ }^{157} Y$ como veremos a continuación, hubo una clara tendencia a la concentración de la toma de decisiones en los cuadros directivos de las Asociaciones. Efectivamente, en la práctica un grupo de los dirigentes comunales
CUADRO 35

Directivos repitentes en Junta Directiva por lo menos una vez (1968-1978) (por regiones)

\begin{tabular}{lccc}
\hline \multicolumn{1}{c}{ Region } & Total & $\begin{array}{c}\text { Directivos } \\
\text { Repiten }\end{array}$ & Porcentaje \\
\hline Central & 8042 & 1368 & 17,0 \\
Periferica & 6115 & 851 & 13,9 \\
Total & $\mathbf{1 4 1 5 7}$ & $\mathbf{2 2 1 9}$ & $\mathbf{1 5 , 7}$ \\
\hline
\end{tabular}

CUADRO 36

Directivos repitentes en Junta Directiva por lo menos una vez (1968-1978) (por sub-regiones)

\begin{tabular}{lccc}
\hline \multicolumn{1}{c}{ Sub-region } & \multicolumn{3}{c}{$\begin{array}{c}\text { Directivos } \\
\text { Repiten }\end{array}$} \\
\hline Metropolitana & 1541 & 282 & 18,3 \\
Resto de San José & 3106 & 499 & 16,0 \\
Resto Región Central & 3395 & 588 & 17,3 \\
Chorotega & 2250 & 330 & 14,6 \\
Pacífico Central & 1013 & 164 & 16,1 \\
Brunca & 1540 & 184 & 11,9 \\
Huetar Atlántica & 841 & 116 & 13,8 \\
Huetar Norte & 471 & 59 & 12,4 \\
Total & $\mathbf{1 4 1 5 7}$ & $\mathbf{2 2 1 9}$ & $\mathbf{1 5 , 7}$ \\
\hline
\end{tabular}

tendió a permanecer en las Junta Directiva de su Asociación. En la investigación detectamos que por lo menos un 15,7\% de los directivos electos entre 1970 y 1977 repitieron como directivos por lo menos una vez. Esta situación fue más frecuente en la Región Central del país tal como observaremos en el Cuadro 35.

Por subregiones, la situación de directivos que repitieron en su Junta Directiva por lo menos una vez, fue más frecuente en la Región Metropolitana, en el Resto de la Región Central, en el Pacífico Central y en el Resto de San José (Cuadro 36).

Por otro lado en la investigación logramos establecer que la mayoría de estos directivos-repitentes ocupaban puestos importantes en la Junta Directiva de la Asociación: Puestos como el de Presidente, Vicepresidente y Tesorero en la mayoría de las ocasiones. Esto significa que quienes repetían como directivos realmente eran quienes en la práctica dirigían a la organización. ${ }^{158}$

\section{Directivos-municipes}

Un porcentaje importante y creciente de directivos de Asociaciones, con frecuencia pertenecientes al 
subconjunto "directivos-repitentes" fueron electos munícipes en sus respectivos cantones. En efecto, un 5,7\% del total de quienes fueron directivos entre 1970 y 1977 resultaron electos munícipes ya se a en las elecciones municipales de 1970, 1974 ó 1978. La distribución de estos directivos-munícipes fue muy similar entre la Región Central y la Región Periférica del país (Cuadro 37).

En el Cuadro 37 también podemos apreciar la distribución por años de los 809 directivos que fueron electos munícipes por lo menos una vez. Vemos que desde los inicios del desarrollo comunal institucionalizado (1970) la cifra fue importante y creciente en los sucesivos años electorales. El porcentaje de 5,7\% para todo el país podría ser engañoso. Porque significa que menos del $6 \%$ de los directivos fueron munícipes. Visto desde otra perspectiva es un dato significativo. ¿Desde cuál otra perspectiva? La de considerar el número de puestos de munícipes posibles de ser ocupados durante el periodo 70-78. Ese número es, aproximadamente de unos 3500 puestos (entre propietarios y suplentes) durante tres periodos electorales. La cifra 809 directivos-munícipes nos indicaría que, aproximadamente, un 23,1\% del total de puestos posibles de munícipes, durante el periodo 70-78, fue ocupado por directivos de Asociaciones de Desarrollo de la Comunidad.

La distribución de los directivos-munícipes por subregiones se muestra en el Cuadro 38.

Podemos apreciar que en la subregión "Resto de la Región Central" y en la Subregión "Pacífico Central" fue mayor la vigencia de este sub-grupo particular de los directivos-munícipes.

\section{Principales conclusiones de la sección}

1. A los actos constitutivos de las 807 asociaciones consideradas en este estudio, asistieron unas 120000 personas. Sin embargo, en las siguientes asambleas generales la asistencia decayó. Se estima en dos tercios de los asistentes la magnitud de esa caída. Las juntas directivas de las asociaciones fueron, entonces, electas por grupos restringido de afiliados, estableciendo con ello diferencias entre la dirigencia y los afiliados.

2. Hubo diferencias notables en ingreso, educación y estrato ocupacional entre dirigentes y miembros de la asociación. Los miembros eran más pobres, con menos educación formal y trabajaban en estratos ocupacionales de menor calificación, como jornaleros, obreros no especializados y dependientes de pequeños comercios. Los directivos, por su parte, tendieron a mayor ingreso, mejor educación formal y pertenecían, en dos terceras partes de las ocasiones, a estratos ocupacionales medios y altos. En razón de estas diferencias, los directivos percibían las necesidades comunitarias de una manera diferente a como
CUADRO 37

Directivos electos munícipes por lo menos una vez, por regiones y años electorales (1970-1978)

\begin{tabular}{lccccc}
\hline \multicolumn{1}{c}{ Región } & 1970 & 1974 & 1978 & Total & $\begin{array}{c}\% \text { del } \\
\text { total }\end{array}$ \\
\hline Central & 102 & 163 & 198 & 463 & 5,8 \\
Periférica & 67 & 115 & 164 & 346 & 5,7 \\
Total & 169 & 278 & 362 & $\mathbf{8 0 9}$ & $\mathbf{5 , 7}$ \\
\hline
\end{tabular}

CUADRO 38

Directivos electos munícipes por lo menos una vez, por regiones y años electorales (1970-1978)

\begin{tabular}{lcccccc}
\hline \multicolumn{1}{c}{ Region } & Directivos & 1970 & 1974 & 1978 & Total & $\%$ \\
\hline $\begin{array}{l}\text { Metropolitana } \\
\text { Resto de }\end{array}$ & 1541 & 18 & 25 & 25 & 68 & 4,4 \\
$\begin{array}{l}\text { San José } \\
\text { Resto de }\end{array}$ & 3106 & 32 & 59 & 68 & 159 & 5,1 \\
Región Central & & 52 & 79 & 105 & 236 & 7,0 \\
Chorotega & 2250 & 27 & 32 & 53 & 112 & 5,0 \\
Pacífico Central & 1013 & 16 & 22 & 28 & 66 & 6,5 \\
Brunca & 1540 & 14 & 32 & 44 & 90 & 5,8 \\
Huetar Atlántica & 841 & 6 & 21 & 26 & 53 & 6,3 \\
Huetar Norte & 471 & 4 & 8 & 13 & 25 & 5,3 \\
Total & 14157 & 169 & 278 & 362 & 809 & 5,7 \\
\hline
\end{tabular}

las sentía el común de los vecinos y ello contribuyó, a su vez, a una menor participación de los afiliados en las actividades de la asociación.

3. Directivos procedentes de los estratos medios y altos en sus respectivas comunidades muy probablemente compatibilizaron su interés de propietarios con el interés estatal por la modernización y la accesibilidad geográfica. Ello explicaría -más que un cambio en sus actitudes- su gran dinamismo durante esta primera década del desarrollo comunal costarricense.

4. La reelección de directivos fue una situación relativamente frecuente. En un corto periodo de 3 a 5 años, casi una cuarte parte de los puestos disponibles en la junta directiva de la asociación fueron ocupados por una misma persona. Eran puestos importantes (presidente, tesorero y vicepresidente). A ello debe sumarse también la situación de hermanos de directivos que ocuparon, también, puestos de importancia. En la periferia del país esta situación fue más frecuente. 
5. Durante tres elecciones municipales $(1970,1974$ y 1978) un $11 \%$ del grupo de personas que fueron directivos de asociaciones en el periodo 1968-1973 llegaron a ocupar un puesto municipal.

6. Estos directivos electos munícipes con frecuencia habían sido reelectos en su asociación (un tercio) y más de la mitad habían ocupado -en su asociación- los importantes puestos de presidente, tesorero o vicepresidente.

7. La tendencia de que los directivos ocuparan puestos municipales fue creciente durante el periodo 1970-1978.

8. También fue creciente la elección de directivos en puestos de mayor relevancia municipal. En concreto, cada vez más directivos fueron electos al puesto de regidor, un puesto trascendente en el engranaje político municipal.

\section{CONCLUSIONES GENERALES}

1. DINADECO nace el 7 de abril de 1967, pero antes hubo un largo historial de desarrollo comunal institucionalizado y sectorial. Es una historia de más de cien años que emerge, se asoma e influye en la construcción de DINADECO, ¿cómo? a través de un grupo técnico que junto recorrió, durante una década, el camino que condujo al acto constitutivo de la institución.

2. Porque hubo un grupo técnico. Un equipo de profesionales, en su mayoría social-demócratas, quienes a su vez eran funcionarios en instituciones públicas, con una vasta práctica sectorial del desarrollo comunal, como por ejemplo, el Ministerio de Salubridad Pública. Este grupo técnico fue designado, desde 1958, para conducir el proceso que precedió a la creación de DINADECO. Este grupo aportó los aspectos más relevantes de su práctica y de su "visión país" al proceso de institucionalización del desarrollo comunal en Costa Rica. Un grupo que recibió el aval de gobiernos muy diferentes.

3. Ingenuo sería pensar que fue este grupo de técnicos quien concibió la idea de DINADECO. Tampoco el que la formuló en su totalidad. Lo interesante de este grupo es su actuación como grupo, como actor nacional, en aquel complejo ambiente institucional para la formulación de políticas que se da en la Costa Rica de los años setenta.

4. Porque este grupo fue un actor nacional relevante, durante un largo periodo (más de una década). Su rol fue de filtro doméstico para cribar el discurso de actores externos, interesados en el desarrollo comunal, actores como UNESCO, CEPAL, AID o DESAL.

5. Este grupo técnico logró identificar y nacionalizar estrategias propuestas por estos actores externos. Más allá: logró introducir ese nuevo marco conceptual sobre desarrollo comunal en la Ley 3859 y logró que ese marco conceptual orientara la práctica de la naciente institución por lo menos hasta 1974.

6. La crítica académica en los años ochenta para DINADECO y para las Asociaciones de Desarrollo de la Comunidad' omitió el rol de ese grupo técnico, de ese filtro doméstico. Esa crítica prefirió partir de una idea simple: DINADECO y las Asociaciones de Desarrollo fueron el capítulo costarricense de una propuesta estratégica del gobierno norteamericano para América Latina. El propósito central de esa estrategia fue evitar o desviar tentaciones hacia modelos socialistas del tipo, Cuba-Fidel, o prefirió invocar una simple versión vernácula: DINADECO y las Asociaciones de Desarrollo son una estrategia del partido Liberación Nacional para controlar espacios locales, allí donde ese partido hubiese perdido, electoralmente, la municipalidad. También dijeron: DINADECO y las asociaciones fueron una estrategia del gobierno para deshacerse de las incómodas Juntas Progresistas.

7. Demostramos la fragilidad de esa crítica. Sin embargo, aún siendo cierta no alcanza para explicar -juntas incluso- el porqué nacieron DINADECO y las asociaciones. En otras palabras, por qué se institucionaliza, con un carácter integral, el desarrollo comunitario costarricense. Así las cosas, necesitábamos otra explicación.

8. En la búsqueda de esa otra explicación, lo primero que hicimos fue sacar nuestras preocupaciones de la esfera de los partidos y del gobierno y trasladarlas a la esfera del Estado. ${ }^{2}$ Quisimos considerar el tema de DINADECO y las Asociaciones de Desarrollo como un tema de Estado. ${ }^{3}$

9. Después fue preguntarse sobre el rol posible de ese Estado en el contexto económico y social de la Costa Rica que emerge con la Revolución de 1948. ¿Cuáles eran las tareas pendientes del Estado en relación con ese contexto, con esa formación económica y social?

10. Redescubrimos que la formación económica y social costarricense de la década de los cincuenta acusaba grandes deficiencias. Ya lo vimos: una estructura agraria débil, centrada en la producción de tres productos, una industria artesanal, un comercio incipiente.

11. Figueres Ferrer -un atento lector de nuestra realidad- (a veces con los lentes que le facilitaba la CEPAL), procuró cambiar, desde el Estado, esta situación. ¿Cómo? Aplicando su remedio infalible y que acertadamente el académico Manuel Solís Ilamó "la utopía tecnológica de Figueres". ${ }^{4}$ El remedio fue diversificar y capitalizar (tecnificar) la producción agropecuaria costarricense. El remedio fue atraer capital extranjero para un ambicioso plan de industrialización sustitutiva, que se insertase en el naciente Mercado Común Centroamericano. Y el remedio fue poner al Estado al servicio de estas pretensiones. 
12. Los resultados económicos de esta decisión estatal, fueron realmente sorprendentes.: El valor agregado agropecuario nacional tuvo un crecimiento superior al de los países latinoamericanos tomados en su conjunto. El valor agregado de la producción industrial también en la industria todavía mayor y más prolongado.

13. Pero las consecuencias sociales también fueron sorprendentes: en el campo los ricos se enriquecieron y los pobres se empobrecieron. Los economistas explican esta situación diciendo que el dinamismo productivo y comercial tendió a concentrarse en aquellos productos agropecuarios que reunían condiciones favorables como: altos precios relativos en el mercado internacional, facilidad para introducir tecnología, acceso a fuentes financieras y amplia disponibilidad del recurso tierra. Por eso -dicen-el $20 \%$ de las familias más ricas del campo se hicieron un 11\% más ricas, tan sólo en seis años, entre 1971 y 1977. Los pobres del campo no tuvieron esa oportunidad. El dinamismo económico no les tocó. Por eso, muchos -no todos- se proletarizaron, perdieron su tierra, se desocuparon o ingresaron a alguna de las modalidades del subempleo. OFIPLAN estimó que unos 125000 tuvieron que emigrar. El campo costarricense se llenó de pobres. Dijo OFIPLAN: en 1977 hubo 45000 familias campesinas en pobreza extrema, otras 31000 no satisfacen sus necesidades básicas. ${ }^{5}$

14. En la Costa Rica urbana la nota fue el crecimiento industrial que tuvo como sede a la pueblerina San José. La naciente industria y el comercio así como una burocracia estatal, atrajeron y concentraron a contingentes desplazados del campo o de otras áreas urbanas. En los primeros años de la década de los setenta el dinamismo de la actividad productiva urbana absorbió la fuerza de trabajo, hacia la segunda mitad, no. Crecieron el desempleo y la pobreza extrema. Por otro lado, un problema central del área urbana, durante toda la década de los setenta fue proveer de vivienda y servicios a la población inmigrante

15. Aludíamos a la decisión estatal de participar activamente en todo el proceso de crecimiento económico, tanto en el sector agropecuario como en el sector industrial. Y así ocurrió. Un indicador de ello pudo verse en su participación en el PIB: sólo entre 1961 y 1976, el Estado más que duplicó esa participación. ${ }^{6}$ ¿Pero cómo participó el Estado?... cuantitativamente: crédito bancario, atracción de inversión extranjera, exoneraciones, subsidio en servicios básicos a la industria y a actividades agropecuarias modernas... cualitativamente -que es lo más interesante-: creando las condiciones para que los procesos de crecimiento agropecuario e industrial fueran legítimos $y$ se llevaran a cabo sin grandes confrontaciones entre fracciones de la clase dominante, por ejemplo entre latifun- distas y los nuevos "empresarios" agrícolas. ${ }^{7}$

16. Tarea ingente del Estado. Para acometerla prefirió endeudarse que tocar a la puerta de los dueños del capital agropecuario e industrial, una medida que al final del periodo bajo estudio, resultó muy cara.

17. Desde la perspectiva cualitativa también, el otro reto impostergable para el Estado fue cómo enfrentar las rápidas transformaciones sociales (por ejemplo, los movimientos migratorios) que eran inherentes a la implantación del modelo de crecimiento económico. Para ello, el Estado costarricense fue pionero entre la mayoría de países en América Latina, en definir y poner en marcha un ambicioso conjunto de políticas sociales relacionadas con la colonización del agro (ITCO); el fortalecimiento Municipal (IFAM) y el combate a la pobreza (IMAS, asignaciones familiares), también, entre otras muchas, DINADECO y las Asociaciones de Desarrollo de la Comunidad.

18. ¿Por qué DINADECO? Porque en ese convulso mundo que provino de la introducción del modelo de crecimiento económico, el Estado tuvo que replantearse sus relaciones con la sociedad civil local y más importante: tuvo que replantearse a través de qué entidad continuaría teniendo tales relaciones. ¿A través de las viejas y rechinantes estructuras de mediación llamadas municipalidad? o, ¿a través de nuevas estructuras, más flexibles, más ágiles, como las Asociaciones de Desarrollo de la Comunidad? Un estudioso del tema, refiriéndose a esos tiempos, concuerda en que lo anterior fue una disyuntiva real para el Estado:"comienza a construir una modalidad de política local que modifica los términos de la relación Estado-sociedad civil local predominantes en el periodo liberal".

19. Coincidimos con el planteamiento anterior y nuestra hipótesis soberana es que DINADECO y las asociaciones fueron parte de una estrategia estatal para participar eficientemente, en los procesos de crecimiento económico a nivel local. La pregunta sigue siendo: ¿cómo?

20. Un paréntesis. A contrapelo de lo que algunos piensan, sostenemos que más allá de cumplir una función asistencial o paliativa en esos años, las Asociaciones de Desarrollo jugaron un rol relevante para la consolidación del modelo de crecimiento económico. Eso es tanto como decir que las asociaciones actuaron, directamente, sobre los aspectos económicos del proceso y no solamente ni mucho menos, paliando, atenuando las secuelas sociales que dejaba a su paso la aplicación de ese modelo económico.

21. Bien. Ahora volvamos al ¿cómo hizo el Estado? Primero, pensamos, creó un modelo jurídicamente privilegiado que se llamó Asociación de Desarrollo de la Comunidad. De entrada, como vimos, se le declaró de interés público, se le dotó de un financiamiento permanente ( $2 \%$ 
del impuesto sobre la renta), se le exoneró de impuestos, se incitó a la administración pública para que cooperase con el modelo, se le proporcionan partidas específicas, se le hizo sujeto de crédito barato y oportuno mediante el Banco Popular...

22. Un modelo ágil y eficiente. Ajeno a los costos de intermediación que siempre supone, por ejemplo, la burocracia municipal. Rápido en la toma de decisiones y sobre todo, capaz de convocar, para la construcción de las obras, al aporte comunal. La agilidad también hace referencia a la posibilidad que tuvo (y tiene) el modelo de asentarse en cualquier parte del país, en cualquier localidad, por pequeña y alejada que fuese. Y efectivamente así fue: hemos visto que en el corto plazo de una década el modelo denominado Asociación de Desarrollo de la Comunidad logró instalarse en el 90\% de todos los distritos administrativos del país.

23. Sí, un modelo privilegiado pero estrictamente sujeto a la burocracia estatal. Jurídicamente se le hace dependiente de DINADECO. En esto no vamos a insistir porque un estudioso del tema lo ha reiterado de manera harto convincente. ${ }^{9}$

24. La forma en que ocurrió esa expansión del modelo es coincidente con la forma en que se expandió el modelo de crecimiento agropecuario, en la década de los sesenta y setenta. Como se recordará, éste tuvo, una característica importante: buscó expandirse hacia la periferia geográfica del país. Fue centrífugo. Tendió a capitalizar las fértiles tierras periféricas ubicadas más allá del Valle Central intermontano y que todavía eran abundantes y baratas, a las Ilanuras del norte, a la vertiente Atlántica y al Valle del Coto, lugares adonde, no por casualidad, durante el periodo, el Estado construyó, por primera vez, una red de carreteras.

25. Ese mismo espíritu centrífugo -hacia fuera del Valle Central- también poseyó a las Asociaciones de Desarrollo de la Comunidad. Hemos visto como en términos relativos (y casi absolutos), la mayoría de ellas se instaló en las regiones periféricas del país; en los cantones más periféricos de esas regiones y en los distritos más periféricos de los cantones.

26. Al respecto y de manera más específica nos fue dable comprobar que allí donde se movilizó más población, también se ubicaron más Asociaciones de DesarroIlo, proporcionalmente hablando, en términos relativos, allí donde el modelo de crecimiento económico implantado movilizó más población, donde atrajo más migrantes. Recordemos: la Frontera Norte; los alrededores de Matina, Sarapiquí y Talamanca; el Valle de Coto y la periferia sureste de San José.

27. Pasemos ahora a un rasgo particular de ese modelo organizativo llamado Asociación de Desarrollo. Este modelo y el Estado establecieron vínculos fuertes a través del financiamiento. Uno en particular fue relevante: las partidas específicas, de hecho, su principalísima fuente de financiamiento. Aquí caben dos preguntas: ¿hacia adónde se giraron más montos en partidas específicas a través de las asociaciones? y ¿para qué se giraron esas partidas?

28. Ese espíritu centrífugo también se posesionó de las partidas específicas. El monto mayor ${ }^{10}$ se fue también para las regiones periféricas del país y dentro de éstas, a las subáreas más periféricas.

29. El financiamiento vía partidas específicas derivó hacia allá, hacia la periferia para ¿construir qué?... en un $80 \%$ de los casos para alguna de estas tres finalidades: a) construir, mejorar y equipar ese imaginario tan del costarricense meseteño: el centro cívico comunitario; ${ }^{11}$ b) para construir, reparar o ampliar obras de vialidad; y c) para dotar de agua y luz a las viviendas.

30. Uniendo estas consideraciones sobre el destino de las partidas con los lugares de mayor concentración de asociaciones, emerge un argumento muy concreto para entender por qué surgen las asociaciones y por qué crecieron tanto durante el periodo. Si bien la razón general es que surgen para acompañar al modelo de crecimiento económico (tanto agropecuario como industrial) implantado en el país, la razón específica sería la siguiente: El trabajo de las asociaciones fue imprescindible para retener y reproducir en su nivel histórico a la fuerza de trabajo en aquellos sitios donde la necesitaba tanto el capital agropecuario como el capital industrial. ¿Y cómo lo hicieron?... construyendo ese hábitat vital, necesario, imprescindible -agua, luz, escuela, cancha de fútbol, iglesia- donde la fuerza de trabajo pudiese vivir y reproducirse.

31. Esto no debe ocultar el otro hecho: que también las Asociaciones de Desarrollo actuaron más directamente sobre el crecimiento económico, principalmente, agropecuario, construyendo caminos, puentes, en fin, medios que contribuyeron a la reproducción misma del capital, a la infraestructura vial que contribuyó, enormemente, al desarrollo de la forma valor en el campo.

32. Este razonamiento supone superar las visiones correctas pero fragmentarias que sólo le atribuyen a las Asociaciones de Desarrollo de la comunidad un papel "ideológico" para la puesta en marcha del modelo de crecimiento económico en la década de los setenta, ${ }^{12}$ y superar también la visión de quienes solo vieron en las asociaciones, de ese periodo, mecanismos para paliar o atenuar las consecuencias sociales que dejaba a su paso el modelo de crecimiento económico.

33. Esta relación Estado-asociación en función 
directa del modelo de crecimiento económico fue posible en la medida en que los intereses del grupo dirigente de la organización, es decir, los directivos, correspondiesen con lo también requerido por el modelo. Por ejemplo, la infraestructura comunitaria, la infraestructura vial, el agua y la electricidad elevaban la renta del suelo para quienes eran propietarios de tierra, en el área rural, o a los propietarios de vivienda, en el área urbana; pero para quienes no lo eran -como los jornaleros- esos aparentes logros podían serles más bien contraproducentes.

34. Eso explica entonces, por lo menos parcialmente, que dos tercios de los puestos directivos de las asociaciones fueron ocupados por personas provenientes de los estratos medios y altos de las comunidades: propietarios, profesionales en educación y trabajadores especializados.

35. Es probable que en tal situación -y a pesar de los esfuerzos de directivos y promotores- las personas pertenecientes a los estratos inferiores de las comunidades no se sintieran representados y dejaran de participar. En efecto, vimos cómo -durante toda la década de los setenta- este fue un problema organizativo central de las asociaciones: la falta de asistencia y participación de los asociados fue una mortificación constante de directivos y promotores.

36. Devino entonces, sin pretenderla ni buscarla, una reedición moderada de aquella vieja institución del cacicazgo local, tan conjurada por los ideólogos primeros del desarrollo comunal. Como observamos en la investigación, en un corto periodo de 3 a 5 años, un porcentaje importante del total de directivos fueron reelectos en una o dos ocasiones. Y agréguese que ocuparon puestos importantes en su asociación.

37. Directivos reelectos, en puestos visibles e importantes, activos y con recursos para hacer obras comunales. Bueno, es natural que rápidamente y en forma creciente, miembros de ese subgrupo fueran promovidos por sus vecinos a puestos de elección popular en la Municipalidad. En el breve plazo de ocho años se observó una tendencia creciente en este sentido. Más aún, se observó una tendencia a que este subconjunto de directivos electos a la Municipalidad, ocupara, cada vez con mayor frecuencia, puestos municipales de importancia como el de regidor. Y esto ocurrió, sobre todo, en las áreas periféricas del país.

38. Este hallazgo de la investigación es muy importante porque debilita el argumento de que asociaciones y municipalidades funcionaron, durante el periodo, como entidades separadas y antagónicas en el espacio de la gestión local. Surge una nueva hipótesis sobre la posible existencia de múltiples vasos comunicantes y complementarios entre ambas entidades en ese periodo.

39. Finalmente, los déficits acumulados por el modelo de crecimiento económico le hicieron zozobrar a finales de la década de los setenta. Junto con éste naufragó también el modelo de Asociación de Desarrollo que tuvo vigencia durante ese periodo. Visto desde otra perspectiva, junto al modelo de crecimiento económico de la década de los setenta, se cierra también esta primera etapa de DINADECO. Casi como un símbolo de ello es la decisión de la administración Carazo Odio, (1978) de trasladar a DINADECO al Ministerio de Cultura (un ministerio de escaso poder político) y reducir su presupuesto. Rápidamente las asociaciones de Desarrollo acusaron el impacto de estas medidas, de una forma que esta investigación no alcanzó a detallar por estar fuera de sus límites. Pero el reto queda pendiente para otra investigación.

\section{AGRADECIMIENTOS}

Agradezco el apoyo de Xinia Zúñiga, Paulino Vargas, Leticia Molina, Léster Osorno, Carlos Ulate, Humberto Aguilar, Cristina Pizarro, Hellen Zuñiga, Yenory Rivera, Fernando Bolaños y Patricia González, Maynor Barrientos, Ruth Chinchilla, Rodrigo Arias, José Luis Torres, Viria Pacheco ,su apoyo administrativo. A Katya Calderón por impulsar la difusión de este estudio, a Marvin Zamora y demás personal de DINADECO; a Lenin Mondol por su apoyo y a Nancy Arias por ordenar la información en DINADECO y la Asamblea Legislativa de Costa Rica.

\section{RESUMEN}

La Asamblea Legislativa de Costa Rica creó la Dirección Nacional de Desarrollo de la Comunidad (DINADECO) en 1967 para apoyar a las asociaciones de desarrollo de la comunidad, constituidas por vecinos que comparten objetivos de mejoramiento económico y social para su comunidad. Aquí describo y analizo, dentro del contexto nacional, la historia de DINADECO entre 1968 y 1978, periodo en el cual se constituyeron 807 asociaciones y 26 uniones cantonales. Para 1978, el 90\% de los distritos, tenía, por lo menos, una asociación. Los resultados económicos de esta decisión estatal, fueron sorprendentes: el valor agregado agropecuario nacional tuvo un crecimiento superior al de los países latinoamericanos tomados en su conjunto. El valor agregado de la producción industrial, también. Y en la industria, el aumento fue todavía mayor y más prolongado. Pero la riqueza producida se distribuyó desigualmente. El $20 \%$ de las familias más ricas del campo se hicieron un $11 \%$ más ricas entre 1971 y 1977. Pero muchos campesinos perdieron su tierra e ingresaron a alguna de las modalidades del sub-empleo; 125 mil tuvieron que emigrar. Por otra parte, propongo la hipótesis nueva de que hubo múltiples vasos comunicantes y complementarios entre asociaciones y municipalidades en ese periodo. Finalmente, los déficit acumulados por el modelo de crecimiento económico hicieron zozobrar muchas asociaciones de desarrollo en la década de 1970. El efecto de la decisión de la administración Carazo Odio (1978) de trasladar DINADECO a un Ministerio de escaso poder político (Cultura) y reducir su presupuesto, sería un buen tema para una investigación futura.

\section{PALABRAS CLAVE}

Historia del desarrollo rural, modelos de desarrollo, interacciones municipalidad-asociaciones, pobreza, enriquecimiento, modelo económico latinoamericano. 


\section{NOTAS}

\section{Notas de la sección de Metodología}

1. Reglamento a la Ley 3859, Decreto ejecutivo 26935G, del 20 de abril de 1998.

2. Artículos 14 y 23 del reglamento a la Ley 3859.

3. Año intermedio del periodo bajo estudio (1968-1978). Según el censo de 1973, existían, para entonces un total de 79 cantones. Por lo tanto -respetando el criterio de una muestra del $20 \%$ - habría que elegir una muestra de 16 cantones.

4. Un obstáculo fue el siguiente: el registro de directivos de asociaciones en DINADECO está formado por un gran conjunto de tarjetas las cuales se archivan por provincias. Este registro, gracias a la diligencia de su personal está actualizado desde el año de 1975 hasta la fecha. Pero ¿cómo obtener el nombre de las personas que habían sido directivos antes del año 1975? Hubo que consultar los expedientes de cada una de las asociaciones cuyos directivos no figuraban en el tarjetero del archivo de DINADECO. Así pues, los expedientes individuales de cada una de las asociaciones fue la otra fuente secundaria consultada en el Departamento Legal y de Registro de DINADECO.

5. Porque existen partidas específicas giradas a las Asociaciones de Desarrollo de la Comunidad mediante otras vías presupuestarias. Son pocas, pero existen.

6. Por la siguiente razón: para poder comparar los directivos electos entre 1968 y 1969 contra los munícipes electos en el año electoral de 1970; y para poder comparar los directivos electos entre 1968 y 1973 contra los munícipes electos en el año electoral de 1974 y aún de 1978.

7. Se descartaron las asambleas generales extraordinarias que renovaban sólo parcialmente a las juntas directivas de las Asociaciones de Desarrollo de la Comunidad.

8. Hoy MIDEPLAN (Ministerio de Planificación Nacional y Política Económica).

9. Además de ponderar como sería el caso de la variable población, analizar la información que habíamos obtenido, por ejemplo: ¿cual información censal utilizar para estimar la migración interna por cantones en el país?, ¿la que proporcionaba el censo de 1973 o la de que proporcionaba el censo de 1984?

\section{Notas de la sección de Resultados}

1. No se trata aquí de recuperar los antecedentes de DINADECO, sólo entresacamos los puntos más importantes en relación con esta investigación. Una buena recopilación de antecedentes se puede leer en Carlos María Campos y José Luis Gonzalez Ramos: Notas y documentos sobre el desarrollo comunal en Costa Rica, San José: Imprenta Nacional, 1977.

2. Celín Arce Gómez, Derecho educativo. San José: EUNED, 2000, p. 226.
3. Jorge Cayetano Mora, La organización comunal y DINADECO (1964-1987). San José: Instituto Costarricense de Estudios Sociales, 1989, p. 26.

4. La exposición de motivos señala a las siguientes instituciones que ya tenían proyectos y aún programas de desarrollo de la comunidad: Instituto Nacional de Vivienda y Urbanismo, Ministerio de Educación Pública. Ministerio de Obras Públicas, Ministerio de Trabajo, Caja Costarricense del Seguro Social, etc.

5. En relación a la mayoría de los países de América Latina, tal vez con la sola excepción de Chile, Jamaica y Venezuela.

6. Entre los viajeros estuvo un joven y activo funcionario del Ministerio de Salud, José Luis González Ramos, quien, seis años después, asumiría la coordinación de la primera Oficina para el Desarrollo de las Comunidades Rurales en el país y quien, en 1970, ocuparía el cargo de director de DINADECO y coordinador de la elaboración del Primer Plan Nacional de Desarrollo de la Comunidad. En el viaje a Jamaica le acompañó Bolívar Cruz, quien luego coordinaría el Departamento de Cooperativas del Banco Nacional y posteriormente sería uno de los fundadores del Instituto Nacional de Fomento Cooperativo (INFOCOOP).

7. Hoy Ministerio de Salud.

8. Carlos María Campos y José Luis González, op. cit., p. 26.

9. Ex-integrantes del Primer Grupo de Trabajo sobre Desarrollo de la Comunidad.

10. Carlos María Campos y José Luis González, op. cit., p. 27.

11. Grosso modo, varios autores coinciden en establecer estas cuatro etapas. Uno de ellos es Cayetano Mora (op. cit., p. 55 et pass.).

12. Cfr. Cayetano Mora, op. cit, p. 35.

13. Walter Payne, "Desarrollo de la Comunidad en Costa Rica: 1969, 1972", citado por Cayetano Mora, op. cit., p. 34. Autores como Juan María Tercero y Olger Salas (cfr. op. cit., p. 73) estiman que había unos 20 funcionarios de campo.

\section{Convenio AID-Costa Rica 515 LO22.}

15. El préstamo fue por US\$16 400000 dólares y exigía una contrapartida del gobierno de Costa Rica.

16. Phillip Thompson había observado, durante el periodo 19681969 el funcionamiento de DINADECO y valoraba en mucho el potencial del desarrollo comunal costarricense. Ver al respecto: Richard C. Livingston, "Desarrollo de la comunidad en Costa Rica. Una historia interpretativa", 1973. pp. 74-75, en: Carlos María Campos Jiménez y José Luis González, op. cit.

17. Richard Livingston, op. cit., p. 93.

18. Citado por Cayetano Mora, op. cit., p. 97.

19. DINADECO, Departamento de Programación, sección de Estadística: "Algunos datos...," op. cit., p. 6.

20. José Luis Vega Carballo señala al respecto: “Pero nada comparable con lo que vendría durante la Administración Oduber cuando repentinamente el DESAF hizo posible aumentar con cien plazas el personal existente. Aquí se produjo una inesperada, aunque bienvenida, frondosidad burocrática que además 
tenía la conveniencia de prestarse a los intereses clientelistas y carentes de profesionalismo o adecuada especialización" ["Aspectos organizativos y estratégicos del Desarrollo Comunal en Costa Rica (1967-1987)". Material mimeografiado, s. f., p. 18].

21. Este trabajo no está llamado a enfatizar en los aspectos teóricos o conceptuales del desarrollo de la comunidad. Lo que sigue es una apretada síntesis de quienes han reflexionado, para América Latina, sobre el concepto desarrollo de la comunidad.

22. De hecho coincide con la propuesta impulsada por AID (Agencia Internacional para el Desarrollo) en esos años. Véase Cesar Montúfar, "Hacia un nuevo marco interpretativo de la asistencia internacional para el desarrollo", material mimeografiado, p. 251.

23. El diagnóstico de CEPAL sobre el atraso rural latinoamericano enfatizaba aspectos como el siguiente: "Todos estos rasgos, en conjunto y en detalle, muestran la enorme distancia que separa los modos de vida urbanos y rurales. Al estancamiento de la economía agraria corresponde, pues, un estancamiento histórico de las relaciones humanas en el campo". (CEPAL, El desarrollo social de América Latina en la postguerra, Buenos Aires: Solar/Hachette, p.10. Cursivas nuestras).

En un encuentro (auspiciado por UNESCO en diciembre 1960) los técnicos de la CEPAL concluían entre otras muchas que: “En su situación actual América Latina no debe abandonarse a un cambio social espontáneo. La planeación tanto como la predicción del cambio deben ser objeto de una política social de carácter racional" (UNESCO 1962).

Este planeamiento del cambio implicaba (principalmente) "se reconoció que un desarrollo económico rápido racional o programado dependería de la voluntad política de los grupos dirigentes y que, por lo tanto, la mudanza en la actitud de estos grupos dominantes (o su sustitución por otros) constituía en la mayoría de los países un requisito previo para resolver los problemas económicos" (UNESCO, op. cit., p.428). De ahí que Raúl Prebish, líder indiscutible de aquella CEPAL, invitara a las poblaciones rurales latinoamericanas a participar, con una actitud de cambio, en los procesos sociales a nivel local: "Si en nuestros esfuerzos de planificación del desarrollo no tomamos en cuenta la participación de la gente misma, nos estamos engañando y no lograremos nunca nuestros objetivos" (Raúl Prebish, citado por Carlos Campos y José Luis González Ramos, op. cit., p. 4). En América Latina estas ideas de la CEPAL-UNESCO impregnaban fuertemente a un grupo de maestros rurales, quienes, a finales de la década de los sesenta comenzaron a asistir a cursos y pasantías que UNESCO patrocinaba en la ciudad de Patzcuaro, México. En estos cursos y seminarios se insistía en un necesarísimo rol del maestro (sobre todo rural) para la transformación de las actitudes tradicionales del campesinado. En concreto, se decía, el maestro debería ser un "agente de cambio" en las comunidades.

24. DINADECO, Departamento Legal. Ley 3859, concordada y comentada con jurisprudencia. San José: DINADECO, 2005, p. 20.

25. Así lo establece el inciso e, artículo 81 del Reglamento a la Ley 3859.

26. En esta misma línea de pensamiento se sitúa Cayetano Mora quien atribuye la siguiente expresión al embajador norteamericano en Costa Rica "la filosofía del desarrollo comunal y la filosofía del Cuerpo de Paz, andan siempre de la mano" (ver Cayetano Mora, op. cit., p. 128).

27. Quien mayormente articula estos dos orígenes es Cayetano Mora (ver Las Juntas Progresistas. Organización comunal autónoma costarricense (1921-1980), pp. 126-128).

28. "Por otro lado la creación de DINADECO era un intento directo de control estatal sobre las organizaciones de vecinos que estaba tomando mucha fuerza y era muy crítico bajo la forma de Juntas Progresistas" (Manuel Arguello, op. cit., p. 12). Daniel Camacho agrega: “Uno de los efectos de la implantación de las Asociaciones de Desarrollo Comunal en Costa Rica ha sido el debilitamiento de las Juntas Progresistas" (Daniel Camacho et al., El desarrollo del movimiento sindical en Costa Rica. San José: Oficina de Publicaciones de la Universidad de Costa Rica, 1985, p. 152).

29. Patricia Alvarenga, De vecinos a ciudadanos, San José: EUNA, 2005, p. 47.

30. Hemos venido utilizando y seguiremos utilizando el término "desarrollo comunal" como sinónimos de desarrollo comunal oficial o desarrollo comunal institucionalizado. Esto es, como una filosofía y una técnica de organización y participación de las comunidades en el desarrollo local impulsada y normada desde el Estado. Cuando no se incluya expresamente la palabra "oficial" o "institucionalizado", deberá sobreentenderse.

31. Manuel Arguello, op. cit., p. 12.

32. Leonardo Garnier y Fernando Herrero, El desarrollo de la industria en Costa Rica. Santo Domingo de Heredia: EUNA, Colección Barba, 1982, p. 88.

33. El grupo de jóvenes profesionales permaneció más de una década juntos, orientando desde diversas instituciones proyectos de desarrollo comunal. Son, cuando menos: Fernando Jones, José María Campos, José Luis González Ramos, Armando Aráuz, Alvaro Hernández, Francisco Rojas...

\section{Casi lo que llaman ahora una "comunidad epistémica".}

35. Pero todo ello no debería interpretarse como si se tratase de un grupo con uniformidad de conceptos sobre desarrollo comunal. Había diferencias conceptuales entre ellos. Ver Juan María Tercero Zúñiga y Olger Salas Fonseca, op. cit.

36. Técnicos pero con pleno apoyo político de los dos partidos mayoritarios y de los gobiernos de turno.

37. En presente porque se sigue diciendo.

38. Ver Cayetano Mora, op. cit., p. 36.

39. Ver Patricia Alvarenga, op. cit., pp. 26 y ss.

40. Ibidem, p. 27, nota al pie.

41. Cfr. Cayetano Mora, op. cit., p. 130.

42. Como por ejemplo, lo que sucedió en el distrito primero del cantón central de Alajuela entre 1974 y 1978. Allí, al perder un partido político el control municipal en las elecciones de 1974, transfirió muchas y cuantiosas partidas específicas a la 
Asociación de Desarrollo Comunal del distrito primero, la cual comenzó a funcionar casi como una municipalidad.

\section{Un claro expositor de esta crítica.}

44. Roy Rivera, op. cit., p. 68.

45. Este punto de partida no es gratuito. En realidad responde a un planteamiento teórico metodológico de Claus Offe, quien insiste en que una investigación sustantiva sobre el Estado, reclama "nociones hipotéticas sobre la conexión funcional entre la actividad estatal y los problemas estructurales de una formación social capitalista" (Offe 1994).

46. OFIPLAN, Evolución socioeconómica de Costa Rica (19501980), San José: EUNED, 1982, p. 52

47. Ibidem, p. 44.

48. Ibidem.

49. Y el banano, además, era un enclave controlado desde afuera.

\section{OFIPLAN, op. cit., p. 82.}

51. El por qué cambiar es otra historia, en buena parte relacionada con intereses económicos extranacionales. Pero la urgencia era cambiar. MIDEPLAN, refiriéndose a esos años, legitimaba ideológicamente el cambio, diciendo: “Fue así como a partir de la década de los sesenta se vio la necesidad de impulsar nuevas actividades dentro del sector agropecuario y en otros sectores a fin de crear una estructura económica más diversificada que garantizara cierta independencia con respecto a las fluctuaciones del mercado mundial y que viniera a compensar en alguna medida la pérdida constante que se observaba en los términos de intercambio con el exterior" (OFIPLAN, op. cit., p. 44).

52. Cfr. Manuel Solís: "el reto exigía un rol activo del sector público, enmarcado en lo que se califica una concepción de economía mixta"(Costa Rica: ¿Reformismo socialdemócrata o liberal? San José: FLACSO, 1992, p. 327).

53. Este concepto de "ideología socialdemócrata" que ha sido fuertemente criticado por Susanne Jonas Bodenheimer en La ideología socialdemócrata en Costa Rica (pp. 13 y ss.).

54. Coadyuvo en la implantación de estas medidas la emergencia de nuevos sectores sociales dominantes que exigían la conducción del proceso económico del país con la antigua "oligarquía cafetalera" y con los extranjeros dueños del "enclave bananero" (Susana Jonas, op. cit., p. 31).

55. Donde los mismos déficits acumulados en el proceso de implantación del modelo, le hicieron zozobrar y naufragar. No es para explicar aquí, pero uno de los principales déficits fue la deuda externa acumulada por el país durante toda la década de los setenta. El entierro del ciclo de crecimiento económico fue decretado, de oficio, por la misma tecnocracia internacional que un cuarto de siglo atrás, había ofertado la tierra prometida:

"Los déficits sucesivos en su balanza comercial y en su presupuesto y el correlativo proceso inflacionario ha llevado a la economía de Costa Rica a una situación límite en cuanto a sus posibilidades de desenvolvimiento futuro" decían, en 1980, unos técnicos internacionales contratados por el país, para explicarnos la crisis de ese final de periodo (cfr. OFIPLAN, op. cit., p.371).

56. En términos constantes -millones de colones de 1966- pasó de 652 millones en 1957 a 1729 millones en 1978. Ver OFIPLAN, op. cit., p. 50.

\section{Ver OFIPLAN, op. cit., p. 55.}

58. Ibidem, p. 59. Sobre este particular agrega: "La causa principal del crecimiento de las exportaciones agrícolas es un salto en los promedios nacionales de productividad que se observa, en primer lugar, en el café y el banano. Políticamente este es un hecho particularmente significativo [...] "(p. 316). Esta tecnificación del agro tiene que ver también con lo que el mismo Solís (op. cit. p. 326) llama la utopía tecnológica de Figueres.

Esto tuvo una consecuencia importante: no hubo confrontación con el latifundista (Manuel Solís, op. cit., p. 316).

59. Ver OFIPLAN, op. cit., p. 62.

60. "El volumen del crédito al sector agropecuario medido por las colocaciones efectivas del Sistema Bancario Nacional, ha pasado de 243,8 millones en 1956 a un nivel de 5235,4 millones en 1980" (OFIPLAN, op. cit, p. 58).

61. En 1956 un tercio del crédito público se orientó a la agricultura y solo un 13,8\% a la ganadería. Veinte años después las proporciones se habían revertido. Ver Daniel Camacho et. al. Desarrollo del movimiento sindical en Costa Rica. San José: EUCR, 1985, p. 120.

62. Cifras trabajadas a partir de un cuadro general aportado por OFIPLAN, op. cit., p. 195.

63. OFIPLAN, para el periodo 1976-1980 informa que mientras los precios reales internos al productor del arroz, maíz, frijol decrecieron a un ritmo promedio mayor al 10\% anual; los correspondientes al café y ganado vacuno crecieron a un ritmo promedio mayor superior al $5 \%$ anual.

64. OFIPLAN, op. cit., p. 195.

65. Ibidem, p. 196.

66. Solís estima lo siguiente: “La inversión nacional y extranjera de los años sesenta y setenta, da lugar a una nueva modalidad de latifundio capitalizado orientado al mercado externo, que será determinante en el proceso de concentración de la tierra que ocurre en estas décadas. El área nacional de pasturas pasa de 630000 hectáreas en 1950 a 35000 hectáreas en 1963 y 1558 100 hectáreas en 1973. Esto ocurre en condiciones de una severa concentración de la propiedad territorial: un 6\% de las explotaciones pecuarias existentes en 1973 controlaban el 55\% del área de pasturas. Más del $50 \%$ de la superficie total de las fincas del país eran pastos" (Manuel Solís, op. cit., p. 318).

67. OFIPLAN, op. cit., p. 188.

68. Daniel Camacho et al., op. cit., p. 126.

69. Escuela de Economía, Universidad Nacional, Ministerio de Planificación Nacional y Política Económica, Evolución socioeconómica de Costa Rica: 1975-1989, p. 193.

70. OFIPLAN, op. cit., p. 214.

71. Este desempleo tuvo mucho que ver con un crecimiento 
agropecuario basado en actividades productivas intensivas en capital: “En el ámbito de las fincas grandes y medianas, quizá con la excepción de café y banano, el cambio tecnológico ha permitido que en los procesos de producción (en ganado vacuno, caña de azúcar, arroz) que son característicos de estas unidades de producción, se haya operado una sustitución de la mano de obra por los factores capital y tierra"(OFIPLAN, op. cit., p. 54).

72. Carlos Raabe, “Estructura agraria y migración: un intento de análisis". Estudios Sociales Centroamericanos, San José: Consejo Superior Universitario Centroamericano, No. 9, setiembre-diciembre, 1974, p. 266.

73. Este foco también fue un fuerte punto de atracción de migraciones durante el periodo 1950-1963 (OFIPLAN, op. cit., p. 219).

74. MIDEPLAN, Dirección de Información, “Migración interna en Costa Rica (1973-1984)". Material mimeografiado. San José, mayo de 1986, p. 8.

75. Leonardo Garnier y Fernando Herrero, El desarrollo de la industria en Costa Rica. Santo Domingo de Heredia: EUNA, Colección Barva, 1982, p. 73.

76. Manuel Solís, op. cit., pp. 332-333.

77. No necesariamente desarrollo. La crítica a este modelo de industrialización sustitutiva de importaciones es abundante y no requiere ser reproducida aquí (cfr. Leonardo Garnier y Fernando Herrero, op. cit, p. 86).

78. Ibidem, p. 99.

79. Ibidem.

80. BID, Progreso económico y social en América Latina, Washington, 1979, p. 31.

81. El crecimiento se la producción energética en el país fue paralelo al crecimiento industrial. La participación del sector industrial en el consumo total de energía eléctrica (proporcionada por el Estado) pasó de un 11\% en 1961 a un 28,1\% en 1976. En el mismo período el índice de tarifas para uso industrial creció de una manera mucho más lenta que para el uso residencia. Cfr. Liliana Herrera y Raimundo Santos, "¿Existe una clase obrera industrial en Costa Rica?", en: Daniel Camacho et al., op. cit., p. 121.

82. Ibidem, p. 120.

83. Citado por Leonardo Garnier y Fernando Herrero, op. cit., p. 89.

84. Ibidem, p. 89. Además es particularmente interesante el análisis que estos autores hacen sobre la inversión específicamente norteamericana en el Mercado Común Centroamericano (Ibidem, p. 88).

85. Leonardo Garnier y Fernando Herrero, op. cit., p. 109. Entre 1962 y 1972 el peso específico de las industrias tradicionales (las que generan mayor empleo) cayó de un 81,3\% a un 65,1\%. En cambio, las intermedias y las metal-mecánicas duplicaron su participación relativa en la estructura del PIB industrial.

86. OFIPLAN, op. cit., p. 113.

87. Ibidem, p. 133.

88. Escuela de Economía, Universidad Nacional, op. cit., p. 186.
89. OFIPLAN, op. cit., p. 191.

90. Ibidem, p. 196.

91. Como lo apuntan Fernando Herrero y Leonardo Garnier "la producción industrial no ha sido capaz reabsorber dinámicamente los excedentes de población generados por el desarrollo del sector agrícola" (op. cit., p. 106). De hecho, las tasas de desocupación fueron crecientes durante todo el periodo bajo estudio: 4,1\% en 1950; 6,9\% en 1963 y 7,3\% en 1973 (ibidem, p. 107).

92. OFIPLAN, op. cit., p. 162.

93. Ver Liliana Herrera, art. cit., p. 129 y OFIPLAN, op. cit., p. 253.

94. Refiriéndose a la primera administración de don José Figueres Ferrer, el sociólogo Vega Carballo ha dicho: "La política económica-social del figuerismo obedeció pues a los principios de una avanzada estrategia desarrollista [...] La tarea primordial de ese núcleo y del Estado era reajustar el modelo agroexportador tradicional" (citado por Fernando Herrero y Leonardo Garnier, op. cit., p. 72). Ver también Manuel Solís, op. cit., p. 328.

95. "Las nuevas tareas que asume el Estado hacen de él una estructura más grande y compleja. Su aporte al PIB pasa de un $10 \%$ en 1961 a un 22,5\% en 1976" (Manuel Solís, ibidem, p. 321).

96. No hubo aquí intentos serios de reforma agraria o algo parecido. Ver Susane Jonas, op. cit., p. 49.

97. Ver Manuel Solís, op. cit., p. 318.

98. Ver OFIPLAN, op. cit., p. 326. Como ilustración, las exoneraciones a la importación en 1970 y en 1980, triplicaron lo recaudado en concepto de impuestos a la importación. Ha de recordarse que la mayor parte de estas importaciones eran insumos y bienes de capital para el desarrollo de la industria. Sobre este particular, Manuel Solís ha dicho: "Una de las particularidades de esta industria inscrita en un círculo internacional de acumulación es el que las importaciones de insumos y bienes de capital superan desde el principio el valor de las exportaciones de bienes finales" (Manuel Solís, op. cit., p. 320).

99. Y este endeudamiento, comparado con el de los otros países centroamericanos fue fortísimo.

100. “Los déficits sucesivos en su balanza comercial y en su presupuesto y el correlativo proceso inflacionario ha llevado a la economía de Costa Rica a una situación límite en cuanto a sus posibilidades de desenvolvimiento futuro". Ver "Informe de misión realizado por Leopoldo Portnoy Cristian Ossa dentro del marco del proyecto Cos/77/004-Planificación, 1980", OFIPLAN, op. cit., p. 371.

101. El otro pie del crecimiento del modelo fue la inversión extranjera directa. No cabe analizar aquí las consecuencias de esta estrategia estatal.

102. Y no olvidemos que parte de este paquete de políticas sociales fue el componente "Desarrollo de la Comunidad".

103. Una política de salarios crecientes, particularmente en relación a las actividades productivas en el medio urbano, lo cual evitó el deterioro del ingreso de los sectores medios y de los trabajadores asalariados en general, en el mundo rural: Instituto 
de Tierras y colonización para la dotación de tierras y servicios a jornaleros, formalización del Primer Plan Nacional de Desarrollo Agropecuario (1970-1974), políticas sociales para la atención de la población en pobreza y en pobreza extrema (en 1973 el IMAS; en 1975, Asignaciones Familiares), políticas sociales sectoriales de corte universalista; en educación: apertura de tres universidades públicas, creación de colegios universitarios, Instituto Nacional de Aprendizaje; en salud: Programa de Comedores Escolares, salud rural (en 1972), Centros de Educación y Nutrición; en vivienda: programa de vivienda social del IMAS, desarrollo habitacional, Instituto Nacional de Vivienda y Urbanismo.

104. Otras instancias de tal naturaleza fueron las cooperativas. La modificación del Código Municipal en 1971 y la creación de los consejos de distrito obedecen también a esta lógica. A un nivel más concreto OFIPLAN agrega refiriéndose a la década de los setenta: "Dado el aumento de los problemas de vivienda, especialmente en el área urbana y al incremento de los niveles de pobreza [...] Se crearon instituciones que pretendieron cubrir el vacío existente respecto a los sectores más necesitados. Se creó así el IMAS, DINADECO y el Programa de Asignaciones Familiares" (OFIPLAN, op. cit., p. 253).

105. El procedimiento oficial para constituir una Asociación de Desarrollo era que mediante un pliego firmado por más de cien vecinos mayores de 15 años se solicitara a DINADECO iniciar un periodo de estudio sobre las posibilidades para constituir una asociación.

106. Fecha en que inició el presente estudio.

107. Decimos "propiamente", porque de esta contabilidad se excluyen las 592 asociaciones específicas, creadas rápidamente, durante los dos últimos años de la administración Pacheco de la Espriella, con el fin exclusivo de ser intermediarias de fondos públicos para los Centros de Nutrición CEN-CINAI.

108. Censo que como dijimos en el apartado metodológico será la base para nuestros cálculos estadísticos.

109. Como establecimos en el apartado metodológico, el escaso número de asociaciones específicas constituidas durante el periodo en estudio, nos permite incluirlas junto a las integrales en una sola categoría: Asociaciones de Desarrollo Comunal ya sean éstas integrales o específicas.

110. La explicación es la siguiente: durante estos años DINADECO hizo un trabajo mucho más cualitativo. Se preocupó por consolidarse como institución y por ofrecer mayor asistencia técnica y capacitación tanto a su personal como a los dirigentes de las asociaciones.

111. Una explicación parcial es el incremento de recursos que tuvo la institución con su ingreso al Programa de Asignaciones Familiares, pero también, a un objetivo explícito de la administración Oduber-Quirós.

112. Junto al interés de la administración Oduber Quirós por extender la presencia de asociaciones en todo el territorio nacional, debe considerarse que también dotó a la institución de los recursos para hacerlo, utilizando para ello el Programa de Asignaciones Familiares, como dijimos en el capítulo dedicado a DINADECO.
113. Una demanda que siempre tuvo que ser avalada por el Estado, por lo cual también podría inferirse el interés de éste por constituir asociaciones.

114. Como hemos venido diciendo, ello parcialmente se explica por la poca capacidad institucional.

115. Este indicador, que empezamos a utilizar aquí pero que seguiremos utilizando tiene una debilidad de origen: divide el número de asociaciones constituidas durante varios años (1968 1978), solo entre la población de un año fijo: 1973. El año censal de 1973, que para nuestros efectos actúa como una especie de promedio de la población durante el periodo 1968 y 1978 (ver parte metodológica).

116. A estos distritos que no son centrales, les llamaremos periféricos.

117. Censo de 1973.

118. OFIPLAN, División de Planificación Regional Urbana, 1977, pp. 3 y ss.

119. Conforme a la población de cada uno de ellos considerada para 1973.

120. Excepto el cantón de La Cruz.

121. Con excepción de Talamanca durante el primer sub-periodo.

122. Además de la estadísticamente obvia: al perder población la cifra de "densidad organizacional" crece automáticamente.

123. Es decir, la tasa de crecimiento neto de la población en el periodo intercensal 1973-1984.

124. Hay un problema estadístico difícil de subsanar, por el momento, es el siguiente: utilizando la población de 1973 para calcular la densidad organizacional y sabiendo que a) la gran mayoría de las asociaciones se constituyeron después de 1973; y b) la población creció rápidamente a partir de este último año, las cifras de la densidad organizacional para los cantones con menor crecimiento poblacional estarían subvaloradas. Ahora bien, si utilizáramos los datos de población del censote 1984, ocurriría lo contrario. Cuando lo hicimos así, la hipótesis (a mayor crecimiento mayor densidad organizacional) siempre se mantiene, pero es menos notoria.

125. OFIPLAN refiere que en el periodo 1968-1973, hubo fuertes inmigraciones hacia el Área Metropolitana de San José, cfr. OFIPLAN, op. cit., p. 13.

126. En un estudio se hizo alusión a la ubicación de estas barriadas y a su composición por estratos ocupacionales. Las conclusiones de ese estudio también refuerzan nuestra hipótesis, cfr. Liliana Herrera y Raimundo Santos, op. cit., pp. 132 y ss.

\section{Fuera de la Región Central.}

128. Por ejemplo, la Región Huetar Atlántica, en la cual durante el periodo bajo estudio, se dio una fuerte expansión de la actividad bananera y pasó a ser un área eminentemente atractora de población, particularmente en sus cantones de Guácimo, Siquirres, Matina y Pococí.

129. Promedio de dólares provenientes de partidas específicas 
giradas a las ADC de un cantón en el periodo 70-78, y que recibiría un habitante de cualquier edad de ese cantón. (Dólares al tipo de cambio de esos años)

130. Teodoro Buarque y Carlos Raabe, 1975, página 41. (subrayado nuestro)

131. CSUCA, 1978, página 301.

132. CSUCA, 1978, p. 300

133. En Santa Cruz el área sembrada con arroz prácticamente se duplicó en el decenio. Cfr. CSUCA, 1978, p.302

134. En San Mateo, durante el decenio 63-73, se incrementó en un $30 \%$ la superficie en pastos.

135. CSUCA, 1978, p. 304

136. CSUCA, 1978, p. 303

137. El concepto "expansión capitalista" deviene de los autores ligados al CSUCA, quienes asociaron ese concepto con "producción para el mercado". Entendemos que el modo de producción capitalista requiere de otras características para definirse como tal.

138. La expresión corresponde al análisis hecho por Manuel Solís (1986)

139. El concepto "capitalista" es aquí perentorio. Casi se refiere sólo para la producción para el mercado. Pero así lo utilizaron los académicos del CSUCA que estudiaron las migraciones internas en Centroamérica en la década de los setentas.

140. Todas estas pretensiones tenían su reflejo en el marco jurídico de las asociaciones. Entre paréntesis se anotan los artículos de ley o de reglamento que hacen alusión directa a cada pretensión.

141. Una sola persona, con capacidad y poder producía todas las decisiones importantes a nivel comunal.

142. Esta firma había sido contratada por DINADECO al amparo del convenio de préstamo que el gobierno había firmado, en 1970, con la Agencia Internacional para el Desarrollo (AID).

143. De manera muy resumida podríamos decir que el estudio consistió en lo siguiente: citar primer tomo de tipología, entrevistas estructuradas a unos 1490 jefes de familia en 101 comunidades del país.

144. Todas ellas más antiguas que las Asociaciones de Desarrollo.

145. Asumiendo que la muestra fue representativa.

146. Por ejemplo en las organizaciones educativas (juntas y patronatos) ese porcentaje era del 72,5\%.Sin embargo debe considerarse que el término "asistencia" tenía otra connotación en las Asociaciones de Desarrollo. Implicaba ir a más actividades y más complejas, como asambleas generales. En otras organizaciones locales "asistencia" era un término menos complejo.

147. DINADECO, Departamento de Programación y Evaluación, Diagnóstico de Asociaciones Seleccionadas (1974), en: Carlos María Campos y José Luis González, op. cit., p. 110.

148. Ibidem, p. 109.
149. Ibidem.

150. Juan María Tercero y Olger Salas, op. cit., pp.151-152.

151. Ibidem, p. 152.

152. Richard Livingston, op. cit., p. 83.

153. Juan María Tercero y Olger Salas, op. cit., pp. 139 y ss.

154. Ibidem, p. 139.

155. Daniel Camacho et al., “Dominación ideológica y movimientos populares en Costa Rica", en: Desarrollo del movimiento sindical..., op. cit., pp. 151 y ss.

156. Ver apartado metodológico.

157. Entre paréntesis, las situaciones de reelección fueron, más frecuentes en el resto del país que en el centro del país.

158. Convocada para cambiar a todos los puestos de junta directiva.

\section{Notas de la sección de Conclusiones generales}

1. Crítica que tuvo un efecto trágico: la academia se olvidó, durante veinticinco años, de las asociaciones.

2. Entre paréntesis, esta es la idea teórico-metodológica que orientó toda la investigación.

3. Así lo percibió, por ejemplo José Miguel Alfaro, ex-vicepresidente de la República, cfr. Daniel Oduber et al, Los problemas sociopolíticos del desarrollo en Costa Rica. San José: Unidad Coordinadora de Investigación y Documentación, Universidad Nacional/ EUNED, 1981. También es útil observar cómo DINADECO, desde el inicio, fue incluido en programas estatales importantes: Plan Nacional Agropecuario (Figueres) y Programa de Asignaciones Familiares (Oduber).

4. Cfr. Manuel Solís, op. cit., p. 326.

5. OFIPLAN, op. cit., p. 196.

6. Solís estima lo siguiente: en 1950 había 17 empleados públicos; veinticuatro años después, 75 000. El Estado absorbía más trabajadores que la industria (Manuel Solís, op. cit., p 321).

7. Manuel Solís (op. cit., pp. 315 y ss.) hace un valioso esfuerzo por explicarnos cómo hizo el Estado, en esa década, para evitar confrontaciones sociales.

8. Roy Rivera, Descentralización y la metáfora de la reforma..., op. cit., p. 13.

9. José Luis Vega Carballo: "revelándose de este modo la orientación de esos organismos a constituirse en extensiones del brazo constructor y mantenedor del Estado, al cual se le ha relevado de múltiples y engorrosas obras locales y de compromisos para cubrir planillas, en la medida en que las dirigencias comunales han asumido esas fundones y obligaciones con bajos costos de operación y aportando ellas recursos adicionales extraídos de las comunidades con tal de satisfacer sus necesidades de crear condiciones más favorables a la reproducción de los pequeños y medianos capitales locales, especialmente de raigambre rural" (op. cit., p. 24). 
10. En términos relativos a su población y al número de asociaciones.

11. Centro cívico comunitario es un concepto construido por el autor para designar ese conjunto de edificios simbólicos que constituyen el espacio central urbano de cualquier comunidad costarricense: plaza, iglesia, escuela, salón comunal, calles, aceras y entubamiento de aguas negras.

12. Cfr. Diego Palma, op. cit.

\section{REFERENCIAS}

Alfaro, J. 1981.Transición hacia la democracia participativa. Unión Ciudadana para la Democracia, Heredia, Costa Rica.

Alvarenga, P. 2005. De vecinos a ciudadanos. EUNA. San José, Costa Rica.

Arce, C. 2000. Derecho educativo. EUNED, San José, Costa Rica.

Argüello, M. 1983 Historia de los movimientos comunales en Costa Rica. Folleto. Centro de Capacitación para el Desarrollo, Cuadernos de Capacitación Popular. San José, Costa Rica.

Banco Interamericano de Desarrollo. 1966. Desarrollo de la Comunidad. Teoría y práctica. México D.F., México.

Banco Interamericano de Desarrollo. 1979. Progreso económico y social en América Latina. Informe de 1978. Washington, EEUU.

Camacho, D. 1985. Desarrollo del movimiento sindical en Costa Rica. Universidad de Costa Rica. San José, Costa Rica.

Campos, C. \& J. L. González. 1977. Notas y documentos sobre Desarrollo de la Comunidad en Costa Rica. Nacional. San José, Costa Rica.

Chan, C. 1976. Un enfoque económico, social y político de Costa Rica, ubicación dentro del mismo del movimiento de desarrollo de la comunidad y una evaluación del Primer Plan Nacional de Desarrollo de la Comunidad, Tesis de grado. Escuela de Trabajo Social. Universidad de Costa Rica, San José, Costa Rica.

Comisión Económica para América Latina y el Caribe. 1966. El Desarrollo Social de América Latina en la posguerra. Solar Hachette, Dimensión americana, Buenos Aires, Argentina.

Dirección Nacional de Desarrollo de la Comunidad. 1977. Departamento de Programación y Evaluación. “Diagnóstico de Asociaciones seleccionadas (1974)", en: Carlos María Jiménez y José Luis González Ramos, Notas y documentos sobre desarrollo de la comunidad en Costa Rica. Nacional, San José, Costa Rica.

DINADECO. 1978. Departamento de Programación, sección de Estadística. "Algunos datos sobre la labor realizada por DINADECO (1968-1977)". Material mimeografiado.

DINADECO. 2005. Departamento Legal. Dirección Nacional de Desarrollo de la Comunidad. Ley 3859, concordada y co- mentada con jurisprudencia. Nacional, San José, Costa Rica.

DINADECO. s.f. "Reflexiones sobre el Desarrollo Comunal". DINADECO, San José, Costa Rica.

DINADECO \& AITEC. 1974. Estudio de tipología de comunidades. Grafo Print, San José, Costa Rica.

Escuela de Economía. 1992. Universidad Nacional y Ministerio de Planificación Nacional y Política Económica (MIDEPLAN). Evolución socioeconómica de Costa Rica (1975-1989). Lil, San José, Costa Rica.

Garnier, L. \& F. Herrero. 1982. El desarrollo de la industria en Costa Rica. EUNA, Heredia, Costa Rica.

Gil, P. 1966. Volver a Liberación. El pensamiento de Daniel Oduber sobre las organizaciones comunales y DINADECO. Material mimeografiado sin datos. San José, Costa Rica.

González, J. 1962. El adiestramiento en la administración de programas para el desarrollo de la comunidad". Escuela de Servicio Social Universidad de Costa Rica. Material mimeografiado. San José, Costa Rica.

González, J. 1975. Una asistencia técnica en desarrollo comunal. Imprenta Nacional, San José, Costa Rica.

Herrera, L. \& R. Santos. 1985. ¿Existe una clase obrera industrial en Costa Rica?", en: Daniel Camacho et al., Desarrollo del movimiento sindical en Costa Rica. Universidad de Costa Rica, San José, Costa Rica.

Jonas, S. 1984. La ideología socialdemócrata en Costa Rica. Educa, San José, Costa Rica.

Livingston, R. 1977. Desarrollo de la Comunidad en Costa Rica (1968-1972). Una historia interpretativa. en: Carlos María Jiménez y José Luis González Ramos, Notas y documentos sobre desarrollo de la comunidad en Costa Rica. Imprenta Nacional, San José, Costa Rica.

Ministerio de Economía, Industria y Comercio. 1975. Censo de población de 1973. Nacional, San José, Costa Rica.

Ministerio de Economía, Industria y Comercio. 1987. Dirección General de Estadística y Censos: Censo de población de 1984. Nacional, San José, Costa Rica.

Ministerio de Planificación Nacional y Política Económica. 1986. Dirección de información. "Migración interna en Costa Rica (1973-1984)". Material mimeografiado. San José, Costa Rica.

Ministerio de Trabajo. 1964. Dirección General de Bienestar Social. Curso intensivo sobre Desarrollo de la Comunidad. Material mimeografiado. San José, Costa Rica.

Montúfar, C. s. f. “Hacia un nuevo marco interpretativo de la asistencia internacional para el desarrollo", material mimeografiado,

Mora, J. s. f. Las Juntas Progresistas. Organización comunal autónoma costarricense (1921-1980). San José: Fundación Friedrich Ebert.

Mora, J. 1989. La organización comunal y DINADECO: 1964-1987. 
Instituto Costarricense de Estudios Sociales, San José, Costa Rica.

Oduber, D. 1981. Los problemas sociopolíticos del desarrollo en Costa Rica. Unidad Coordinadora de Investigación y Documentación (UCID), Universidad Nacional, EUNED, San José, Costa Rica.

Offe, C. 1994. Contradicciones en el Estado de Bienestar. Alianza, Madrid, España.

Oficina de Planificación Nacional y Política Económica. 1982. Evolución socioeconómica de Costa Rica (1950-1980). EUNED, San José, Costa Rica

Palma, D. 1980. El estado y la desmovilización social en Costa Rica. Estudios Sociales Centroamericanos. Consejo Superior Universitario Centroamericano. San José, Costa Rica.

Programa de Las Naciones Unidas para el Desarrollo. 1994. Costa Rica en cifras: 1950-1992. Programa de las Naciones Unidas para el Desarrollo San José, Costa Rica.

Programa de las Naciones Unidas para el Desarrollo. 1994. Costa Rica en cifras: 1950-1992. Programa de las Naciones Unidas para el Desarrollo San José, Costa Rica.

Raabe, C. 1974. Estructura agraria y migración: un intento de análisis. Estudios Sociales Centroamericanos. Consejo Superior Universitario Centroamericano. San José, Costa Rica.

Raabe, C. \& T. Buarque. 1975. Costa Rica: migración rural-rural y estructura agraria en el periodo 1950-1963. Estudios Sociales Centroamericanos. Consejo Superior Universitario Centroamericano, San José, Costa Rica.

Rivera, R. 1995. Descentralización y la metáfora de la reforma del Estado. FLACSO, San José, Costa Rica.

Sojo, C. 2000. La relación Estado-Sociedad Civil en el marco de la globalización. Cuadernos de Ciencias Sociales. FLACSO, San José, Costa Rica.
Solano, J. 2001. Educación y Desarrollo en América Latina: un análisis histórico.conceptual. EUNA, Heredia, Costa Rica.

Solís, M. 1992. ¿Reformismo socialdemócrata o liberal?. FLACSO, San José, Costa Rica.

Solís, O. 2000. Una experiencia concreta de descentralización. El caso de Pérez Zeledón. Cuadernos de Ciencias Sociales. FLACSO, San José, Costa Rica.

Tercero, J. \& O. Salas. 1986. El desarrollo comunal en Costa Rica. Asociaciones de Desarrollo Comunal. Alternativas de participación Popular. Tesis de Grado. Escuela de Historia y Geografía, Universidad de Costa Rica, San José, Costa Rica.

Tribunal Supremo de Elecciones. 1970. Cómputo de votos y declaratoria de elección. Elecciones de 1970. Lil, San José, Costa Rica.

Tribunal Supremo de Elecciones 1974. Cómputo de votos y declaratoria de elección. Elecciones de 1974. Lil, San José, Costa Rica.

Tribunal Supremo de Elecciones 1978. Cómputo de votos y declaratoria de elección. Lil, San José, Costa Rica.

Tribunal Supremo de Elecciones 1997. División Territorial Electoral. Nacional, San José, Costa Rica.

UNESCO. 1962. Aspectos sociales del desarrollo económico en América Latina. UNESCO, Paris, Francia.

Vega, J. s. f. Aspectos organizativos y estratégicos del Desarrollo Comunal en Costa Rica (1967-1987). Material mimeografiado sin datos.

Vega, J. 1989. Las Políticas de distribución del Poder: la descentralización y la regionalización, el papel de las municipalidades, las Organizaciones Comunales y los Consejos Regionales de Desarrollo. Friedrich Ebert, San José, Costa Rica. 